\title{
AN INTRODUCTION TO
}

\section{PUBLIC OPINION}

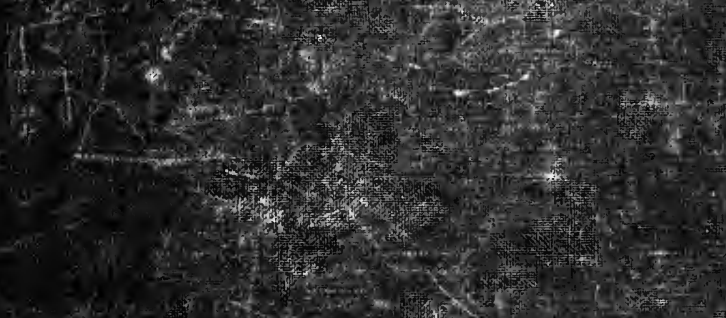

30

20.
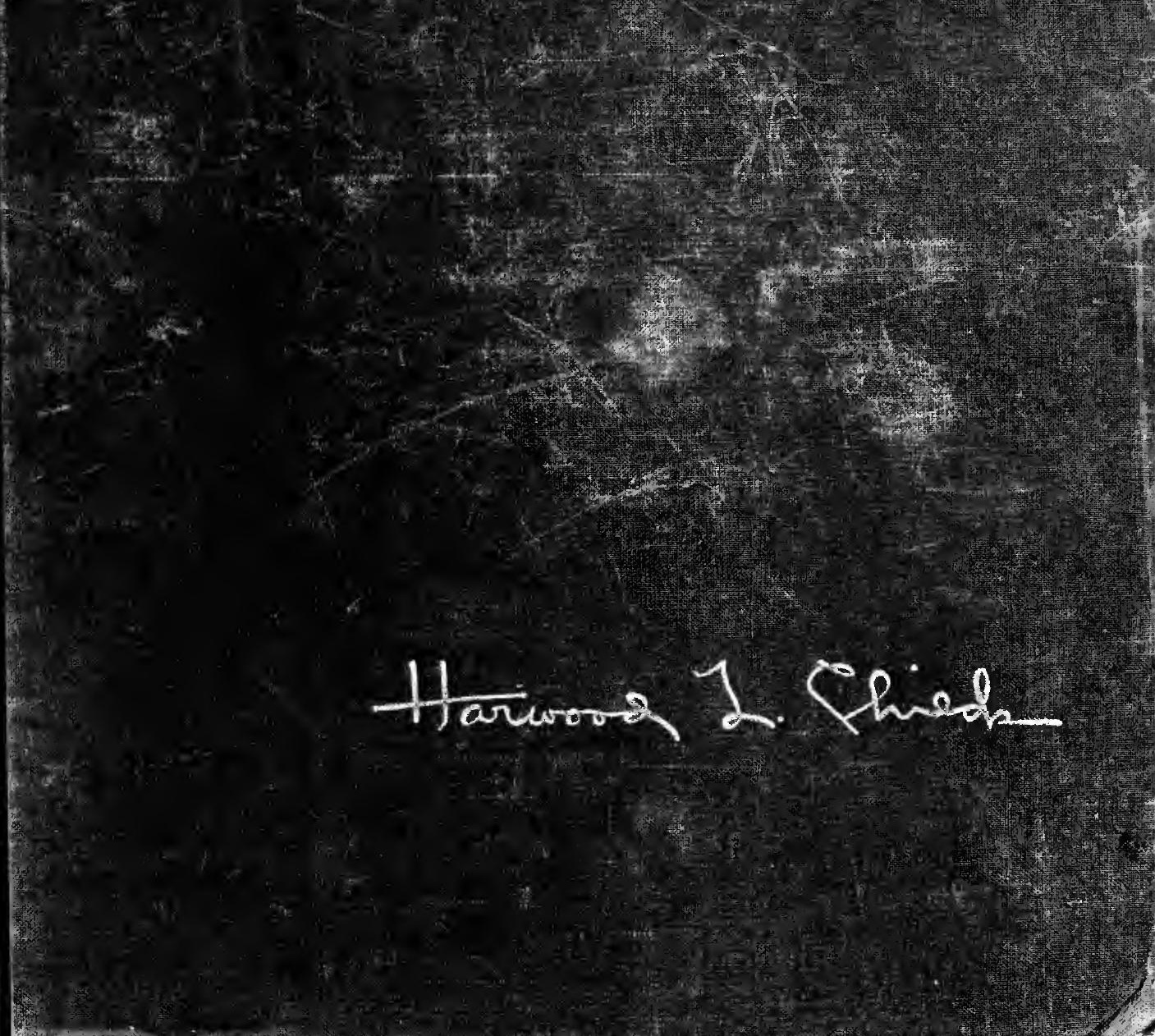


\section{UNIVERSITY OF FLORIDA}

L I B R A R Y

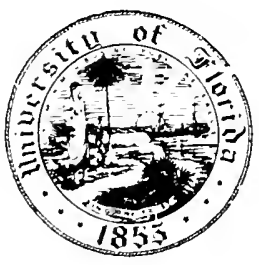

COLLEGE LIBRARY 
/ 

An elntroduction to

\section{PUBLIC OPINION}

BY

HARWOOD L. CHILDS

Associate Professor of Politics

Princeton University

New YORK: JOHN WILEY \& SONS, INC.

London: CHAPMAN \& HALL, Limited

I 940 


\section{Copyright, I940}

BY

Harwood L. Childs

All Rights Reserved

This book or any part thereof must not be reproduced in any form witbout the written permission of the publisher.

Printed in the U. S. A.

THE HADDON CRAFTSMEN, INC.

CAMDEN, N. J. 


\section{PREF ACE}

ThIs volume is the outgrowth of a series of lectures constituting $\perp$ a part of a two weeks' course on public relations organized by the American Council on Public Relations and presented to groups of business men at Reed College, Portland, Oregon; Stanford University; and the University of Washington in Seattle, during the summer of 1939. They were also included in the short course offered by the Council in Milwaukee in February, I940.

Public-relations problems are essentially public-opinion problems. Moreover, the academic student of public opinion soon discovers that those most realistically concerned with his field of study are men and women seeking to solve public-relations problems. Starting with the practical problems of public relations I have tried to show how a knowledge of public opinion will aid in their solution and what an understanding of public opinion involves.

The purpose of these lectures is twofold: (I) to present a theory of public opinion which will serve as a frame of reference for public officials, political leaders, business executives, labor leaders, and group leaders generally who are today at grips with public-relations problems; (2) to clarify the meaning of such terms as public relations, public opinion, public interest, and propaganda, and to appraise the role of certain institutions and practices in the public-opinion arena. Special attention is given to public-opinion polls, public-opinion research, current attempts to analyze propaganda, and the impact of foreign propaganda on the American scene. Some suggestions are offered for improving the functioning of public opinion in a democracy.

Limitations of the lecture platform precluded a detailed elaboration of the theses presented. Nevertheless, it may be of value to publish the papers substantially as they were delivered, even though the satisfaction that comes from meticulous refinement of statement is, to some extent, sacrificed. Definitions and philosophies are, by their very nature, personal matters. If Humpty Dumpty could make words 
mean what he wanted them to mean, so can we; and so can we make our philosophies mean what we want them to. The important thing is as George Cornewall Lewis once stated: "Where all people talk on the same subject, they should be agreed about the vocabulary with which they discuss it: or, at any rate, they should be aware that they are not agreed."

I wish to express my gratitude to Professor Rex F. Harlow of Stanford University, President of the American Council on Public Relations, for the opportunity afforded me to test my thinking in the fire of comment, criticism, and suggestions that came from those enrolled in the Council's short courses. I wish also to acknowledge my indebtedness to the publishers of Fortune magazine, the Public Opinion Quarterly, F. S. Crofts and Company, William Morrow and Company, the Institute for Propaganda Analysis, and the Macmillan Company for permission to quote various passages from their publications as indicated in the text. The publishers of the Dictionary of American History, Charles Scribner's Sons, have generously permitted me to make use of material I prepared for them in the lecture on The Concept "Propaganda." The National Council for the Social Studies and the Atlantic Monthly have been similarly gracious in permitting me to draw upon some material from previously published articles of mine in the lectures on Public-Opinion Polls and Public Opinion and Social Control.

Harwood L. ChILdS

Princeton University

March 1, 1940 


\section{CONTENTS}

What Are Public Relations?

PAGE

The Basic Problem of Public Relations

What Is the Public Interest?

What Is Public Opinion?.

Public-Opinion Polls

35 .

Formation of Opinion

The Concept "Propaganda"

The Art of Propaganda 75

Propaganda and Dictatorship

Propaganda and Democracy

Public Opinion and Social Control

Notes

Selected References

Name Index

Subject Index 



\section{What Are Public Relations?}

$\mathbf{T}$ a recent article in the magazine Fortune, the author introduces 1 a discussion of the subject, "The Public Is Not Damned," with this statement:

The year 1938 may go down in the annals of industry as the season in which the concept of public relations suddenly struck home to the hearts of a whole generation of businessmen, much as first love comes mistily and overpoweringly to the adolescent. Indeed, during 1938 there was scarcely a convention that did not feature an address on public relations, scarcely a trade magazine that did not devote some space to the subject, scarcely a board of directors that did not deliberate weightily on the powers of the new goddess. And they found that the sphere of this Mona Lisa was all of industry and that she presided over its most bewildering and least tangible aspects. ${ }^{1}$

Current interest in the subject of public relations is matched only by widespread disagreement and confusion regarding its meaning. In order to discuss intelligently the backgrounds of public relations we must have a meeting of minds so far as the concept itself is concerned. And right at the outset I wish to stress a note of warning. If there are some who subsequently come to feel that my conception of this vitally important subject is too idealistic, I can only say that I am not primarily concerned with public relations as they are, but with public relations as they should be. Furthermore, I hold no brief for much that is labeled public-relations work-the antics, stunts, tricks, and devices by which individuals and corporations often seem to obtain good will without actually trying to remove the real causes of ill will. I am not particularly interested in any one thousand ways to win friends and influence people. For me the subject of public relations goes much deeper than many current treatises on professional and corporate etiquette would suggest. In my opinion the ${ }^{1}$ Superior numbers refer to numbered notes beginning on page ${ }_{4} 43$. 
prevailing interest in public relations will continue and increase, for it epitomizes one of the fundamental problems of our times.

Public relations may be defined as those aspects of our personal and corporate behavior which have a social rather than a purely private and personal significance. The increasing importance of public relations is due primarily to the increasing number of personal and corporate activities which do have this social and public significance. Personal freedom is rapidly assuming a new meaning in the face of widespread technological and cultural transformations. To define public relations is to define private relations, to draw a line between personal freedom and social responsibility. Such a line can never be static. It is a moving line that must be redrawn continually as conditions change. All that we can reasonably attempt to do is to draw the line as of today. We cannot see far into the future. In order to draw the line today, however, it will be useful to take stock of the immediate past to find out why this problem of public relations has become such an important, vital phase of our social, political, and economic life.

In defining public relations as "those aspects of our personal and corporate behavior which have a social rather than a purely private and personal significance" I am aware that I may be taking liberties with a concept that has different meanings for many students of the subject. The origin of the term is shrouded in mystery. It certainly was employed in somewhat its current connotation during the early years of the present century. I have in my possession an address delivered by an executive of the Baltimore and Ohio Railroad in 1906 on the subject "The Public Relations Problem of the Railroads." And it is worthy of note that public utilities were among the first, apparently, to give attention to the problem. Frequent references are made, for example, to the early efforts of the Bell Telephone System in the public-relations field. ${ }^{2}$ And this is not surprising, because the Bell Telephone System, as well as railroads and other economic units "affected with the public interest," were among the first to feel the necessity of redefining economic freedom in terms of growing social responsibilities. The officials of the Bell Telephone System realized, even at a time when some prominent officials in steel and other manufacturing industries were pursuing a policy of "the public be damned," that the social effects of their business operations made it 
impossible for them to define their own personal freedom in such language.

Before reviewing the important developments of the recent past that have given rise to current interest in the subject of public relations I shall comment on a few definitions of the term in order to underscore the nature of the problem as I see it. One writer has defined public relations as "the planned presentation of your point of view in terms that will create public understanding and win public acceptance." ${ }^{3}$ Of a similar character are these definitions: "By public relations is meant the art of tempering the mental attitude of humanity in general towards a company, so that its position with the public shall be impregnable," or again "the development of cordial, equitable and, therefore, mutually profitable relations between a business, industry, or organization and the public it serves."

Each of these definitions misses, I believe, an essential point. Public relations as such is not the presentation of a point of view, not the art of tempering mental attitudes, nor the development of cordial and profitable relations. It is not the label for a new technique of propaganda that will necessarily bring fame and fortune to those who use it. It is simply a name for activities which have a social significance. Our problem in each corporation or industry is to find out what these activities are, what social effects they have, and, if they are contrary to the public interest, to find ways and means for modifying them so that they will serve the public interest. The public-relations executive is not primarily a press agent or a propagandist. He is a student of the social effects of personal and corporate conduct who undertakes to use his knowledge so as to minimize the harmful consequences of such conduct and to maximize the beneficial effects.

Another author has defined public relations as "the name business gives to its recognition of itself as a political entity," ${ }^{, 6}$ and still another as "a fundamental attitude of mind-a philosophy of management-which deliberately and with enlightened selfishness places the broad interest of the customer first in every decision affecting the operation of the business." ${ }^{\text {"T }}$ These definitions display a broader and deeper philosophical insight. But public relations is more than a new philosophy of management, a new ism that will serve as an antidote to Communism or Fascism. Public relations simply refers to those 
relations or activities of ours which have a general, social significance. It is the function of public-relations counsel to find out what these relations are, what social effects they have, whether these effects are contrary to the public interest, and what modifications in them may be necessary to bring them in line with the public interest.

I know that many will ask: What is the public interest? This is a crucial question, and I propose to deal with it at some length later. For the present I merely wish to stress the point that public relations is not a new technique of propaganda, nor is it some novel panacea or philosophy to be foisted on business. It is simply the name for certain types of activities, many of which were once of personal significance, but now, owing to the dynamics of social change, are affected with the public interest. An outstanding phenomenon of recent times has been the increasing scope of these public relations, the multiplication of social consequences from personal and corporate acts. These acts are the subject matter of public relations.

Some have defined public relations as simply the relations of a business or corporation with the public "judged by the common concept of sound human conduct." If, by this definition, we mean relations having a public or social significance I raise no objection. To insist, however, that the term be restricted solely to relations or activities generally regarded as sound is to prescribe ethical limitations which ignore the neutral, objective character of the expression.

Our conclusion, therefore, is this: Public relations is simply a name for those activities and relations of ours which are public, that have a social significance. The student of public relations wishes to know what they are, what social effects they have, whether these effects are in the public interest, and, if not, what can and should be done. Public relations is not the name for a new ideology, nor the designation for an esoteric art of propaganda. It is simply the name for a class of personal and group activities whose changing dimensions affect the lives of all of us.

The starting point in our thinking about public relations logically begins, therefore, with a consideration of the more important reasons why so many of our personal relations have suddenly been transformed into public relations. The farmer, for example, is often referred to as our staunchest individualist. For decades he was quite free to conduct his farming operations as he jolly well thought best. 
He tilled the soil, planted seed, harvested crops, raised cattle, picked apples, cut lumber, mended fences, raised and educated his children about as he chose. Whatever he did or failed to do affected only slightly the welfare of his neighbors and even less the welfare of the community generally. His public relations were the least among his worries.

The situation of the farmer was not exceptional. The doctor and the lawyer, the teacher and the business man lived their lives in comparative isolation-at least, the number of persons affected by what they did was small. Out of this environment emerged a philosophy of public relations that was essentially a dogma of personal freedom. Slowly at first, then with accelerating tempo conditions changed. At first blush it seemed as though some evil spirit motivated the change. Men tried to identify the evil genius. They attributed the change to the grasping, selfish aims of individuals and groups; to the party in power; to labor; to radicals surreptitiously befouling the minds of the masses; to all sorts of personal devils.

One indication or measure of the increasing scope of public relations was legislation. Legislative bodies began to pass laws regulating the hours and conditions of work of women and children. Laws were passed regulating the practices of railroads and utilities. Purefood laws were passed; milk had to be tested; fire escapes had to be built; doctors and lawyers had to be certified by the state before they could practice their profession; teachers had to undergo specified types of training before they could enter the classroom. The final straw, in the minds of many, was the adoption of the prohibition amendment, a measure which brought the drinking habits of the American people within the scope of public relations. How may we account for these transformations? Shall we attribute this broadening scope of definition to legislative maliciousness or the perfidious activities of would-be despoilers? Or must we look deeper to the very elements of social change themselves?

The fact of the matter is, as I see it, that impersonal, sociological forces were at work, having a centripetal tendency to draw individuals together into ever larger, ever closer, interdependent units. These forces were everywhere at work in society, but their effects were often minimized, especially in a country such as the United States, with an abundance of natural resources. 
One of the mast obvious of these sociological forces was population growth. From the national, historical point of view population growth brought about westward expansion, the opening up of new areas, the enlargement of the electorate, and expanding dimensions of publics and markets. With it went an increasing urbanization of the population. After the passing of the frontier, however, and the end of the nineteenth century the rate of population growth declined. Students of population tell us that this rate is likely to continue its downward tendency until we have a much more stable relation between population and natural resources. No student of public relations may ignore the implications of this great sociological force. It has affected and will continue to affect the social character of our activities. Personal and economic freedom in sparsely settled communities has a very different connotation from what it has in metropolitan areas or in a country with a high degree of population density.

I have mentioned some of the implications of population growth in quantitative terms. But the quality of the population, its composition, the interrelations of different nationalities within it, and the ever-changing character of its customs, mores, and attitudes exert a power influence upon the scope and nature of public relations.

Of equal importance as an explanation of the growth of public relations are political changes. Democratic government, in the sense of popularly elected officials, representative assemblies, and written constitutions, experienced a slow and uncertain expansion until the end of the eighteenth century. Even then the suffrage was narrowly restricted and mass opinion as a factor in government was largely ignored. The nineteenth century, however, witnessed a rapid and continuous development from these early beginnings. State after state adopted written constitutions. The suffrage was progressively extended. Not only did the proportion of the population officially participating in public affairs steadily increase, but formal responsibilities likewise expanded. The adoption of direct primary laws and the increase in number of elections, as well as the spread of the initiative and referendum, added to the civic responsibilities of citizens. The opinions of the masses became politically significant. Corporations and groups generally were compelled to recognize the political as well as the financial implications of what they were doing. 
Another reason for the increasing significance of public relations is the spread of educational facilities with the accompanying increase in literacy. The public support of schools and colleges, the introduction of compulsory school-attendance requirements, and statutory rules affecting child labor made the three R's the general rather than the exceptional equipment of the population. It is estimated that more than two and three-fourths billions of dollars are spent annually for education in this country, and that one out of every two persons of secondary-school age, and one out of seven of college age, are in a secondary school or college. The full sweep of the changes accompanying this development is only partially suggested by the fact that nearly one-fourth of the population of the United States is directly or indirectly engaged in educational activities.

Democratic government not only assigns a large proportion of its citizens increasing responsibilities in the determination of public policies, but also seeks to make its citizens competent to deal with them. Whether the competence of public opinion is actually increasing, and even more important, whether the increase in competence, if there be such, keeps pace with increasing responsibilities, are questions of far-reaching importance. The significant thing so far as the student of public relations is concerned is that the spread of educational facilities raises the expectations and increases the demands of citizens. In many cases it aggravates discontent with existing conditions, multiplies efforts to remedy them, and makes public opinion a more volatile, articulate factor in state life. Masses of illiterates and uneducated persons may be contemptuously ignored in our pursuit of happiness and freedom. Not so the growing numbers of people turned out by our mammoth educational systems. The social and public consequences of our actions may remain the same; the size of the population and its composition may remain unaltered; even our form of government may remain unchanged. If, however, an increasing proportion of the population visualizes new ideals and expects higher standards of living, the social implications of our activities assume a new meaning. Discontent arises because of the gap between expectations and realities. It is not enough for American citizens to know that they have a higher standard of living than the Russians or the Orientals. They evaluate conditions in terms of their own ideals, not those of other peoples. 
For many years the subway system of New York has operated shuttle trains between Times Square and the Grand Central Station. These trains operate today much as they operated when the system was built. At times the congestion at both terminals is indescribable. The foul air, the dust, the poorly constructed platforms, the clangor, noise, and jamming are almost unbelievable. Guards shout, as they have done for decades, "Watch your step," as you leap from platform to train. You hold your breath and squeeze into the train on the general theory that there is always room for one more. Only the pressure of steam or forced air could possibly close the doors.

No doubt when the shuttle was constructed people using this mode of transportation were more or less satisfied. At any rate, from the operating company's point of view passengers could take it or leave it. The subway was a purely private undertaking, and the company need assume no responsibility for social consequences or public attitudes. The management had no public-relations problem.

Today the situation has changed, owing in part to the growth in population; to an increase in the number of people using this supposed "convenience"; to the fact that people in New York have become more articulate politically, perhaps, but owing especially to the fact that people have come to expect more from transportation agencies than simply a piece of rolling stock that rolls between two terminals. They have been educated to demand more. The situation has become a public-relations problem. This is only one instance which illustrates the interaction of forces bringing about a changing concept of personal freedom and public relations.

The development and improvement of agencies of mass impression may also be cited as a reason for the increasing significance of public relations. Although journalism in a crude state came to this country with the early colonists, it was not until after the close of the Revolution that a daily paper was published in this country. For many years thereafter circulation figures were extremely modest. In spite of improved methods of news-gathering, typesetting, printing, financing, and distribution, it was not until the last few decades of the nineteenth century that newspapers with a daily circulation of over a million copies were possible.

The advent of motion pictures and radio broadcasting is largely the story of the last twenty years. Radio communication prior to the 
World War was used chiefly for maritime and experimental purposes. The first real broadcast in this country did not occur until 1920. However, after the creation of the Radio Corporation of America in 1919 and subsequent improvements in sending and receiving apparatus, the growth of radio was phenomenal. Today nearly three-fourths of the families in the United States own radio sets, and it is estimated that broadcasting stations have a daily audience of more than thirty-seven millions. The tempo of technological changes in this field may even be accelerated now that television and facsimile transmission have become realities.

And so with the motion picture, which really started its dramatic career during the last years of the nineteenth century. It was not until after the World War, however, that its possibilities as an agency of mass impression began to be realized. In fact these possibilities were definitely restricted until after the invention of sound-recording devices and the installation of talking pictures in theatres throughout the country, beginning in 1928 .

Technical improvements in means of communication have produced marked effects upon the scope of public relations. They have greatly enlarged the size of publics. They have increased the power and influence of those in a position to control and use these instruments and, at the same time, have weakened the relative influence of those who do not have access to them. We have to do not only with larger, better-informed, and more responsible publics. We also deal with publics whose opinions probably are changing at a rate more rapid than ever before. A mechanized world which enables individuals to establish contact with millions of people simultaneously is a world in which opinion changes over wide areas are certain to occur more frequently and suddenly. Nationwide hookups, feature pictures displayed at the same time throughout the country and over the world, newspapers and magazines with circulations in the millions can produce opinion revolutions as different from the slow evolutionary changes of the past as TNT is different from gunpowder.

New doctrines and ideologies which in the past could not be brought to the attention of the masses except by a slow process of infiltration can now be broadcast one minute with the expectation that they will take effect the next. A speech by the President, by an 
industrial or political leader, which formerly would have taken weeks and months to bring to the attention of the bulk of the American people, may now be heard simultaneously by millions and affect the result of an election or the course of international relations the next day.

One consequence of this is that individuals are subjected to many more stimuli than formerly, are brought into closer touch with everybody's problems. To their own problems of family and occupational life are added the worries and problems of central Europe, the Orient, Africa, and South America.

But this is not all. Almost over night each of us may find himself living in a glass house. The doors of our skeleton closets are thrown wide open. Inquiring reporters and congressional investigating committees stand ready to headline any or all of our activities for the entertainment of curious masses. The press, the radio, and the motion picture have upset traditional notions of privacy. and exposed us to the gaze of the multitude. Probably nothing has so profoundly affected our traditional freedoms as these developments in the field of communications. In face-to-face communities and groups our friends generally knew us for what we really were and could evaluate our motives and activities in the light of this knowledge. Not so the masses who are incessantly peering at us through the magnified, but sometimes distorted, lenses of journalists, broadcasters, and motionpicture producers.

The concept of public relations in our times has been affected, therefore, by sociological, political, cultural, and technological changes of a fundamental nature. Our personal freedoms have been increasingly circumscribed. Our social responsibilities have expanded and probably will expand, to what limits no one knows. No better evidence of this can be found than in the economic sphere, where economic forces have step by step vested our personal freedoms with greater and greater social responsibilities. Indications of this are numerous: the increasing size of undertakings, the concentration and integration of business units, specialization and division of labor, multiplication and refinement of products, standardization, trade unionism, mass production, and widening of markets. The activities of manufacturers affect directly the welfare of farmers, workers, and the consuming public. The activities of farmers in turn have a direct 
bearing upon both the purchasers and the users of their products. The production and manufacture of intricate and refined goods necessitate the cooperation of an ever-increasing number of economic units. We usually cite the example of assembly lines in our large automobile industries. There we can see vividly how the actions of one affect the work of many. The failure of one person to do his job properly may throw the whole undertaking out of order.

In a very real sense, however, our whole economic system is an assembly line, and the welfare of the national economy is dependent upon the proper functioning of each unit. If it is difficult to keep an automobile assembly line functioning efficiently from the ore mines at one end to the garages at the other, how much more difficult must it be to order the functioning of an entire national economy? The introduction of this assembly-line principle into our national economy is the inevitable price we pay for the many kinds of goods and services we have. To run trains on time, to have radios in our homes, to purchase automobiles at the prevailing price, to have submarines, and to use typewriters, natural resources from all parts of the country and the world have to be processed and assembled, manufactured and distributed. To lament the increasing centralization of control within industry, to decry the advent of bigness and monopoly, is to plead for cruder commodities and less refined services. We do not wish to lower our standards of goods and services, and yet we insist upon a type of national economy in which they cannot be provided. Business through its inventive capacity has awakened in the minds of the masses wants that never existed and has provided the means for satisfying them. What it has failed to do is to take account of the social responsibilities it assumed by so doing.

Any satisfactory explanation of the growing significance of public relations may not ignore the many events of the post-war period that have disposed the masses to criticize the traditional functioning of our economy. Economic crises, periods of depression, unemployment, threats of dictatorial aggrandizement, price changes, demands for greater security, profits, taxes-all these have served to multiply tensions, create feelings of discontent and insecurity, and produce a more vigorous struggle for control over that instrument of salvation, public opinion. In order to realize many of their hopes and expectations discontented groups have turned to the government for aid. 
To obtain control over the government they have become more and more politically minded, which in the American sense of the term means that they have become more and more conscious of the importance of public opinion. Labor and agrarian groups almost from the outset were politically minded in this sense, but it has taken a New Deal to awaken business to this point of view. Previously confident of the power of money and material resources to assure their supremacy, business leaders ignored, very largely, the mass effects of their actions.

In a world in which social change is taking place at a greatly accelerating rate and in which governments are being forced to assume greater responsibilities, the tenets of personal freedom, the functions of government with respect to leadership of opinion, and the role of public opinion with respect to government are being subjected to more searching analyses than ever before. It is evident that, confronted with a domestic situation which calls for an increasing amount of social budgeting and cooperation, and in the face of an international situation which calls for a united front against dictatorial aggression, we are being forced to modify our traditional conceptions of where the line should be drawn between personal freedom and social responsibility. We cannot have a planned economy capable of satisfying our wants efficiently and continue to exercise our accustomed liberties quite as we have done before. We must face the problems of public relations, the problems that arise because of the increasing scope of our activities which have a social significance. 


\section{The Basic Problem of Public Relations}

UR last lecture dealt with the meaning of the term "public relations." We defined it as those aspects of our personal and corporate behavior which have a social rather than a purely private and personal significance; and we focused attention upon some of the reasons why the concept has broadened in scope and importance in recent years. We discovered that an adequate explanation presupposed an understanding of the operation of certain basic sociological, political, cultural, and economic forces which make for greater social interdependence. We now turn to the question: What, in the light of these changes, is the basic problem of public relations?

The basic problem of public relations, as I see it, is to reconcile or adjust in the public interest those aspects of our personal and corporate behavior which have a social significance. One of the first tasks of the counsel on public relations and students of the subject is to analyze personal and corporate behavior in terms of their effects upon the community. And by community I do not mean simply the corporate community of stockholders, employees, and consumers. These publics are important, and the relations with them constitute a part of the problem. But the effects of personal and corporate activities extend far beyond the limits of our immediate corporate family to the masses generally. This analysis of our personal and corporate activities cannot be pursued satisfactorily unless we have an adequate understanding of the sociological, political, economic, and cultural background of these activities. Without this knowledge we cannot evaluate properly the social implications of our work.

Within the past few years, for example, a new industry has appeared on the American scene-television. Whether we are manufacturers or users of television receiving sets, the introduction of this new medium of communication is certain to affect the scope and nature of our activities. But how? This is a problem of public relations. It is the job of public-relations counsel and students to study these effects, ascertain the extent to which the production and manu- 
facture of television sets affect the habits and interests, not only of employers and employees, stockholders and customers, but of all elements in the population.

There is first of all the public-relations problem of the television industry itself and the various units that compose it. How does the introduction of this new instrument affect other industries, their profits, their employment conditions, their methods of carrying on business? How does it affect other groups in the population-farmers, teachers, public officials, housewives? How will its use by a government agency, by an educational institution, by a private corporation affect the relations of these agencies or institutions with the numerous publics with which they come in contact? How does it alter the relations of such publics with us, and how does it modify the relations of such publics with one another?

It is not only necessary to identify effects as they occur, but it is equally important to forecast what those effects are likely to be in the future. Otherwise serious difficulties may arise before there is an opportunity to control or modify practices. The counsel on public relations must be in a position not only to follow day by day the ever-changing nature of public relations, but also to anticipate probable trends and consequences. This foresight is one of his most priceless possessions. It is not something that comes as manna out of heaven, but it is the product of wide knowledge and experience, a real understanding of sociological trends in contemporary society.

Numerous illustrations could be cited to show how this knowledge has actually been used by farseeing executives to anticipate the probable effects of specific changes in corporate policy upon public relations. Only an intelligent appreciation of the historical backgrounds of industrial relations could have given the management of Big Steel the foresight to anticipate the wide implications of its decision some months ago to modify its employee policy as it did. The United States Steel Corporation recognized from the time of its founding in rgor the nationwide importance of news of Big Steel's activities. Throughout its history it has continued to publish detailed information regarding its operations. But for a long time steel operators failed to take account of the social implications of many other aspects of their corporate practices-their basing-point system, their labor policy, the import of sociological changes outside the industry. The 
dramatic signing of an agreement with the C.I.O. in March, I937, which came as a shock to many business leaders, really reflected an exceptional appreciation of current trends, a foresight all too unusual in the business field.

Much is made in the literature of public relations of recent efforts by the United States Steel Corporation to improve its relations with the public: the new pressroom at 7I Broadway with every conceivable facility for contributing to the comfort and convenience of representatives of the press, the new era of executive cordiality, "open-house" programs, the use of films and pamphlets to tell the "Story of Steel." These efforts are good as far as they go. They evidence some recognition of the changing panorama of social change. But the problem of interpublic adjustment goes much deeper-and necessitates a far more comprehensive and detailed diagnosis of social trends than even Big Steel has envisaged.

One of the earliest, farsighted public-relations programs ever conceived in the history of American business was that of the Bell Telephone System. As far back as I 883 Theodore Vail perceived, as few did at the time, the public-relations implications of the business. He noticed, for example, that the work of his telephone operators, men for the most part, failed to display the patience and tact necessary for meeting satisfactorily the annoying problems which arose at the switchboard in dealing with subscribers. At once he substituted women for men operators.

Further recognition of the public implications of the business came with the inauguration of a national advertising campaign in I908. Long before the electric-light, gas, and power industries sensed the growing antipathies of the masses to corporate practices in the public-utility field telephone executives had divorced their business, so far as the public mind was concerned, from other types. Attacks on the utilities, particularly the defunct National Electric Light Association, which culminated in thoroughgoing governmental investigations, left the telephone industry virtually unscathed.

This is not the place to describe in detail the mechanics of publicrelations practice as followed by the American Telephone and Telegraph Company. Many of them have since been followed by other industries. Considerable progress has been made in the electrical, food, manufacturing, banking, retailing, petroleum, airplane, auto- 
mobile, motion-picture, railroad, radio, brewing, and other fields. Relations with the press have been improved; business reporting has been modernized; the film and the radio have been used; in some cases contacts with the public have been improved by "open-house" parties, advisory committees, etc.; employees have been trained to "say it with a smile"; the basis of stock ownership has been broadened; advertising appropriations have increased; community welfare programs have been introduced.

It is because of these efforts, good in themselves, that public relations has come to be defined solely in terms of publicity. Telling one's story is certainly an important development. My only contention is that it does not go deep enough. It does not, and cannot, take account of the gaps and lags in social progress out of which the real problems arise. The basis for an enlightened public-relations policy is and always must be a thorough understanding of the forces that make those relations what they are, a careful analysis of the social implications of specific practices. Public-relations advice, to be worth anything, must be grounded on a comprehensive knowledge of the past, of trends and relationships in the field of social change. It must begin with the life history of the person and the corporation, and more than that with the life history of the American people: their economic, political, and social background.

It is evident that the adjustment of corporate and personal relations having a public and social significance with fundamental social trends has not taken place in many spheres of human affairs. One example of maladjustment is in the field of international relations. Governments as well as unofficial groups and institutions have their public-relations problems: The actions of government agencies as well as individuals have more far-reaching implications today than ever before. The freedom of individual states to act as they wish without regard to the general social worldwide implications of their activities has been steadily diminishing. Even the dictatorial powers will slowly, all too slowly perhaps, come to realize that they are integral parts of an international community, and simply cannot pursue a policy of complete isolation from the rest of the world. They apparently do appreciate the import of changes in the field of communication upon international relations. They sense the importance of propaganda and the necessity for taking into account the 
opinions of the masses throughout the world. Nevertheless they seem to ignore other changes, other forces quite as important-economic, social, political-persistently delimiting the bounds of state discretion.

But the dictatorships have not been alone in failing to take account of the changing character of government public relations. The democracies, and the United States in particular, during the years immediately following the World War tried, ostrich-like, to avoid the implications of activities that affected people throughout the world. Our failure to take part in the League of Nations; our delay in joining the World Court; our tariff policies, our trade policies, our immigration laws reflected an old spirit of nationalism developed in an era when the dimensions of national freedom were much greater. One of our most lamentable shortcomings as a nation, I believe, is our tendency to act, legislatively and otherwise, without careful consideration of the social, the worldwide significance of our actions.

We say: Well, what difference does it make what effect this act has upon the peoples of the Far East, of South America, of central Europe? Years ago it might not have had much significance. But the interdependence of nations and states is far different today from what it was then. Our international difficulties can be solved only if we attempt to adjust our public relations on a basis more in accord with the public interest, internationally perceived, than on a purely national basis. I am not prescribing a foreign policy for the United States. What I am seeking to do is to emphasize the importance of adjusting our foreign policies to the operation of social, economic, and political forces that are definitely affecting our relations with other nations.

Another striking example of maladjustment is in the field of labor relations. If I were to assign one basic reason for the difficulties I would say that they are due primarily to a failure on the part of both parties to take full account of social changes that have materially affected the implications of their activities. Management, for example, has introduced new machines, fabricated new products, introduced new labor-saving devices, altered technological processes, all too often without due regard to the far-reaching and cumulative effects of these changes. Management restricts its research activities to the technical field, focuses attention solely upon the material fac- 
tors involved, and provides no machinery for a comprehensive and continuing study of the implications of business activities upon social relations generally.

Ever since the beginning of the twentieth century, and even before, our institutions of higher learning have been devoting an increasing amount of attention to the study of the social sciences; to an examination of sociology, social psychology, political science, and economics. Unfortunately, however, these findings have not been placed at the disposal of business units within our society to the extent that they should. Where some effort has been made to take advantage of this work, such as the attempt to apply principles of psychology and social psychology to advertising, the objective has been the interests of a particular business unit, profits, an enlarged scope of freedom rather than an adjustment of activities to growing social responsibilities. How many business firms now have a public-relations department within their organization, a social science division capable of analyzing and interpreting for them, not merely the balance-sheet significance of their operations, but the social implications of what they are doing? Members of managerial staffs have introduced new machines and processes, but where have they attempted to measure the effects upon the conditions of employees, attitudes of mind, standards of living, or, for that matter, the effect of these changes upon competitors, upon consumers, upon the economic system generally?

Industrial problems arise, so students of sociology tell us, because of cultural lags, because of the varying rates at which different aspects of social change take place. Every change in corporate and personal behavior has widespread repercussions and tends to throw economic and other systems out of joint unless the change is properly synchronized with other changes. In moving forward towards a goal, whether it is economic or military, it is imperative that all units advance at something like the same rate or else invite disaster. Using the military analogy one might say that the public-relations difficulties of American business have arisen because some divisions have moved ahead so much more rapidly than others that they have lost touch with neighboring units and disorganized the general advance. This is true, not only for individual units within the economic system, but also for the national economy as a whole. It has got out 
of touch with allied forces of social, cultural, and economic change and tried to win the war itself.

In the field of labor relations, progress in the technological sector has advanced much more rapidly than progress in the sociological sector. There has existed no general staff to synchronize and direct operations on a broad, general front. Too little account has been taken of the direction and rate of change in employee attitudes, of their hopes and expectations; the effects of widespread popular education, improvements in communication and transportation agencies; the fundamental effects occasioned by the World War; the rise of new philosophies; crises and depression. To be sure we read about them, but seldom did we transfer our knowledge to the arena of our own activities. We knew that a World War occurred. We knew something about the havoc it occasioned. And yet we failed to take account of the many fundamental changes that ensued. We still talk about a return to normalcy and the American Way, as though its course had been fixed in rigr4. We zealously try to pick up where we left off in 1917 and insist on the same old freedoms without regard for all these fundamental changes that have taken place since in the lives and attitudes of peoples throughout the world.

I should like to cite just one more example of what I mean by a public-relations problem. We are all aware of the current emphasis upon what is called socialized medicine. For decades states have been passing statutes designed to promote the health of its citizens. These statutes reflect in large part changed conditions brought about by the rise of cities, the introduction of new types of employment, and more particularly by changing attitudes toward the responsibility of the community in matters of health. More recently we have been witnessing the spread of various types of social, old-age, and hospitalization insurance plans. A point has now been reached where the medical profession is on the defensive.

Dr. Rock Sleyster, President of the American Medical Association, in an address before the I73rd annual convention of the Medical Society of New Jersey on June 6, 1939, said:

The nation's physicians are being libeled and threatened with a regularity that shows method and purpose by a storm of propaganda for socialized medicine. Notice has been given that we are to be investigated, excoriated, flagellated and perhaps 
excommunicated. ... God help us, for we too have dared to differ with the all-wise, have called attention to their inaccuracies, have refused to be stampeded into agreeing with their unAmerican and revolutionary doctrines. No credit is given to a profession that has given a million dollars a day in free service and millions more at far below cost. What comparable record have the purveyors of other necessities of life to offer?

And so the American Medical Association finally discovers that it has a public-relations problem! But what is the nature of this problem, and why has it arisen? If our preceding analysis is correct the problem has arisen because social change has proceeded more rapidly in some sectors of our social life than others; because the medical profession as a whole has not been following carefully enough the social implications of its work, its import upon and relation to activities in other fields. The medical profession is not the victim of a malevolent group of people with wild-eyed schemes of social reform. Its difficulties are largely due to its own blindness to social, economic, and cultural forces that have been operating for a long time. It should have been aware of these forces long ago. It should have anticipated these social trends. It should have tried to keep pace with these changes.

This is not to say that all phases of social change are necessarily desirable. It does suggest, however, that an enlightened publicrelations policy would have anticipated them, would have taken measures long ago to deal with them. The frantic efforts to preserve former freedoms now seem a bit ill-timed. It is always an exasperating and frequently a painful process to try to catch up with the times. No public-relations counsel can wave a magic wand and suddenly turn back the onward surge of social forces. The publicrelations problems of the medical profession have been growing like a cancer for years.

In all fields-international relations, labor relations, medicine, and throughout our national economy-we may observe similar trends; struggles for progress without a sufficient understanding of the progress that is really going on. A public-relations policy envisaged solely in terms of propaganda, of word and symbol manipulation, is certainly a shortsighted policy. No amount of publicity can really stem the operation of basic, socialized forces. The method of con- 
trol must be predicated on a continuous, searching analysis of these fundamental forces. Throughout the rank and file of our population bewilderment prevails. We have pressed buttons, turned switches, installed machines, and opened flood gates without fully understanding the basic laws of biology, psychology, and sociology. And if there have been some who have thought that they understood them, their plaintive voices have been silenced by the onrush of the mob, intent on turning on more switches and pressing more buttons.

I have stated that the basic problem of public relations as I see it is to reconcile or adjust in the public interest those aspects of our personal and corporate behavior which have a public significance. This principle applies regardless of the size of the unit concerned. The starting point in working out a public-relations policy is a careful analysis of our personal and corporate behavior in the light of social change generally. Without knowing the basic economic, cultural, political, and social trends of our times we cannot ascertain, much less anticipate, the public implications of what we are doing. It is the lag between social trends that gives rise to our problems, and the search for answers must be a search for the reasons why these lags exist, where they exist, and what can be done to synchronize social movement. The business of producing and distributing goods and services must be studied in relation to the total situation, the total environment in which we are functioning. Executives of corporations cannot afford to devote all or even the major portion of their energies solely to technological considerations. They must raise their eyes to the level of wider horizons. The public-relations counsel must be something more than a publicist, a journalist, or a statistician. He must be a social scientist capable of advising management regarding the environment in which it is operating. 


\section{What Is the Public Interest?}

T Have tried to establish, in our discussions thus far, these two 1 propositions: (I) that our public relations are essentially those aspects of our personal and corporate behavior which have a social significance; (2) that the basic problem of public relations is to adjust such relations to the broader aspects of social change in a way that will promote the public interest. It is my thesis that our publicrelations problems arise because we are unable or unwilling to assume the social responsibility for our actions we should, either because we fail to recognize their social implications or because we insist on a definition of personal freedom in terms that are outmoded. It is our failure to adjust in the public interest our conception of what are and what are not public relations that is the real source of our difficulty. It is not only shortsightedness but also unwillingness to act that produce catastrophic gaps and lags within the arena of social change.

Now the social scientist himself must accept a part of the responsibility for this state of affairs. He has been quite as indifferent to his own social responsibilities as leaders in other walks of life. He declaims incessantly about "science" but all too little about "social." The obvious difference between a social science and a natural science is the fact that one is social and the other is not. This truism has been frequently ignored in the interminable discussions about the nature of a science and the applicability of the methods of physical sciences to the study of social phenomena.

It is not enough, however, for the social scientist to analyze personal and corporate behavior in terms of their social effects. He must posit a standard or criteria of social welfare. And the fruits of his research should be placed at the disposal of the community. All too frequently he discovers principles or invents techniques only to have them seized and used to the detriment of his fellow men.

Recently the press of the country announced that a famous natural scientist at Harvard University had refused to allow citizens of 
Fascist countries to use his discoveries because they would presumably employ them, not to promote public welfare, but to implement racial selfishness and aggrandizement. Here was an academic research worker and world-renowned scientist who had the courage to act upon a recognition of the broad public-relations implications of his work and to insist that his discoveries be devoted to what he believed to be the public interest. The fact that his action was headline news only goes to show how dramatic a departure it was from the ordinary. The prevailing attitude among many natural scientists seems to be that their profession relieves them from all responsibility for taking the public interest into consideration in what they are doing. And I regret to say that this point of view exists to a large extent among social scientists. And with what result?

Over and over again the laboratories of the social scientists have been ravaged to promote the interests of private groups with little or no thought of the social effects. The fruits of advertising research, for example, have been taken and used by patent-medicine vendors and manufacturers of adulterated foods with even greater avidity than by those seeking to promote even indifferently worth-while social services. In many cases our psychological laboratories have been prostituted to the uses of socially undesirable causes. And I regret to say that much of the prevailing interest in public relations is often based upon no broader idealism than the desire to find out how to promote some profitable cause irrespective of its social usefulness. There is always a lurking, curious interest in the question: How can I mold public opinion? How can I persuade the masses to accept my ideas, my gadgets, my services? Now where is one to look for a social purpose, a public interest, in all this?

But what is the public interest, our smart friends will ask? Who is competent to say? The fact of the matter is, so the clever argument runs, that no one knows what the public interest is. Even the scholars, the learned, the scientists, the intelligentsia disagree. Who really knows whether tariffs are in the public interest or not? Who is competent to say whether prevailing utility rates are contrary to the public interest? As a matter of fact, who can prove beyond the shadow of a doubt that the sale of narcotics, adulterated foods, and deleterious nostrums may not, from the long-time point of view, be serving the true public interest? How often have we heard the 
argument that intemperance may really be a blessing in disguise, for those who use alcohol to excess, so we are told, may better be dead than alive. Intemperance serves to weed out the unfit; likewise the rigorous operation of an uncontrolled, competitive system. Does not the latter ensure the survival of the fittest?

The concept "public interest" in company with much idealism has suffered a severe setback in recent years, especially since the World War. In a world of multiplying ideologies and conflicting interests, absolute standards of value have gone into the discard. Theories of relativism and pragmatism have tried to give some semblance of philosophical sense to the situation but without much satisfaction except, perhaps, to philosophers themselves. And in the midst of perplexing uncertainties social scientists themselves have retreated to the four walls of their laboratories, and with monastic fatalism and skepticism insisted that they have no concern with questions of values, of social responsibility, and of the public interest.

Current interest in the subject of public relations can materialize into something worth while only if it brings social scientists and executives together on the basis of mutual concern for the public welfare. If one side merely seeks to discover a few more tricks, a few more schemes for promoting private objectives irrespective of the public interest, there is little point to the undertaking. If the other side is simply looking for an opportunity to endow or finance some form of research activity merely to gratify the desire for prestige and social recognition, then the results will be futile, the problems of public relations will become more rather than less acute and distressing. The underlying motivation for public-relations study must be a desire to serve the public interest. That is obviously the inspiring motive behind this great undertaking-the American Institute of Public Relations.

It is my thesis that the public interest, so far as the United States is concerned, is and can only be what the public, what mass opinion, says it is. By mass opinion I mean the collective opinions of the American people as a whole.

Now it is clear that public opinion is a dynamic and changing thing. The rate of change is affected by many influences and is greater with respect to some subjects than others. Public opinion with respect to the social value of adulterated foods and narcotics 
is certainly far more stable than it is with respect to the use of alcohol or the desirability of a given neutrality policy. In our consideration later on of the efficacy of public opinion as a criterion of public interest this fact of the relative degree of stability of public opinion regarding different subjects should be kept in mind. Moreover, the degree of certainty and conviction with which public opinion supports or disapproves of public policies varies. The public conception of public interest will be clearer and more precise in some fields than others.

The American theory of social adjustment and public interest has been gradually divorced from other notions that prevailed for a time. The theory that divine revelation via specific human channels gave to one man or group of men a monopolistic preview of public interest is gradually losing its convincingness. There is less danger, the masses have discovered, in assuming that divinity reveals the public interest through the minds of the masses than there is in the belief that it reveals this interest through specially inspired individuals or groups.

There was a time when churches purported to be the sole repositories of divine insight into the true nature of the public interest, but persistently the impact of social change forced them to recant at least so far as temporal matters are concerned. The invention of the printing press in the fifteenth century, the Renaissance and Reformation, geographic explorations, and the Industrial Revolution started a chain of developments which finally brought about the undermining of the church as the sole dispenser of truth and revelation. The advent of Fascism and National Socialism would seem to mark a revival of earlier tendencies. Nevertheless it is significant to note that these self-ordained, dictatorial élites are careful to point out that the source of their will and inspiration is really public opinion. Skeptics observe, however, that sometimes dictators are compelled to employ the far-fetched argument that their will may, in some instances, be a truer expression of public opinion than the votes of the electorate on election day.

Americans have become accustomed to the ever-recurring claims of special-interest groups that they, and they only, speak in terms of the public interest. So far a 'I know, such special-interest groups have never indulged it the species of scholastis diaiettics of the 
Fascists, however, and sought to differentiate between a true public opinion and the ordinary, garden variety of public opinion that expresses itself at the ballot box. Most of these claims are discounted or discredited altogether. But there still persists in some quarters the notion that somehow or other the opinions of the masses are less likely to be expressions of public interest than the pronouncements of savants.

One of the principal contributions of nationwide polls, such as those conducted by the American Institute of Public Opinion and the magazine Fortune, has been the light they have thrown on the matter of the competence of the masses, the wisdom of the electorate, to pass upon questions of public policy. The results of these surveys tend, I believe, to reestablish faith in the underlying tenets of democracy, the theory that, by and large, over reasonably long periods of time, public opinion is as safe a guide to follow as the opinions of smaller and select groups. Of course these experiments cannot establish, in the absence of objective absolute standards, the wisdom of the masses. They do suggest, however, that the masses are by no means as destitute of common sense as is sometimes supposed.

Perhaps it will help us to comprehend some of this common sense that resides in the collective mind of the masses if we glance at the results of the American Institute polls during the last few years. It may astonish us, perhaps, to find how closely the judgments of the masses coincide with our own. And of course we assume that our conception of the public interest makes sense! If time permitted it would be interesting and profitable to poll the opinions of our own group on a set of Institute questions and compare the results with those of the nationwide polls. Experience indicates that divisions of opinion within this group would probably be about the same as those in the larger public. At least it would be unlikely that the differences would be due solely to an intelligence-quotient factor.

The American Institute of Public Opinion launched its nationwide polling activities in October, 1935. Since that time the people of the country have been polled on more than five hundred issues: on political and economic questions, on foreign affairs, and on a wide variety of social problems ${ }^{9}$ For many questions the division of opinion was marked, indicating no convincing preponderant state of opinion me wiy or another. In such cases it would be hazardous 
to use public opinion as a guide to public policy. In other instances the questions were of transitory interest and have no lasting significance. Very often they dealt with exceptional situations, and the answers were undoubtedly influenced by the particular conditions. The lack of stability in these conditions warrants the assumption that changes in public opinion on these questions will be frequent.

Moreover, some were questions of fact or asked the respondent to prophesy the future. For example, the question, "Do you think there will be another World War?," asked in August, I937, merely undertook to test the prophetic genius of the masses and shed little light on the question of public interest. Of a similar type were the questions, "Do you think stock prices will go higher or lower in the next six months?" "Have you heard about the Wall Street case of Richard Whitney?" and "Is the Republican Party dead?"

Of particular significance, however, are the answers to questions regarding matters of widespread social import on which the masses take a decided stand, answers which show, for example, a 70 per cent or more agreement. Undoubtedly many of these questions could have been phrased so as to elicit more significant answers, but a review of them may not be without value. The question which I should like to have you keep in mind as the results of these polls are considered is: Do they indicate that mass opinion is or is not a safe guide to follow in defining the public interest?

Let us examine first of all the questions on political and economic issues:

I. Do you favor a third term for Roosevelt?

$$
\text { (April, 1938.) No-70\%. }
$$

2. Would you favor changing the term of office of the President of the United States to one six-year term with no re-election?

(June, I936.) No- $74 \%$.

3. Should the federal government reduce expenditures now?

(September, 1936.) Yes-77\%.

4. In your opinion, which will do more to get us out of the depressionincreased government spending for relief and public works or helping business by reducing taxes?

(April, 1938.) Help business-79\%.

5. Should the government do away with the WPA and give only cash or direct relief?

(May, 1937.) No-79\%. 
6. Do you think that people on relief in your community are getting as much as they should?

(April, 1938.) Yes-71\%.

7. Would you favor a law making it a crime for a relief official to attempt to influence the vote of persons on relief?

(May, 1938.) Yes-86\%.

8. Should the government take a census of the unemployed?

(May, 1937.) Yes-73\%.

9. Whenever Congress has voted to amend the Constitution, should the amendment then be put up to the state legislatures or directly to the people of each state for approval?

(March, 1937.) Directly to the people-82\%.

Io. Do you believe the Roosevelt administration should try to defeat the reelection of Democratic Congressmen who opposed the Supreme Court plan?

(September, 1937.) No-73\%.

I I. Should employers and employees be compelled by law to try to settle their differences before strikes can be called?

(July, 1937.) Yes-89\%.

12. Would you favor laws regulating the conduct of strikes?

(July, 1937.) Yes-84\%.

13. Do you approve of citizen groups, called vigilantes, which have sprung up recently in strike areas?

(August, 1937.) No-76\%.

I 4. Should labor unions be required to incorporate?

(May, 1937.) Yes-86\%.

15. Are you in favor of labor unions?

(July, 1937.) Yes-76\%.

16. Should government employees join labor unions?

(August, 1937.) No-74\%.

17. Would you like to see the C.I.O. and A.F. of L. labor unions settle their differences and work as one labor organization?

(October, 1937.) Yes-79\%.

18. Should government positions, except those which have to do with important matters of policy, be given to (I) those who help put their political party in office, or (2) those who receive the highest marks in Civil Service examinations?

(March, 1936.) Civil Service-88\%.

19. Do you think inflation would be a good thing?

(April, 1937.) No-80\%.

20. Do you think the C.C.C. should be made permanent?

(April, 1938.) Yes-78\%.

21. Should military training be part of the duties of those who attend?

(August, 1938.) Yes-75\%. 
22. Are you in favor of government old-age pensions for needy persons? (January, 1936.) Yes-89\%.

23. Do you approve of the Social Security tax on wages?

(January, 1938.) Yes-73\%.

24. Do you think a single man earning less than $\$ 1,000$ a year should be required to pay a federal income tax?

(March, I938.) No-87\%.

25. Should state and federal employees be exempt from income taxes?

(March, I938.) No-8\%

26. Should people who own federal, state, and municipal securities be required to pay taxes on the income from these securities?

(April, 1938.) Yes-74\%.

27. Do you believe the government should buy, own, and operate the railroads?

(February, 1938.) No-70\%.

28. Do you approve of Secretary Hull's policy in seeking a reciprocal trade agreement with Great Britain?

(March, I938.) Yes-73\%.

29. If Great Britain reduces tariffs on American goods, should we reduce tariffs on British goods?

(March, I938.) Yes-73\%.

On the above-mentioned political and economic questions public opinion expressed itself very clearly. Doubtless some would disagree with the views expressed on particular issues. But can we honestly say that a domestic economic and political program along the lines approved by the masses would be lacking in common sense, obviously inimical to the public interest?

Without reviewing in detail the questions asked in other fields we find that in foreign affairs 70 per cent of the people agree:

(I) That if other nations agree to reduce their spending for armaments, America should agree to reduce its expenditures to the same extent.

(2) That the United States should build a large navy and enlarge its air force.

(3) That a larger navy, as favored by President Roosevelt, will be more rather than less likely to keep us out of war.

(4) That the manufacture and sale of war munitions for private profit should be prohibited.

(5) That in order to declare war Congress should be required to obtain the approval of the people by means of a national vote.

(6) That if another war like the World War develops in Europe America should not take part.

(7) That all nations should agree not to bomb civilians in cities during wartime. 
(8) That the colonies taken from Germany after the World War should not be given back to her.

(9) That the United States government should continue to maintain the present armed forces in China for the protection of American citizens.

( 10$)$ That in view of conditions in the Orient the United States should not give the Philippines their independence now.

In the field of social policy we discover that the American people believe most emphatically:

(I) That the distribution of information on birth control should be made legal.

(2) That the Government should create a bureau to distribute information concerning venereal diseases, should set up clinics for the treatment of such diseases, that Congress should appropriate $\$ 25,000,000$ to help control them, that states should pass legislation requiring tests for venereal diseases for all persons seeking marriage licenses.

(3) That habitual criminals and the hopelessly insane should be sterilized.

(4) That Congress should enact a law which would make lynching a federal crime.

(5) That married women should not earn money in industry or business if they have husbands capable of supporting them.

(6) That divorces should be made easier to obtain.

(7) That the federal government should aid state and local governments in providing medical care for mothers at childbirth.

(8) That parole boards should be more strict than they are now in granting paroles.

(9) That all owners of pistols and revolvers should be required to register with the government.

As Professor Paul Cherington recently stated: "We have been told by motion picture magnates, radio-vaudeville program devisers, certain sardonic advertising men and even some newspaper men that the army intelligence test results of a twelve-year average mental age were about right." ${ }^{10}$ This seems to be a prevailing impression among many who scoff at the intelligence of the masses. Dr. George Gallup, director of the American Institute of Public Opinion, has this to say, however.

The sampling surveys of recent years have provided much evidence concerning the wisdom of the common people. Anyone is free to examine this evidence. And I think that the person who does examine it will come away believing as I do that, collectively, the American people have a remarkably high degree 
of common sense. These people may not be brilliant or intellectual or particularly well read, but they possess a quality of good sense which is manifested time and again in their expressions of opinion on present-day issues. . . . It would of course be foolish to argue that the collective views of the common people always represent the most intelligent and most accurate answer to any question. But results of sampling referenda on hundreds of issues do indicate, in my opinion, that we can place great faith in the collective judgment or intelligence of the people. ${ }^{11}$

Another clue to the answer to our question is afforded by the experience of our states with direct legislation. Professor Edwin A. Cottrell has recently published an evaluation of "Twenty-Five Years of Direct Legislation in California," and his conclusions are most illuminating. ${ }^{12}$ Among other things they show that:

These votes were not only a check on hasty or ill-considered legislation but also excellent as education. ... Evaluation of the measures ... shows a decidedly conservative attitude on the part of the masses.... There is no evidence that a large number of measures are sectional-in application, support, or opposition. ... Where there have been sinister or special interests behind measures, both the Legislature and the people have usually refused to enact their proposals into law. . . . There has certainly been a sustained number of measures presented at each election and a corresponding interest in voting upon them. ... Neither fear of much radical legislation on the one hand, nor of an ultra-conservative attitude of the people on the other, has proved justified. . . . There is some evidence that the people are more anxious to adopt and obey legislation passed through the direct process than through the usual method of legislative enactment. ... There is certainly more intelligent discussion and deliberation of measures by the electorate than is found in a session of the Legislature with its obscure and inefficient committee system. . . . Most editorial writers and students of government agree that over the whole period of direct legislation the people have understood most of the measures and as a whole have acted wisely in making their decisions. . . Those who predicted that direct legislation would lead to government by newspapers were far from correct. . . . Conflicting 
measures often appear on the same ballot. However, the voters have never adopted any which were in direct opposition.... The early charge that direct legislation would arouse passions between different elements of the population has failed to materialize.

The experience with the initiative and referendum in California and the sample polls of the American Institute of Public Opinion tend to support the prophetic saying of Theodore Roosevelt that "The majority of the plain people will day in and day out make fewer mistakes in governing themselves than any smaller body of men will make in trying to govern them."

I have just been reading with considerable interest a study of World War propaganda by Professor Peterson, dealing primarily with the efforts by Great Britain and the Allies to undermine the American policy of neutrality during the years $1914-17 .{ }^{13}$ It is interesting to note that, whereas the campaign was markedly successful in bringing about an early and decided pro-Ally attitude on the part of a great majority of the newspapers of the countries, a majority of the Cabinet members including President Wilson himself, as well as leaders in business, academic circles, and politics, the campaign was surprisingly ineffective in producing changes in the attitudes and opinions of the masses. In I9I7 as in 19I4 they were still sympathetic toward the Allies but were quite unwilling to throw overboard enthusiastically the policy of neutrality and go to war. Were they wise or right in taking this position? Some will say no. But I think the perspective of the years would justify us in saying that they acted, collectively, quite as intelligently as their leaders.

I do not wish to press this point too far. Without objective, fixed standards for doing so, we cannot claim with absolute assurance that the masses have always acted wisely and intelligently. Nor can we say that they are as competent to pass upon some questions as others. There are few who would boldly assert that on technical questions, on questions that deal with matters far beyond the common experience or interest of the average citizen, the opinions of the masses would be worth very much. But the evidence points unmistakably to the conclusion that, on broad questions of social, political, and economic policy, the opinions of the masses seem to show a "remarkably high degree of common sense." 
There is an even more important reason for asserting that public interest is what public opinion says it is. Lord Bryce once wrote that "The excellence of popular government lies not so much in its wisdom as in its strength." And he goes on to state, "Once the principle that the will of the majority honestly ascertained must prevail, has soaked into the mind and formed the habits of a nation, that nation acquires not only stability, but immense effective force. It has no need to fear discussion and agitation. It can bend all its resources to the accomplishment of its collective ends." He does point out, however, two possible dangers: (I) the difficulty of ascertaining the will of the majority; (2) the possibility that minorities may not sufficiently assert themselves. I believe that these dangers are not so real now as they were in 1893 when he wrote, for reasons that will be given later.

Definitions of the public interest which reflect the collective opinions of the masses also have a strength and stability which far exceed the judgments of restricted minorities. This does not mean that public opinion is inflexible or static. Its movements on matters of fundamental importance are, however, likely to be slower and more predictable than those of smaller groups. It is true that the advent of agencies of mass impression, and improvements in facilities of human contact, tend to speed up the process of social change. Nevertheless the force of mere numbers may and does serve to filter the impurities of selfish desires.

In stressing the virtues of public opinion as a guide to public interest I am not unmindful of its defects. We are unable in any case to deal with absolute standards of value, and the question is whether the collective judgment of the masses is, in the long run, likely to be a better guide than that of an individual or a specially selected minority. The competence of the masses is, of course, conditioned by the environment and by the opportunities they have to acquire information, to listen to different points of view, to discuss and express their opinions freely, and to use their reasoning powers. Conditions might become such that it would be absurd to speak of public opinion as a safe guide to public policy, if and when virtually all facilities and conditions for forming enlightened opinions did not exist. This has been true in some countries in the past and may be true in dictatorial countries today. 
We have argued that our public relations are those aspects of our corporate or personal behavior which affect the public, the community; that the basic problem of public relations is to adjust those aspects of our behavior which affect others in such a manner as to promote the public interest; and that the public interest is what public opinion says it is.

Before concluding this phase of our discussion I wish to quote an excerpt from a recent study of public relations. It indicates, I believe, that, even within the arena of professional practice, students are beginning to realize that they do have at hand tangible criteria for finding out what the public interest is. As individuals or corporations we may no longer excuse our negligence in attempting to adjust our public relations to the public interest on the ground that we do not know what the public interest is. We do know, or, with a little effort, can find out. As the authors of this study state: "One common basis underlies all sound public relations. It must adhere, in fundamental policies, to the commonly recognized standards of personal ethics and the highest concept of the public welfare. . . The ultimate arbiter of corporate and institutional acts, policies, services, relationships and products is public opinion." ${ }^{, 4}$ 


\section{What Is Public Opinion?}

Thus far I have submitted to you the following propositions: I (I) that the term public relations refers to those aspects of our corporate and personal behavior which have social implications; (2) that the basic problem of public relations is to adjust those relations to current cultural, economic, and political trends so as to promote the public interest; and (3) that the best way to determine what the public interest is is to find out what public opinion says it is. I wish now to consider the question: What is public opinion? I think it is evident that public opinion lies at the very heart of our problem. By knowing what public opinion is we possess criteria for evaluating the state of our public relations.

The origin of the expression "public opinion" is a mystery. ${ }^{15} \mathrm{In}_{\mathrm{n}}$ the literature of early Greece and Rome, and throughout the Middle Ages, political philosophers were keenly aware of the importance of the opinions of the masses. The phrase Vox populi, vox Dei dates from the latter part of the Middle Ages. It was not until the eighteenth century, however, that the term "public opinion" was subjected to systematic analysis and treatment. During the seventeenth and eighteenth centuries such writers as Voltaire, Hobbes, Locke, and Hume paid tribute to the power of public opinion. But it was the period of the French Revolution, and more particularly the writings of Rousseau, to which we must turn for the first careful discussions of the subject. Hobbes spoke of the world as being governed by opinion; Locke used opinion as one of his three categories of law; and Hume gave expression to the classic statement that "It is ... on opinion only that government is founded; and this maxim extends to the most despotic and most military governments, as well as to the most free and most popular." Blaise Pascal referred to public opinion as the "Queen of the World," to which Voltaire replied, "If opinion is the Queen of the World the philosophes govern the Queen."

Rousseau, writing in the eighteenth century, developed one of the 
most explicit formulations of the concept of public opinion up to his time. He applied his theory of popular infallibility to the state, claiming that the "most general will is also the most just." 'This view has been repeated many times since. Rousseau believed that even despotism rested on public opinion, for, he said, "Despotic rule is servile even when it is based on opinion; for you depend on the prejudice of those whom you rule through prejudice." Rousseau seems to have been the first to use the phrase l'opinion publique, and his discussion of the relation between public opinion and law is significant. He stated that "Whoever makes it his business to give laws to a people must know how to sway opinions and through them govern the passions of men."

One of the first to discuss the significance of public opinion as a factor in statecraft, one of the first to sense, apparently, the problem of public relations in its relation to statecraft, was Jacques Necker, French finance minister. His experience led him to emphasize the relation between public opinion and public credit. He found that the salons of France played a very important part in the formation of the public opinion of his times, and that the opinions of the bourgeoisie were really decisive in their influence. Necker produced the only detailed analysis of the concept of public opinion during the French Revolution, although there were numerous references to the subject in the ephemeral writings of the period.

The French Revolution did, however, stimulate discussion of the subject of public opinion on an unprecedented scale, much of it centering around the question of the competence of the masses to rule. In Germany the Revolution inspired systematic treatments by Wieland, Garve, Fries, and Hegel. Out of these discussions emerged more precise definitions of terms as well as attempts to ascribe the proper role of public opinion in public affairs. Garve, for example, defined public opinion as "the agreement of many or of the majority of the citizens of a state with respect to judgments which every single individual has arrived at as a result of his own reflection or of his practical knowledge of a given matter." This definition has come down to us virtually unscathed in the writings of Lowell and other political scientists. Most of the German writers during this period held that the competence of public opinion to rule extended only to general principles. Hegel advanced the theory, a forerunner of 
Fascism, that public opinion was to be respected only for the essential principles that it embodied and that it was the task of the great man to find out what these essential principles were.

Jeremy Bentham was the first to present a detailed discussion of the subject in English. He emphasized the importance of public opinion as a means of social control, discussed its relation to legislation, and was one of the first to examine the role played by the press in its formation. He held that public opinion was necessarily an integral part of any democratic theory of the state. The basic problem of public opinion as he saw it was "to maximize the rectitude of the decisions by it."

It is evident, therefore, that students have been concerned with the subject of public opinion from earliest times. Many of the problems we face today were perceived and considered at least as far back as the late eighteenth and early nineteenth centuries. It would serve no useful purpose at this point to catalogue references to public opinion in the writings of the nineteenth century and later. The number of such references is legion. Much attention was given to the problem of the competence of the masses to express intelligent opinions on matters of public policy. This matter was discussed rather fully by such writers as Ancillon, Rosenkrantz, Mackinnon, Buckle, Dollfus, Biedermann, Bluntschli, Stahl, Urquhart, Maine, Gneist, Bryce, Lowell, and Lippmann. The increasing importance of the press in its relation to the formation of public opinion enlisted the interest of many. Students of law and jurisprudence, such as Taylor, Lieber, Austin, Ritchie, Esmein, Willoughby, and Dicey, made careful analyses of the relation between public opinion, law, and political institutions. More and more attention was given to the question of how public opinion was actually formed by sociologists and psychologists. Tarde, Wallas, Christensen, Lippmann, and many others emphasized the emotional and irrational character of the public-opinion-forming process.

A. F. Bentley, writing in 1908, inspired a long list of studies dealing with the influence of pressure groups upon public opinion. The World War and the writings of Lasswell, Stern-Reubarth, and others focused attention upon the role of propaganda. The variety of specialized studies of particular factors influencing the formation of 
public opinion was matched only by the multiplicity of factors that might be studied.

Sociologists stressed the significance of public opinion as a means of social control; psychologists, the role played by various inherited and environmental factors in the formation of personal opinions; students of law and jurisprudence, the influence of public opinion upon public policy; students of politics, its influence upon government and the influence of official as well as unofficial agencies of government upon it. Among the more comprehensive and systematic treatments of the subject were those of Gersdorf (1846); Lewis (I849); de Tocqueville (I835-40); Holtzendorf (I879); Bryce (I888); Dicey (I905); Lowell (I913); Bauer (I914); Tönnies (I922); and Lippmann (I922).

Public-opinion research and study today cut across and transcend the traditional lines separating social-science departments and may be found in practically all social-science disciplines. Considerable attention is now being given by statisticians, psychologists, journalists, advertisers, and market researchers to the problem of ascertaining the state of public opinion on particular issues. Various types of polling and sampling techniques are being used. Shrewd and prudential observations are being supplemented by precise methods of opinion census-taking. Noteworthy in this field are the activities of the American Institute of Public Opinion and the magazine Fortune.

Studies of pressure-group activity, propaganda, communication agencies, as well as psychological researches into the genesis of individual opinions continue to throw additional light on the process of opinion formation. Because so many different factors influence the formation of public opinion this field attracts an unusually large number of students.

The management and control of public opinion have always interested many students. Considerable progress was made in advertising research before the World War, and since I9I9 interest in opinion management has expanded to include the study, not only of commercial propaganda, but also of propaganda of all sorts. Probably no aspect of the whole subject arouses more interest than the problem how to win the support of public opinion.

The advent of autocracies in new forms has given rise to renewed discussions of the proper role of public opinion in the life of the state. 
Again and again the questions are asked: Is public opinion in the sense of mass opinion a safe guide to follow? Upon what types of questions is it competent to express an opinion, if any? Where is the line to be drawn between those questions upon which it is and is not competent to pass judgment? These questions go to the very roots of the theory of democracy and have been considered rather carefully by such writers as Bryce, Lowell, Lippmann, and Catlin. Most advocates of the democratic way of life stress the importance of an informed, intelligent public opinion. The question how the role of public opinion in public affairs can be improved has been the starting point for many studies. Educators particularly are concerned with the problem. In the minds of many the basic problem of public opinion is the problem of education.

One of the most disturbing aspects of the whole subject of public opinion is the growing intensity of conflicts of opinion, the deepening cleavages between groups, the absence of generally accepted premises and goals. War, whether it is between nations, races, or classes, is a reflection of this state of opinion. The problem of minimizing international and class differences of opinion is largely a psychological one, the problem of reconciling and harmonizing differences of opinion. To do so it is necessary first of all to find out why states of opinion are what they are, the real causes. Sometimes these causes are imaginary, based upon misconceptions and misunderstandings. Whenever this is so the difficulties may be remedied by information, the dissemination of facts, and the educational enlightenment of the groups concerned. Many difficulties and obstacles stand in the way of this procedure, however, and every effort must be made to remove them. Many differences and clashes of opinion are based, not on misunderstanding, but on conflicting interests and aims. No amount of information and purely intellectual enlightenment can, unaided, change the human heart, remove individual and group selfishness, reconcile fundamental cleavages in philosophical outlooks on life. Stronger medicine is needed. Wills must be molded as well as minds. Enlightened selfishness may, indeed, be the worst kind of selfishness, because it implements selfishness, as recent events in Europe and throughout the world have demonstrated. One of the most difficult problems in the arena of public opinion is to reconcile the wills of men as well as their opinions. 
The term "public opinion" has been employed in a great many different senses, so many in fact that some students have questioned the advisability of using the term. ${ }^{16}$ Many attempts have been made to define the expression in a way that will be generally acceptable. Periodically some student will attempt to assemble a collection of definitions and classify them with a view to reconciling differences in meaning. Inevitably he concludes with another addition to the already long list. Virginia Sedman, for example, after a careful analysis of the definitions of Lippmann, Lowell, Dewey, King, Holcombe, Bogardus, and others, concluded that "Public opinion, for us, is an active or latent force derived from a composite of individual thoughts, sentiments and impressions, which composite is weighted by the varying degrees of influence and aggressiveness of the separate opinions within the aggregate." 17

Floyd H. Allport, in the first issue of the Public Opinion Quarterly, also tried to bring order out of the conceptual chaos by surveying the literature of the field and specifying several fallacious notions that have given rise to misunderstandings. He called attention specifically to such fictions and blind alleys as (I) the personification of public opinion; (2) the personification of the public; (3) the group fallacy; (4) the fallacy of partial inclusion in the use of the term "public"; (5) what he calls the fiction of ideational entity; (6) the emergent theory; (7) the eulogistic theory; and (8) the journalistic fallacy. And he, too, contributed another definition. It reads: "The term public opinion is given its meaning with reference to a multiindividual situation in which individuals are expressing themselves, or can be called upon to express themselves, as favoring (or else disfavoring or opposing) some definite condition, person, or proposal of widespread importance, in such a proportion of number, intensity, and constancy, as to give rise to the probability of affecting action, directly or indirectly, toward the object concerned."18 If this is what we mean by the term public opinion it is easy to understand why novitiates shudder and shun the problem.

The term "public opinion" is obviously a general and rather inclusive expression like many other useful English expressions such as "political party"; "weather"; "democracy." Only as it is related to a particular public and to specific opinions about definite subjects does it become significant in the sense that it can be studied. In this respect 
it is similar to the word "weather," which a dictionary defines as "a state of the atmosphere." Students of meteorology are not usually concerned about weather in general, but about the state of the atmosphere at a particular time and in a particular place. Defined in these terms the word "weather" becomes significant and can be studied. Similarly the term "public opinion" must be related to a specific public and to definite opinions about something. Then it is possible to study it, find out what the state of public opinion is, why it is what it is, what changes have been and are taking place, and what if anything should be done.

It is obvious that there are many kinds of publics. In some cases a public will be a group of individuals with common interests and possibly a formal organization. But the public in which we are interested may be composed of a very heterogeneous collection of individuals without organization, lacking identifying symbols and attributes. Designating or defining the word "public" does not mean "selecting a common attribute of a group and postulating this as the characteristic which gives this mass of individuals a distinctive entity." A public is simply any collection of individuals. The failure to specify the collection of individuals constituting the public to which we are referring has led to no end of difficulty.

The number of different publics in a community is theoretically the number of distinct combinations of individuals possible in that community. Among the more significant publics, as a rule, are such organized groups as the citizens of a state and the members of political parties, trade unions, business organizations, churches, fraternal groups, and political and professional associations. But publics also include such unorganized groups as crowds, customers, newspaper readers, and clienteles of different types. A public may mean for purposes of study merely a collection of individuals composed of all persons who pass a given mailbox on a specified day. Moreover, individuals may be members of different publics simultaneously. That is to say, they may at one time be members of a football crowd, a physicians' clientele, a fraternity, a church, and a political party. Students of public opinion as well as leaders and managers of public opinion display interest in different publics and in different aspects of these publics.

There is no such thing as the public except in the sense that there 
may be a particular group of persons about which we are speaking. As students of public relations we may be and quite naturally are interested in a great many different publics, particularly those that have and exercise an influence on public policy. An important public in this respect is the group which comprises all the eligible voters in the United States. This is obviously a very important public, but one difficult to deal with because of its size. Within this larger public are numerous smaller publics exercising influence on the larger and of considerable influence with reference to it.

It is frequently stated that for a business corporation there are four principal publics with which it is concerned: ( $I$ ) the internal group comprising management and employees; (2) customers; (3) stockholders, competitors, or the trade; and (4) the general public. This is an over-simplification of the picture. To analyze satisfactorily the effect of corporate behavior on employees, for example, it may be important to distinguish subpublics such as members of trade unions, company unions, and the unorganized; or, using other bases of classification, to study different age groups, wage groups, married and unmarried, and even those who walk and those who ride to work. For any individual or corporation a great many distinctive publics are significant.

The question is often raised whether or not the term "public opinion" should or should not be restricted in meaning to collections of individual opinions from large publics, from the "masses." The opinions of large numbers of people are usually more interesting and significant than those of small publics. But not necessarily so. In democracies the opinions of those constituting the electorate are undoubtedly of great importance. In Italy, Germany, Russia, and other autocracies, however, the opinions of very small publics, of two or three key men even, may be of greatest importance.

Perhaps the word "opinion" can best be defined as "a verbal expression of attitude." There are, of course, many other expressions of attitude such as laughter, the shaking of the head, and the look in one's eye. The question may be asked whether opinions expressed in words are accurate indices of attitude, and the answer must be that in many cases they are not. But what a person says is very often not only an indication of attitude but also an indication of what we may expect him to do. Whether accurate expressions of attitude or 
not, they are objective, and are significant in themselves-so significant that hundreds of thousands of dollars are spent annually to find out what they are. Opinions as expressed in the voting booth are determining factors in social and political life.

Some will ask for a definition of attitude, but we do not need to pursue the ultimate meaning of things indefinitely. For our purposes it is sufficient to quote the definition of attitude given by a psy-c chologist who says that it is "the sum-total of a man's inclinations and feelings, prejudice or bias, preconceived notions, ideas, fears, threats, and convictions about any specific topic." "In other words, it is a tendency to act in a particular manner, a tendency which is liberated whenever the proper stimulus is presented. Whereas attitudes are subjective, opinions are objective, taking the form of written or spoken words.

The word "attitude" as used in current academic discussions presents some difficulties. To say that a person has a favorable attitude toward a proposition raises the question whether or not this statement means anything more than to say that he is in favor of it. To say that he is in favor of it because he has a favorable attitude toward it really does not tell us very much. Is there such a thing as an attitude, a distinct entity, which has a distinct life of its own? Can attitudes have any real meaning until we know to what objects and subjects they refer? Perhaps it would be better to think of the word "attitude" as an expression used to describe a series of habitual responses, typical responses, rather than a pre-existing force that causes certain expressions of opinion. ${ }^{20}$

Opinions differ from one another in many respects, such as content, the form in which they are expressed, their quality, their stability, their intensity, and the way in which they have been formed or elicited. Any one or more of these aspects may assume importance depending on the interest of the observer or the investigator. A scientist may be interested primarily in the truth of the opinion, or the way in which it has been formed; a novelist, in the style in which it is expressed. A national advertiser or a politician may focus his attention upon the types of persons holding a particular opinion, their wealth, social standing, influence.

It is clear that an opinion is always the opinion of a person, not of a group as such. Public opinion always refers to a collection of indi- 
vidual opinions, not to some mystical entity that is floating about in the atmosphere over our heads. To find out what a given state of public opinion is, therefore, we have to collect the opinions of individuals. This point would require no special emphasis were it not for the fact that some writers have thought in terms of a "group mind" quite separate and distinct from the minds of tangible persons.

By public opinion I mean, therefore, simply any collection of individual opinions designated. If we are studying the opinions of the individual members of a forum audience it is quite as definitely a study of public opinion as if we were studying the opinions of the voters of the United States. We are usually interested in those collections of opinions which exert considerable influence upon our affairs.

This definition is admittedly a very broad one. The questions may be asked: What is to be gained by attempting to define public opinion so broadly? Is there not a difference in degree that amounts to a difference in kind between the opinions of a small group and those of very large groups?

Perhaps the best way to answer these questions is to ask another. What is to be gained by defining the word "weather," as dictionaries do define it, as simply a state of the atmosphere? Is there not a difference in degree that amounts to a difference in kind between the state of the atmosphere in a lecture hall and its state generally throughout the United States? I do not think so, unless we are prepared to admit that the word "weather" is not applicable to all states of atmosphere.

The source of the difficulty seems to be this. Individual students are continually seeking to restrict the meaning of the term "public opinion" to particular collections of individual opinions or aspects of these collections in which they happen to be interested. By keeping the term broad, a common meeting ground is provided for students who are really interested in the same fundamental problems although at first blush their activities may seem unrelated. The problem of focus is one for the individual investigator. It would be a mistake for students of public opinion to insist that those particular aspects of it in which they happen to be interested are the only important ones, much less that public opinion itself is confined in meaning to their foci of interest.

Social-science research has been handicapped rather than helped 
by the effort to give personal interests the added prestige of definitional exclusiveness. What is political science? All too often the scope of the field as a whole is imprisoned within the walls of interest of the person defining the term. The same is true with such expressions as "public interest," "democracy," and "justice," and many, many others. The public interest is all too frequently defined in terms of the individual and group interest. Democracy refers to what we would like to have it be. Social scientists have no more reason for defining the term "public opinion" in terms of their own special interests, I believe, than the author of a dictionary would have in defining the word "dog" so that his own pet proves to be the only exemplar of the concept.

All students of public opinion can meet on one common ground, a general interest in collections of individual opinions. Some will focus attention upon some collections, others on different ones. Some will be interested in what the opinions are about, others in the degree of uniformity expressed, how the opinions were formed, who holds the opinions, how intensely they hold them. The multiplicity of definitions of public opinion is really due to the effort of students to restrict the meaning of the term to some aspect of public opinion in which they are especially interested.

Both "public opinion" and "public relations" have this in common -that they are very broad in meaning and become interesting only as they are related to particular publics. Discussions of public opinion in general or public relations in general suffer because there is comparatively little that can be convincingly said about collections of individual opinions in general or the relations between all types of publics. Each of us, however, is vitally interested in certain publics and our relations with specific groups. As employers we wish to know all that we can know about the labor public. I have read many articles and attended many conferences dealing with public relations, and out of them emerges the fact that for business men employees are the public. In a majority of instances public relations signifies labor relations. As teachers we are especially interested in our student publics. As Americans we are concerned about the attitudes and opinions of other nationals regarding us. This audience in this room is a public of tremendous concern to me! But how can I know the specific publics in which its members are interested, and is there any 
common denominator of this interest? Is there one public in which all of them are interested? Is there one public, relations with which are of major concern to each of you?

If this audience consisted solely of employers, or bankers, or Protestants, or teachers, the task of public-opinion analysis would be easier. What are the common attributes of this group? All are American citizens, presumably. All live on the West Coast of the United States. Beyond that it is difficult to go. Doubtless there are considerable differences in tastes, habits, problems, hopes, possessions, age, cultural background, and the rest. Certainly the publics in which you as individuals are interested are very different.

But are there not propositions that can be made about public opinion and public relations in general that will be applicable regardless of this lack of homogeneity? Are there not certain statements that can validly be made about public opinion regardless of the individual composition of the particular collection of individuals, statements regarding the sort of opinions that all people hold, or at least all persons with whom we are likely to come in contact, statements regarding the way in which public opinion is formed, the influence of particular factors, the techniques that may be used for molding opinions generally? In other words, are there not certain principles of public opinion and public relations applicable under all circumstances?

The answer is disappointing. All principles hold true only under certain conditions. Given the conditions, the principles will apply. But the conditions must be stated. This is what makes the study of public opinion and public relations so difficult. Conditions vary; publics differ; the relations between groups are always changing. Generalizations regarding human behavior and human relations are peculiarly hazardous to make. We note that the opinions of a public change. Why? Until we know all the conditions accompanying the change we are not in a position to answer the question. Too often we are deceived by mirages, by fortuitous coincidences. We know, for example, that in the years from 1918 to 1932 there occurred a decided change in the attitudes and opinions of Americans regarding prohibition. Coincident with that change we find that various groups were carrying on a vigorous propaganda campaign in this country. The relationship exists, but to what extent was it a causal 
relationship? A corporation adopts a new plan of employee relations. An improvement in these relations is noted at once. But the extent of the causal relationship is unknown.

Although it is impossible to identify the publics in which this audience is interested and therefore relate the discussion to matters which are most meaningful, there are some aspects of public opinion, certain questions, which are generally interesting. We all wish to know the degree of uniformity of opinion on the subjects that interest us. In a democracy the actions and policies of government officials are presumed to reflect the opinions of a majority of the citizens. This is not always true, however, partly because of the difficulty of ascertaining precisely what public opinion is regarding a particular policy or candidate. Any state of public opinion is continually changing, and election machinery can give only periodic and rather crude information regarding these changes. Nevertheless, it is important to find out, if possible, the degree of uniformity existing at any given time, for election figures which reveal a majority opinion are usually acted upon.

Because of the importance of collections of individual opinions that reveal a substantial degree of agreement, many students of government and public opinion would narrow the meaning of the term to include only those collections of opinion having a specific degree of uniformity. James Bryce, for example, defines public opinion as any view, or set of views, "when held by an apparent majority of citizens." "'1 And Professor Dicey expressed much the same viewpoint when he stated that public opinion comprises the "wishes and ideas as to legislation held by the people of England, or to speak with more precision, by the majority of those citizens at a given moment taking an effective part in public life."'?2

Although mainly interested in the degree of uniformity, some writers narrow the term even further to include only those collections of opinions revealing complete or substantial unanimity. Professor Gault expresses this point of view when he states: "Gradually there emerges, as a result of a slow but more spontaneous than deliberate analysis, a certain apprehension of common and fundamental interests by all members of the group. This is public opinion." ${ }^{23}$ Similarly, Professor Maxey interprets public opinion as "the coming together in common agreement on the same definite conclusion or 
body of conclusions." ${ }^{24}$ Needless to say, such common agreement is seldom if ever found, especially in a public as large as that comprising all citizens or voters in the United States. None of the Gallup polls, for example, have revealed roo per cent agreement on the questions asked. ${ }^{25}$

Clearly, any given collection of individual opinions with respect to the matter under consideration may reveal degrees of unanimity varying all the way from complete unanimity to a considerable degree of diversity. The degree of unanimity is not a condition of the existence of public opinion, but an aspect to be investigated. If an investigator starts out to find a state of public opinion which represents a definite degree of agreement such as complete unanimity or majority agreement, or such vague aspects as the "normative aspects of collective consciousness," "fairly uniform collective expressions of mental or inner behavior reactions," or "uniform mental reactions to stimuli," his focus of attention is not only restricted to a single aspect of public opinion, but the search will be fruitless.

The point I wish to underscore is simply this: Public opinion is any collection of individual opinions, regardless of the degree of agreement or uniformity. The degree of uniformity is a matter to be investigated, not something to be arbitrarily set up as a condition for the existence of public opinion.

Even though the term public opinion may refer to any collection of individual opinions, however, the significant phenomenon of our times is the increasing importance of large publics. For reasons that have been listed earlier, the area of human contacts and social intercourse has expanded tremendously. It is because of this that public relations have become so important. Our personal and corporate behavior affect increasingly large publics. Our public-relations problems involve not only our employees, our stockholders, and our customers, but extend far beyond to include the masses. Public opinion is not necessarily restricted in meaning to mass publics, but mass publics really give our problem its new dimension. 


\section{Public-Opinion Polls}

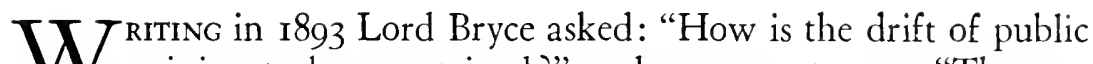
opinion to be ascertained?" and went on to say: "The mechanical difficulties, as one may call them, of working such a method of government are obvious. How is the will of the majority to be ascertained except by counting votes? How, without the greatest inconvenience, can votes be frequently taken on all the chief questions that arise? . . . But what I desire to point out, is that even where the machinery for weighing or measuring the popular will from week to week or month to month has not been and is not likely to be invented, there may nevertheless be a disposition on the part of rulers, whether ministers or legislators, to act as if it existed; that is to say, to look incessantly for manifestations of current popular opinion, and to shape their course in accordance with their reading of those manifestations."

In view of the interest which is now displayed in public-opinion polls, the question arises: What progress has been made since Bryce wrote in ascertaining the state of public opinion? Have the mechanical difficulties to which he referred been resolved? Is it now possible for public officials to know from week to week and month to month precisely what public opinion is?

Nearly fifty years have elapsed since Bryce posed his question, and it is interesting to note the answer he gave long before the advent of "scientific polls" and before the existence of refined methods of public-opinion measurement. He wrote:

The best way in which the tendencies at work in any community can be discovered and estimated is by moving freely about among all sorts and conditions of men and noting how they are affected by the news or the arguments brought from day to day to their knowledge. In every neighborhood there are unbiased persons with good opportunities for observing, and plenty of skill in "sizing up" the attitude and proclivities of their fellow citizens. Such men are invaluable guides. Talk is the best 
way of reading the truth, because in talk one gets directly at the facts, whereas reading gives not so much the facts as what the writer believes, or wishes to have others believe. Whoever, having himself a considerable experience of politics, takes the trouble to investigate in this way will seldom go astray. There is a flair which long practice and "sympathetic touch" bestow. The trained observer learns how to profit by small indications, as an old seaman discerns, sooner than the landsman, the signs of coming storms.

The upshot of Bryce's statement is that the task of identifying public opinion is essentially an art; that only those gifted with the "flair" which "long practice and a sympathetic touch bestow" can hope to succeed in practice. The Bryce method is still the method used by a great many politicians and business executives with a "flair" and a skill for finding out the state of public opinion by means of talk and discussion. The same method is often followed by travelers and tourists who return from far-distant lands to report on the state of public opinion as they have found it. Some of their observations are unusually shrewd, but more often their findings are colored by the types of people with whom they speak. One of the criticisms of Bryce's own observations regarding the state of public opinion in the United States is that they were based upon contacts with very selected publics. ${ }^{26}$

In the minds of many the press is one of the best indices of public opinion that we have. In fact, the expressions "press" and "public opinion" are often used synonymously. Many studies of public opinion prove to be studies of public opinion as revealed in the news and editorial columns of newspapers. The newspapers of a country do undoubtedly reflect the opinions of a large number of persons. The difficulty is that we do not know what persons. We do not know just how positive the correlation is between the editorial opinions of particular newspapers and given publics. A well-known research agency recently published a study entitled "A Statistical Survey of Public Opinion."' Public opinion in this case proved to be the opinions of some 5,000 newspaper editors throughout the country. Such a group is, of course, a very significant and a fairly definite public. One criticism is that the author implies that the results represented the opinions of a much larger public. 
The press not only reflects but also influences public opinion. The presidential election of 1936 demonstrated dramatically how wide a chasm may exist, however, between editorial opinion and public opinion, when, in spite of the opposition of a majority of the newspapers in the country, public opinion swept Roosevelt into office for a second term.".8

Newspapers undoubtedly do reflect the opinions of important publics and at times indicate the state of opinion of large majorities of the American people. Some believe that by more careful newspaper analysis a way can be found for using the press, particularly the newspaper press, as a fairly reliable index of the American public mind. Professor Julian L. Woodward has advanced this thesis." The problem, as he sees it, would be to construct two time series: one for newspaper content, another for reader attitudes; one an index of newspaper opinion, the other an index of public opinion; and then correlate the two. Evidences of a lead or lag would suggest inferences regarding the causal relations between the two. Moreover, if they fluctuate in unison the newspaper-content variable could be used as an index for charting changes in public opinion.

This suggestion offers interesting possibilities, but also some difficulties. The American Institute of Public Opinion, for example, is in a position to furnish public-opinion data on selected issues. The more difficult problem is to provide equally satisfactory indices for charting newspaper-opinion trends. If this can be done, as Professor Woodward thinks it can, then students of public opinion would be well on their way toward formulating more precise and significant propositions with respect to the reliability of newspapers as indices of public opinion.

Within the past two decades, and more especially during the last five years, the possibilities of devising techniques for accurately ascertaining the state of public opinion have been explored by numerous institutions and private agencies. Dr. Robinson has pointed out that the development of polling techniques may be divided into five phases. ${ }^{30}$ The first was the era of newspaper polls. The sampling techniques employed were crude, owing to lack of statistical training on the part of sponsors. Some newspapers like the Columbus Dispatch, the Cincinnati Enquirer, and the Chicago Journal achieved creditable results, but on the whole these straw polls were of more 
value as circulation builders than as instruments for ascertaining the true state of public opinion.

The second phase was the Golden Age of the Literary Digest. In I9I6 this magazine discovered the possibilities of straw polls as vehicles for circulation drives. Subsequently it conducted nine nationwide polls on such subjects as prohibition, the presidential primary, the New Deal, and candidates for the presidency. In these polls millions of ballots were distributed over the country, and the returns were liberally reported in the press and over the radio. "The Literary Digest made America conscious of the validity of straw samples as gauges of public opinion."

Dr. Robinson distinguishes a third phase marked by studies of straw-poll technique by research students, notably Professor W. L. Crum of Harvard and Dr. Robinson himself.

Then came the fourth phase and the use of marketing-research techniques previously applied in the fields of advertising, marketing, and corporate relations. Dr. Gallup began experiments with nationwide polls on political and social issues in February, I934. The American Institute of Public Opinion was organized the following year. The Fortune polls were inaugurated in 1935 by Paul T. Cherington and Elmo B. Roper, Jr. The Crossley poll was launched during the I936 presidential campaign, and since then numerous other agencies specializing in opinion census-taking have appeared.

We are now in what Robinson calls the fifth phase in the development of "scientific" public-opinion polls. It is a phase in which students of public opinion not only are concerned with questions of method, but also are raising questions regarding the social and political significance of these techniques. The polling agencies themselves are seeking to refine and improve their methods. Business executives and others are displaying an extraordinary interest in public opinion, and are eager to find out what it is in order that they may bring their conduct into conformity with it. And students of public affairs are trying to evaluate present trends and determine what, if anything, needs to be done in order to enhance the social usefulness of polling procedures.

"Scientific" polls of public opinion such as those conducted by Gallup, Crossley, and Fortune differ from others in that the sponsors seek to apply well-established principles of statistical sampling. In- 
stead of collecting opinions indiscriminately they try to obtain a small sample of the opinions of the public as a whole which will be truly representative. There is nothing mysterious or particularly novel about the technique. In buying and selling commodities sampling is a familiar practice. The quality of a carload of oranges is judged by opening a few boxes taken from different parts of the shipment. The effect of allowing the sewage of New York City to flow into the surrounding waters is tested by an examination of many small samples of river and harbor water taken from different areas and at varying depths. If it is possible to test the quality of a supply of oranges, or water, in this fashion, why is it not possible to do the same with public opinion? Proceeding on the assumption that it is possible, "scientific" polls of public opinion have emerged.

The principal problem of sampling is to find a formula of selection that will give the results desired. With a barrel of apples, it is a problem of finding a method for selecting a few apples which will indicate what the real contents of the barrel are. In respect to public opinion, it is a problem of selecting a few opinions truly representative of the opinions of the public as a whole.

One method of selecting a sample is the random method. No attempt is made to analyze or classify the contents of the barrel or the opinions of the public as a whole. The sample is selected in such a way that pure chance determines the result. Every item in the whole collection is given an equal chance to appear in the sample. One common method is to select every tenth or every twentieth apple or opinion.

How large should a random sample be? That depends, of course, upon how homogeneous the material is. If the material is not homogeneous a larger sample will be required than if it is. Great care must be exercised to ensure the absence of bias in selection. Conditions which make it easier for some apples or some opinions to appear in the sample vitiate it. If, as the size of a pure random sample is increased, no appreciable change in the character of the results is noted, the sample is probably large enough. Obviously the adequacy of the size of a sample depends upon the nature of the subject matter.

The polling agencies to which reference has already been made, the American Institute of Public Opinion, Crossley, Inc., and the 
magazine Fortune, do not rely on the method of random sampling. They proceed on the theory that a person's opinions are what they are because of the influence of certain factors: age, sex, income, place of residence, etc. They try to find a sample of persons who, with respect to age, sex, income, etc., are truly representative of the people of the country as a whole. From available statistics they determine the proportion of people in the country in different age, sex, and income groups and then select a small group of several thousands representative of the people of the country as a whole as far as these factors are concerned.

The obvious difficulty with this method is that we have no proof that the factors used in selecting the sample are the most important in the opinion-forming process. Nor do we know the relative influence of the factors in this process. Instead of assuming that all persons in the same sex, age, income, and residence categories think alike it would seem more reasonable to assume that the relative influence of these factors depends upon the type of question at issue. Evidence so far accumulated indicates that persons in particular categories tend to think alike on certain types of questions, but not on others.

How then are we to account for the alleged success of some of the polls in predicting the outcome of elections? In the first place the measure of success is much less than generally supposed. ${ }^{31}$ Thus far we have had only a few opportunities to check the accuracy of these polls, and the experience with the Literary Digest poll showed that a few successes were by no means a positive proof of the reliability of the methods employed. Moreover, except for polls on candidates where the sampling techniques can be checked against the official election returns, there exists no infallible method for checking the reliability of the results.

There are, to be sure, some indications that point in the direction of reliability. In the 1936 presidential election a few of the polls were reasonably successful in predicting the outcome. In some cases the agencies have undertaken to test reliability by increasing the size of the sample and noting changes in results. Often these tests suggested that the formula used for selecting the sample was fairly satisfactory. But we need to know much more than we do at present before 
we can affirm that "scientific" polls are absolutely reliable. There are some reasons suggesting the contrary.

It is improbable that the factors which influence the formation of opinion in one instance are the same in all. If a reliable formula had been found there would be no need for further experimentation, and no reason why different agencies should employ different formulas. Much is made of the point that the samples used are representative, true cross sections. The question arises, however, of what are they representative? Even assuming that the samples are truly representative of the population in terms of age, race, religion, income, residence, etc., it does not necessarily follow that they are representative of the opinions of the people of the country as a whole unless it is established that only these factors are significant in the opinionforming process.

On February 14, 1935, a bill was introduced in the House of Representatives to prohibit the use of the mails for the taking of straw votes. And on January 8, 1937, a resolution was introduced in the House of Representatives providing for the creation of a committee to investigate polls purporting to measure public opinion on questions or issues which have "a bearing upon any election held to fill any office under the Government of the United States." Neither measure was passed, nor even acted upon. Meanwhile these polls are assuming an increasing importance in the social and political life of the country. The weekly results of the American Institute polls are published widely throughout the country in more than seventy-five leading newspapers.

Immediately after the election of 1936 the New York Times published an editorial on straw ballots. Among other things it stated:

This is an appropriate time to raise the question whether the public interest is actually well served by unofficial polls which attempt to reflect the shift of American opinion on matters of great political importance. A fundamental objection to such polls is that they so frequently tend to develop a "bandwagon" rush on the part of the electorate. . . . The risks are even greater when a poll is aimed not at attempting to predict how the public will vote but at attempting to interpret its will on complex and controversial issues. For in this case the poll tends to intensify the "bandwagon" instinct present in all legislators. 
... The American form of government is not really built to function successfully on this pattern. Ours is a "representative" democracy, in which it is properly assumed that those who are chosen to be "representatives" will think for themselves.

Since then the New York Times has become a client of the American Institute of Public Opinion and publishes its weekly reports on the state of public opinion throughout the country.

Assuming the infallibility of polls, which, as we have seen is hazardous, the Times editorial raises two important questions. What is the effect of the public-opinion polls upon the public at large? What is their effect upon our official representatives, and is this effect desirable?

No study has been made, to my knowledge, of how extensively these public-opinion reports are read and what effect they have upon the opinions of those reading them. It would appear that they were read widely in view of the fact that they are carried by a large number of newspapers with wide circulations and in view of the attention given to them by magazines, books, and papers generally. It is improbable that such a paper as the New York Times would pay several thousand dollars a year for these reports if they did not have wide reader interest. Many of the leading magazines have published articles about them.

The Times refers to the "bandwagon" effect of these pronouncements. The assumption is that a great many people like to be on the winning side of an issue. Politicians believe this and try assiduously to create the impression that their candidate and their point of view are bound to win. The psychologists have a name for it. They call it the impression of universality. As students of war propaganda have pointed out, military leaders likewise try to create the impression that they are bound to win. Such an impression strengthens the morale of their own troops and tends to discourage the enemy.

As yet there is no concrete evidence to show precisely how much influence a release of the Gallup, Crossley, or Fortune type has on the opinions of citizens generally. There is some reason to suppose that the influence is considerable. To be able to state as convincingly as some of these polling agencies do what the state of public opinion is, places in their hands a tremendous power. The agencies of government purport to reflect public opinion in their actions. Suppose that 
their interpretations of the state of public opinion conflict with those of the private polling agencies. The consequences may be serious. For various reasons Congress has persistently refused to pass a law providing for a war referendum. And yet the possibility exists that these agencies may conduct just such a referendum, thereby embarrassing the national government in the conduct of foreign policy. I am not taking a position against such referenda. I merely wish to point out the importance of the problem.

For a long time pressure groups have followed the practice of trying to convince the government and the public that they voice the will of the people, or, if not the will of the people as a whole, at least a large section of it. Phrases like the "voice of agriculture" and the "voice of business" have been frequently used. The claims of such groups are often suspect. But now we have private institutions purporting to speak the voice of all the people and rapidly convincing us that they do. It is important, therefore, that these polling agencies be subjected to social control; that the accuracy of their reports be assured; and that they be used in the public rather than the private interest.

The second question raised by the New York Times is even more perplexing. Assuming that the voices of Gallup and the magazine Fortune are the voices of the people, the question arises whether they are also the voices of God and should govern the acts of legislators. Are we prepared to have public opinion not only reign but also govern? Our government is a representative democracy and not a direct democracy. The Times editorial emphasizes this fact. The problem we are facing goes to the very heart of the whole problem of democracy. Are the masses of citizens competent to express their opinions on all matters of social and public policy? They are doubtless more competent than they were in years past, but there are grave doubts concerning the wisdom of the masses to pass upon all questions regardless of their technicality and complexity. Even in those states where the initiative and referendum are used most frequently and extensively, restrictions have been placed upon the number and types of questions that may be submitted.

The attempts now being made to improve methods for ascertaining the state of public opinion on social and political questions are, in many respects, socially useful. In the first place they emphasize 
the shortcomings of the cruder indices and manifestations of the American public mind. Periodic elections are cumbersome, slow, and have come to be devices primarily used for selecting public officials, rather than instruments for bringing to light the precise state of public opinion on specific issues. Moreover, public-opinion polls serve as useful checks on the state of public opinion as indicated by the press, the claims of pressure groups, and the assertions of politicians.

In the second place, these newer experiments will probably produce a more critical attitude on the part of the public generally toward claims of groups and individuals purporting to speak the voice of the people. A public that reads discussions of the technical accuracy of the Gallup or Fortune polls, and begins to think in terms of the adequacy of a sample, probable errors, and coefficients of correlation, is certain to become more skeptical of statements by individuals and interested minorities that public opinion is thus and so.

In the third place, these mechanisms of opinion identification may encourage a more widespread and intelligent discussion of public questions. In framing their questionnaires these polling agencies have to clarify and define issues. Political leaders and group leaders are often quite as interested in confusing as in clarifying issues. Whatever the reaction of the voter may be to the questionnaires he received, he has before him as a rule a list of questions which not only focus his attention upon important public problems, but may even stimulate a little more thought, and help him to clarify the issues.

And finally, it should be noted that these experiments result in the accumulation of a wealth of data of considerable scientific value. The files of the American Institute of Public Opinion and the Fortune magazine contain a mass of data concerning the expressed opinions of people throughout the United States regarding innumerable questions of significance. These opinions have been collected in such a way that they can be classified by age, sex, income, residence, and sectional groupings. This fact enables the investigator to draw conclusions regarding the opinion-forming habits of different groups, their patterns of thinking, and the relative influence of different factors in the opinion-forming process. Already the accumulation of these data has suggested some rather interesting hypotheses. Dr. Gallup believes, on the basis of his findings, that a poll of the opin- 
ions of a group of university faculty members on a general political question will reveal substantially the same cleavages as a poll of the citizens of the United States as a whole. In other words, he finds little ground for the popular assumption that the masses are less certain of their opinions than the intelligentsia.

He also finds that, so far as political and most economic questions are concerned, party affliation seems to be the deciding factor. The degree of unanimity on such questions is greater among members of a political party than among those of the same age, sex, or income group. By classifying opinions according to different age, sex, income, and sectional groupings it is possible to throw a good deal of light upon the problem of how public opinion is formed. If over and over again it is found that 90 per cent of the members of a party think alike, whereas repeatedly there is a 50 to 50 split within a given age group or income group, there are strong grounds for believing that the influence of the party factor is greater than the influence of the age or income factor. Whatever other values these experiments may have, the scientific usefulness is clearly indicated.

"Scientific" polls do give rise to problems. One of these is the fact that they are so generally accepted as reliable. It is very difficult if not impossible to establish their accuracy, especially on questions of political and social significance. No one, I believe, can fairly question the honesty of purpose and painstaking care that go into the polling efforts of most of the agencies. They have taken every effort to avoid the danger of ballot stuffing and manipulation. They desire to find the truth, if for no other reason than a commercial one. But they are dealing with instruments of power. And in other hands our reverence for statistics might be used against us.

The dangers are not those of crass fraud, merely. There are an infinite number of ways, some of them very subtle, for using these techniques for private rather than public advantage. The selection of questions, their phrasing, the timing of polls, as well as the statistical treatment of results, are phases of the problem that present difficulties. In polls on candidates the results can be checked against official election returns. But in polls on issues there exists no obvious check, not even the check of competition. For it would be only the most extraordinary coincidence that would enable the public validly to check one poll against another. 
All the nationwide polling agencies are commercial enterprises. They are financed by the sale of their surveys to private interests. They must cater to some extent to these interests, and this fact affects the list of questions used and the publication of results. The financial supporters exercise both a negative and a positive influence. Positively, they influence the choice of questions. Negatively they often prevent the polling of public opinion on questions which have great social significance. The problem is to turn these efforts at "scientific" polling into channels that will be of the greatest social usefulness. If a method has been found for accurately sampling public opinion then it should be socially controlled. Polling public opinion may well be regarded as an activity vested with a public interest. 


\section{Formation of Opinion}

$A^{\text {Ttempts to find reliable indices of public-opinion trends and to }}$ $A$ measure states of public opinion have been accompanied by equally searching inquiries into the nature of the public-opinionforming process. The purpose of this lecture will be to chart the progress which has been made in studies of this kind, call attention to some of the hypotheses advanced, and indicate the nature of the problem as it faces us today. In the preceding lecture we noted that such polling agencies as the American Institute of Public Opinion and the magazine Fortune based their procedures on certain assumptions regarding the role of such factors as age, sex, income, etc., in the public-opinion-forming process. Are these assumptions valid? What, after all, do we really know about this process?

In the first place, it is important to re-emphasize that public opinion is merely a collection of individual opinions. If we can find out how personal opinions are formed we will know how public opinion is formed. Opinions are always individual expressions of attitude. The notion that there exists a group mind, an entity disassociated from individual human beings, has been thoroughly discredited.

In the second place it is necessary to refer again to our definition of opinion. It is merely an expression, one expression of attitude in words. It always takes the form of words, either written or spoken. But do all the words we speak or write constitute expressions of opinion? Should we distinguish between statements of fact and expressions of opinion?

Dr. A. Lawrence Lowell believes that we should, and he defines opinion as the "acceptance of one among two or more inconsistent views which are capable of being accepted by a rational mind as true." ${ }^{32}$ This definition raises two perplexing questions. What is a fact? And what is a rational mind? Personally, I see no valid reason for restricting the word "opinion" to verbal expressions of attitude, to views "which may be rationally held," because of the difficulty of defining what we mean by rational. Irrational views and opinions 
may have as much political significance as the purely rational. I do think, however, there is value in distinguishing facts from opinions, although it is very difficult to do.

But what is an attitude? Professor Gordon Allport has given this question careful consideration. After pointing out that the word has a wide range of application, and is used by writers in many different senses, he gives the following definition: "An attitude is a mental and neutral state of readiness, organized through experience, exerting a directive or dynamic influence upon the individual's response to all objects and situations with which it is related." ${ }^{33}$ In this sense the term is distinguishable from such words as reflexes, habits, instincts, wishes, sentiments, and traits. Professor Thurstone defines it as "the sum total of man's inclinations and feelings, prejudice or bias, preconceived notions, ideas, fears, threats, and convictions about any specific topic." In general, therefore, we may think of an attitude as a disposition on the part of an individual to act or react in a certain way, usually favorably or unfavorably, toward a particular issue or object.

The third point I wish to stress is that a thorough understanding of the process of opinion formation presupposes a knowledge of how attitudes are formed, which in turn presumes a knowledge of how personality itself develops. The problem is not simple but extremely complex. Biologists and psychologists have given more attention to it than any other group of specialists. But it is by no means a problem exclusively interesting to them. The very fact that so much political philosophy and so much social and political engineering are based on theories of personality emphasizes the importance of keeping abreast with psychological researches. Whether or not the study of public relations is merely a branch of psychology, the important thing is to bring to bear upon our major political and social problems the best-informed opinion available.

Why do people express the opinions they do? Why do people, supposedly well informed and reasonably objective, have different opinions regarding the same question? Why do some people express opinions whereas others do not? Why do we find considerable agreement on some questions, and little or no agreement on others? Why are some opinions more intense than others? How may we account for sudden changes in opinion on some issues, and pronounced 
stability on others? What factors are most important in the opinionforming process? Are there any general propositions regarding these matters that are valid?

At least one statement or proposition can be made with assurance: that our opinions are what they are because of the influence of a multiplicity of factors. Beyond this it is hazardous to venture. In attempting to explain why reasonable, unprejudiced men reach different opinions, even though they have the same information, Dr. Lowell stresses the effect of ascribing different weights to the evidence presented; the varying degrees of attention people bestow on a problem; and the influence of emotion. But why do men experience different emotional reactions to an issue or a question? Why do some attend to the matter in hand more carefully than others? And why, therefore, do they ascribe different weights to the evidence presented?

Walter Lippmann emphasizes the role played by stereotypes in the opinion-forming process, images of things created in our minds as a result of what we actually see, hear, and experience. ${ }^{35}$ What these images are depends, of course, not only upon our access to facts, but also upon the impact of these facts upon our constantly changing personality. And so we could go on through the literature to find different, even contradictory, explanations of the opinion-forming process.

Again we come to the proposition that the problem of determining why our opinions are what they are can be solved only by finding out why we are what we are. No one knows the complete answer. But we do know some things. We know that our opinions as well as our personalities are what they are because of the interacting influence of heredity and environment. Students of biology and psychology have listed and described many of these hereditary and environmental factors, particularly those of an organic nature. Students of sociology and the social sciences have done the same for environmental influences.

The question may be asked: Why is it necessary to trace the genesis of opinions in such a comprehensive fashion? Why is it not sufficient to confine our consideration simply to important influences? But which are the important? Undoubtedly what we read has a good deal to do with our opinions on certain subjects. But two persons 
may read the same book or newspaper and arrive at diametrically opposed views.

Various attempts have been made to enumerate and classify the influences which make our opinions what they are. The starting point is usually a distinction between hereditary and environmental factors. From this point on, there is consicterable variation. So far as heredity is concerned the notion that persons have specific instincts at birth has been largely discredited. It may be that we come into this world with certain "preponent reflexes," as Professor Allport calls them, but recent psychological studies emphasize the plastic and malleable nature of our hereditary equipment. We do possess certain potentialities which take different forms according to the environment in which they develop. Opinions are certainly not inherited, nor are attitudes. Men are not born radicals or conservatives, much less adherents of the New Deal or Communism. At birth they are merely bundles of potentialities. This does not mean that we cannot predict to some extent the color of skin, the texture of hair, and some other traits. And yet, even with respect to such physical traits, our predictions may miscarry. So much depends upon the influence of environment.

This is not to say that environmental influences are determinative. Man's potentialities, even at birth, vary from person to person. Environment may serve to equalize differences in some respects and magnify them in others. We are confronted with a growing, developmental process in which both hereditary and environmental factors are acting and reacting upon each other. Out of this interacting process emerges an individual personality with certain habits, attitudes, and traits which are common to many, with others that are unique.

On the environmental side it is customary to classify factors as physical, biological, psychological, and social. From this point on, the categories are divided and subdivided indefinitely. There seems to be no generally accepted basis of subclassification. Physical factors comprise geography, climate, mineral resources, topography, and many other aspects of our material surroundings. Undoubtedly the place where we live and work has a great deal to do with our opinions. But how much we do not know. Many students have even undertaken to explain differences and also uniformities of opinion 
largely in terms of one of these factors. Our biological surroundings, the presence or absence of specific forms of animal and vegetable life, and the racial character of the people with whom we associate have much to do with our attitudes and opinions. Our psychological surroundings are also important-the attitudes and opinions of our associates, the ideas they hold and express. Moreover, we must take account of patterns of social organization and institutional life. Our opinions and beliefs are constantly being affected by the character of the political, social, economic, and religious institutions which surround us. The problem of merely listing all these factors making our opinions what they are is a baffling one, to say nothing of the problem of weighing their relative influence.

As previously noted, the American Institute of Public Opinion, the magazine Fortune, and other polling agencies proceed on the theory that sex, age, place of residence, income, and possibly race, religion, and party affiliation are the more important influences making our opinions what they are. They base this theory on their experience, which seems to show that a comparatively small sample of the population which mirrors the whole population in these respects will also mirror its opinions. If this is true, it is an unusually significant discovery. If, by knowing where a person lives, how old he is, what his sex is, whether he has a large or small income, and whether he belongs to a particular race or party, we can predict what his opinions will be, much of the mystery surrounding the problem of opinion formation disappears. But there are some difficulties with this assumption.

An examination of the polling experience of the American Institute of Public Opinion from October, 1935, to May 15, 1938, shows a considerable variation in the extent of agreement on the questions submitted. On a number of questions, as previously pointed out, more than 85 per cent of the respondents expressed the same opinion. Of course, on most of the questions there was less agreement, and in a great many instances the state of opinion was evenly divided, or nearly so.

If, however, such factors as age, sex, place of residence, and income are the factors which make our opinions what they are, how may we explain the fact that on many questions we all think so nearly alike in spite of these differences? 
Furthermore, we find, after examining the returns, that on some questions the extent of agreement is very great when the returns are classified according to age levels, but not when classified on the basis of income, sex, etc. This suggests that the influence of these factors varies from question to question.

These observations indicate the difficulty of ascertaining empirically what factors are important and what their relative influence is. On some questions apparently, none of the factors employed by the polling agencies in their sampling formulas were important. Otherwise, how can we explain the high degree of agreement on certain questions in spite of differences in age, sex, income, etc.? On others, certain factors, such as income or age, seem especially important because of the unanimity of opinion expressed by those in a particular category.

Another important point should be noted. The fact of a high degree of correlation between the age of a person and the opinions he holds does not necessarily establish a causal relationship. It may be that his age determines what he reads and hears, and that the content of his reading and hearing is actually the decisive factor in determining his opinions. This in no way minimizes the significance of a high degree of correlation between age and opinion. It merely shows that some influence other than age may be the proximate and direct cause of his views on issues.

After all, the proximate factors affecting our opinions are practically the most important. Without knowing what they are we shall be at a loss to explain sudden and far-flung changes in public opinion at times when such factors as age, sex, income, and place of residence remain virtually constant.

I think it fair to assume that the proximate causes of our opinions are the things we read, hear, or see. The influence of these factors may be, and probably is to a considerable extent, determined by where we live, how old we are, and how prosperous we are. And these in turn may be conditioned by our biological, physical, social, and psychological heritage. We may call these secondary factors latent, in contrast to the primary factors, which are active. They condition our personalities and predispose us to act in specific ways. In many instances, however, they are poor indicators of what our opinions will be on specific issues. They do not explain rapid and 
widespread changes in states of public opinion when they in turn remain constant.

The immediate determinants of opinion are the channels of communication and what comes through them-the ideas, reports, news, representations that constitute our world of verbal symbols. By concentrating our attention upon conflicts of ideas, and the groups that are propagating them, we shall obtain a much better understanding of why our ideas and opinions are what they are than by studying the remote influence of climate, human biology and psychology, or even social institutions as such. Within the limits set by these rather firmly fixed conditioning factors the opinion-forming process goes on with lightning-like speed.

A few experiments have been made to measure the influence of specific factors in the opinion-forming process. The size of the factors ranges all the way from a small magazine advertisement to institutions such as the press, the radio, or a pressure group. Advertisers wish to know what effect a specific advertisement has upon public opinion. Corporation executives wish to measure the success of a public-relations campaign. Politicians wish to know whether newspapers are more effective than radio broadcasts in an election campaign. We speak glibly of the influence of this and that pressure group, but usually we have only the vaguest notion of what that influence is. In many cases no special attempt is made to isolate the factor and determine its influence. It is enough for many business concerns to know that after they have spent a million dollars on an advertising campaign their sales increase, or, for politicians, that a propaganda campaign resulted in the election of their candidate to office. They are not concerned about the question of the precise extent to which the advertisement or the particular medium used was responsible for the result. Motion-picture producers judge the public's reaction to a motion picture by box-office receipts; broadcasters, by fan mail; newspaper publishers, by the circulation of their papers. An infinite number of manifestations of public opinion may be used as rough indices.

Why is it desirable to determine more precisely, therefore, the effects or influence of particular factors? One reason is financial. To know what factors are most important is a saving of money. Throughout the business world efforts are constantly being made to 
test the influence of particular kinds of advertisements, the effectiveness of various types of appeal, the usefulness of particular media, the responses to different kinds of programs, products, services, etc. But knowledge of this sort has a propaganda as well as a commercial value. Knowing which factors are of greatest significance in the opinion-forming process, campaign managers can plan with greater assurance.

In every problem of this kind the experiment begins with a publicopinion poll to determine the state of public opinion before the experiment, and ends with a poll after the experiment to determine the extent of the change. But how can all factors affecting the change be held constant so that the precise influence of the one in which we are interested can be measured?

Professor Gosnell attempted an experiment of this kind to ascertain the effect of a non-partisan mail canvass to get out the citizen vote in selected districts in Chicago. ${ }^{36}$ He selected twelve districts known to be typical as far as the economic and racial characteristics of the population of the city as a whole were concerned. The voters in each district were divided into two groups in such a way that they did not differ fundamentally with respect to racial, economic, and other important characteristics. One group was subjected to a barrage of non-partisan appeals through the mails. The other group was not. In this way the effect of other influences was kept constant, so that whatever differences appeared in the voting of the two groups might fairly be attributed to these non-partisan appeals. By means of this method of controlled groups it is possible to test rather carefully the precise influence of some factors in the opinion-forming process. The crux of the problem is to select two groups which are subject to the same influences except for the one to be measured.

A common device for testing the relative influence of different factors in the opinion-forming press is the method of classification. Such classifications do not necessarily establish causal relationships, nor do they always indicate even the relative influence of the factors. Referring again to the work of polling agencies we find that they segregate their returns according to age, sex, race, income, residence, and other classifications. If all within a certain age group have the same opinions on selected issues there is a strong presumption that the age factor has a great deal to do with the expressions of opinion. 
If the returns show a roo per cent agreement in terms of age groups, a 75 per cent agreement in terms of sex groups, and only a 50 per cent agreement so far as income groups are concerned this suggests that the age factor is more important than the sex factor, and that the income factor is of almost no significance.

The fact that the extent of agreement on a given question varies so much for different factors indicates that they do not always have the same weight. Moreover, the fact that the distribution of percentages varies with a change in question suggests that the phrasing of the question affects the relative influence of different factors. Nevertheless, such classifications have value and can be used to describe what may be called patterns of opinion for different groups. As previously indicated, however, the attempt to set up a particular formula for selecting samples of public opinion on the basis of these factors is not likely to be successful. If, for example, tests show that sex is a determining factor in the formation of opinion, the effect of using with it a number of insignificant factors in constructing our formula may distort rather than improve the results.

Classification techniques have been used to compare the votes of men and women at elections; differences in the political attitudes of those living in urban, village, and open-country communities; and political alignments according to religion, nationality, race, and many other factors. ${ }^{37}$ Students of government have given more attention to election statistics than to any other type of opinion data. These statistics are classified by states, counties, and in many cases by wards, precincts, and election districts. Treated in this way they can be used to chart the voting behavior of particular sections of the country; to compare trends in voters' opinions with other trends; and arranged in time series, as Dr. Stuart A. Rice has used them, to ascertain the existence and character of cycles of party turnover, or to study what he called the "amplitude" of electoral swings in recent as compared to past times.

Perhaps a word should be added regarding the significance of time series. As Dr. Rice states:

The invention and improvement of precise statistical methods for analyzing time series has been one of the more important developments of recent years for the whole domain of social science. The use of these methods has been almost confined, 
however, to the special field of economics. There they have come to be of invaluable aid in charting those myriad fluctuations of business activity in which practical men are interested. . . As illustrations might be mentioned such studies as those between the production and the prices of various agricultural commodities, or between the prices of stocks and bonds.

Dr. Rice was one of the first to apply similar methods to the study of political phenomena and public opinion. His studies show that types of variation familiar in economics are to be found also in public opinion such as secular trends, cyclical variations, seasonal influences, and fortuitous changes.

In one case, for example, he attempted to find out whether changes in public opinion as reflected in election statistics accompanied selected economic variations. He thought that changing percentages of Republican votes might be an index of what is often called the pendulum of politics, and that changing percentages in minor party votes might give some measure of the growth or subsidence of dissent from both of the major party organizations. His conclusion, based on election statistics in New Jersey, was that "cycles are present, although they do not seem to occur so frequently as the business cycles," suggesting that "cycles of party turnover in New Jersey are to be attributed to some factor or factors of changing attitude which are not closely related to changes in business prosperity." Whether this is true or not, the point to be underscored is that public-opinion time series are very useful for testing hypotheses regarding opinion formation, as well as the influence of different factors in the process.

One other illustration of the application of time series to the analysis of opinion data may be noted. Dr. Rice wished to test the proposition that a mass tendency by the electorate to favor one candidate over others would carry its influence farther today than formerly. The question was whether the "amplitude" of the electoral swing has tended to increase during the past century. It occurred to Dr. Rice that "more fundamental causes than were suggested by factors in the immediate political situation might be operating to account in part for the striking reversals of attitude that were indicated by election landslides. Increasingly throughout the past century the people in this country have been placed in closer contact with 
each other, and hence more certainly subjected to whatever currents of opinion or emotion might arise in any part of the group." As contributing factors to this phenomenon he mentioned urbanization, universal education, developments in transportation, communication, newspapers, moving pictures, radio, etc. Since he wrote we have witnessed a series of landslide elections in 1928, 1932, and 1936. This raises the interesting question whether large publics because of the developments just mentioned are progressively assuming the character of mobs, tending to move in one direction or another with greater force and intensity.

In order to test this hypothesis several tables of election statistics were used to show variations in the "swing" toward the winning candidate. Indices of "landslide tendency" were then determined. The presence of cyclical swings, especially after the Civil War, was manifest. From i867 to ig2 I an upward trend and five completed cycles were noticeable. These cycles were compared with cyclical trends in business, and the comparison suggested a definite relationship between business cycles and swings of political majorities. Although the data presented some rather perplexing questions, Dr. Rice states, "Perhaps the best evidence that the data mean something is to be found in the comparative regularity of the cycles of landslide indexes."

These illustrations suggest only a few ways in which election statistics may be used to study the opinion-forming process. Such figures have considerable value as indices of attitudes and opinions and have been used more extensively than any other. They are comprehensive and have been regularly reported for a long period of time. They are official and reliable as far as they go. And they have been broken down for various geographical districts. Unfortunately, because of the secrecy of the ballot, it is impossible to classify them according to age, sex, race, religious preferences, and other categories extremely useful to the student of public opinion. Until the advent of nationwide polling agencies election statistics were the most important opinion data available. Recently, however, these agencies have been collecting a mass of data in such form that innumerable classifications and correlations can be made. These opinion data can now be used to test various theses regarding the opinion-forming process. 
Professor Clark of the University of Pennsylvania has recently undertaken a study to determine what correlations exist between President Roosevelt's popularity, as shown by the Gallup and Fortune polls, and various economic indices. Although high degrees of correlation would not indicate necessarily a causal relationship, the comparisons would be of value in indicating trends, and possibly in predicting them.

Professor Clark is interested primarily in four types of relationships: ( 1 ) the President and agricultural economics; (2) the President and industrial economics; (3) the President and labor economics; (4) the President and federal spending. In each type, trends in the President's popularity are compared with indices of the respective economic trends. In the field of agricultural economics, trends in the President's popularity are correlated with variations in wheat prices, dairy prices, corn prices, wheat, corn, and farm production. In the field of industrial economics such indices as industrial production, stock-market quotations, interest and discount rates, new building construction, cost of living, retail prices, and wholesale prices are used. In the field of labor economics such indices as employment and unemployment, earnings, strikes and lockouts, wage rates, and union membership are used. And in the field of federal spending, WPA expenditures, PWA expenditures, other federal expenditures, employment by federal agencies, and relief expenditures are employed.

By noting the degree of correlation in each case, as well as the character of lags, if any, information may be obtained regarding the relative influence on President Roosevelt's popularity of his agricultural, industrial, labor, and spending policies; the probable character of his policies in the immediate future; causes for changes in the degree of his popularity, and many others.

The availability now of such opinion data as the polling agencies are collecting opens up a whole new field of public-opinion and statistical research. Too much emphasis has probably been given to the forecasting activities of the polling agencies, and too little to the data accumulating.

A recent device for determining the relative influence of factors in the opinion-forming process is the statistical technique of partial correlations, which has been simplified and called the method of 
multiple-factor analysis. It seeks to accomplish by means of available statistical data the same end result obtained by the method of the controlled experiment. It undertakes to hold constant, simply by neutralizing their effect statistically, important factors in the opinionforming process and to determine the effect of one.

Professor Gosnell has recently applied this technique to a study of the influence of the press on public opinion. ${ }^{38} \mathrm{He}$ stated his problem as follows: "There are many difficulties confronting any attempt to estimate the role of the press in the democratic process. Are the newspapers molders or followers of public opinion? How can the incidence of the policies of the press be separated from the many other complex variables which are woven together in a complicated pattern?"

Without attempting to explain the statistical techniques used, the procedure employed may be summarized as follows. It was possible to obtain information for 47 selected areas in the city of Chicago regarding the circulation of four leading daily newspapers. For these same areas the votes received by candidates at primary or general elections during a given period were obtained and expressed as percentages of the total vote cast. The attitude of the newspapers toward these candidates was determined by estimating the number of column inches in each devoted to editorial and cartoon endorsements of a given candidate. Eight other variables were then selected, each of which was assumed to have some relation to the election results. A master table expressing each of the $2 \mathrm{I}$ variables in percentage form (except median rental) was then prepared for the 47 areas.

Product-moment coefficients of correlation were then calculated for all possible combinations of the $2 \mathrm{I}$ variables and presented in symmetrical form, providing what is commonly known as a correlation matrix. The question was: Did these intercorrelations show patterns of behavior which could be interpreted in the light of the newspaper recommendations?

Factorial methods assume that there are primary tendencies which are to be estimated in terms of the variables given. The aim of factor analysis is to ascertain how many general and independent factors must be postulated to account for a whole table of intercorrelations. It seeks to reduce a complicated set of relationships to a relatively small number of factors. In the problem at hand it was discovered 
that the 210 intercorrelations could be satisfactorily explained in terms of four general factors: (I) traditional Republican vote in national elections; (2) Thompsonism in local and Republican primary elections; (3) wet Democrats in national and local elections; and (4) Republican vote in state and local elections.

These illustrations of current activities in the field of public-opinion research suggest the complexity of the problem of analyzing the process of public-opinion change. It is not enough to list and classify the numerous factors involved. We need to know more precisely what their specific and relative influence is. Public opinion is not only a criterion for evaluating our public relations; it is also a force over which we have some control. The more intelligent our participation in the process of its formation, the more capable it will be in exercising its function of social control. 


\section{The Concept "Propaganda"}

D Ropaganda is a noun. It refers to the material being propagandized. To propagandize is to propagate-not human beings, animals, or plants-but ideas, principles, and doctrines. To propagate ideas is to advance, further, spread, transmit, disseminate, promote, and increase them.

The word "propaganda" has a long history. It is found in the name of that department of the Catholic Church charged with the responsibility for spreading Catholicism and regulating ecclesiastical affairs in non-Catholic countries-the Sacred Congregation for the Propagation of the Faith-whose official title is Sacra Congregatio christiano nomini propagando. There have been various accounts of the origin of this institution. In reality it is the result of slow evolution.*

Sometime between 1572 and 1585 while Gregory XIII was Pope a Commission of Cardinals for the Propagation of the Faith (Cardinalitial Commission de propaganda fide) was established under the presidency of Cardinal Santorio for the purpose of founding foreign seminaries and printing catechisms and similar works in many languages. Under Clement VIII (I592-1603) weekly meetings were held, and every fifteen days the decisions and recommendations of the Commission were referred to the Pontiff. On June 22, 1622, the Papal Bull Inscrutabili Divinae finally instituted the Sacred Congregation for the Propagation of the Faith, composed of thirteen cardinals and two prelates, to whom were added a secretary and a consultor. Its formal organization dates from i65o.

I refer to the Sacred Congregation for the Propagation of the Faith because for centuries and even today this institution is one of the best examples of what the word "propaganda" signifies. In earlier times religious organizations were the principal disseminators of

* This description of the evolution of propaganda is based on an article by the author in the Dictionary of American History published by Charles Scribner's Sons. Grateful acknowledgment is hereby expressed for permission to use this material. 
ideas. The clergy were the scholars. Often they were the only persons able to read and write. Because of this they were frequently vested with important clerical and other responsibilities by secular rulers as the western state system developed. Students of English history are aware of the role they played in the constitutional development of England, in the evolution of its judicial system, Parliament, and other institutions.

The advent of printing during the middle of the fifteenth century, the Protestant Reformation, the Renaissance, the rise of merchant and business classes, the discovery of new continents, and the Industrial Revolution tended, however, to undermine the monopoly of the Roman Church over the propagation of ideas. Economic, political, social, and non-Catholic organizations of all kinds began to enter the propaganda arena. Educational facilities were made available to an increasing number of people. Propaganda was no longer the peculiar prerogative of the clerics, but described the activities of all sorts of organizations. The history of propaganda is the history of the dissemination and propagation of ideas. As a subject of scientific study it is as comprehensive and difficult as it is important.

The spread of democracy and the extension of the suffrage; the expansion of educational facilities and the increase of literacy; technological changes and improvements in the field of communications; economic transformations in the production, distribution, and consumption of wealth; as well as an accelerating tempo of social change and an increasing need for social cooperation have greatly affected the role of propaganda in society. Propaganda assumes greatest historical significance when carried on systematically over long periods of time by large and well-organized groups.

During the colonial period in America extensive propaganda activities were carried on by religious institutions, such as church denominations and the Society for the Propagation of the Gospel; by trading companies, chambers of commerce, groups of workers, and political associations. Political propaganda assumed large proportions during the years immediately preceding the Revolutionary War under the astute direction of Samuel Adams, using the channels of Committees of Correspondence. The propagandistic writings of Thomas Paine were also very effective. The struggle for the rati- 
fication of the Constitution of 1787 produced the classic compilation of arguments known as the Federalist papers.

The development of political propaganda in the United States is largely the story of the development of political parties. The presidential campaign of 1828 , in which Andrew Jackson won, was a landmark. Since then political propaganda has been affected by the increasing size of the electorate, the deepening of sectional, class, and economic cleavages, the growing importance of economic issues, and improvements in means of communication and contact. The advent of radio broadcasting, and its use in political campaigns since 1924, have altered techniques and probably influenced the tempo of public-opinion changes. The expansion of governmental activities, increases in public expenditures, the rising costs of political campaigning, and refinements in propaganda techniques have altered the character of political campaigns and given decided advantages to the party in power.

The rise of large aggregations of labor and capital has greatly intensified the competition of propagandists. The two most comprehensive and active propagandists for American business are the National Association of Manufacturers (I895) and the Chamber of Commerce of the United States (1912). In 1938 these two organizations launched one of their most comprehensive campaigns with the slogan "What Helps Business Helps You." The practice of lobbying-the attempt to influence public officials directly-has been supplemented and in some cases supplanted by propaganda activities designed to influence government indirectly through public opinion.

The American Federation of Labor (1886) and more recently the Committee for Industrial Organization (1935) have been preeminent propagandists of labor doctrines. In general their methods are similar to those of business groups, except that they take a more active part in elections and political contests.

The National Grange (1867) and the American Farm Bureau Federation (1919) have been active propagandists of agricultural policies. There are approximately io,00o commercial and industrial organizations in the United States of which I,500 or more are interstate, national, or international in scope. Most of these organizations carry on propaganda activities to a greater or less extent.

There is scarcely a field of human activity in which propaganda 
organizations have not arisen. In addition to political and economic formations there are racial, religious, professional, age, and sectional groups, as well as a multiplicity of special-purpose organizations. More than 500 national associations have headquarters in Washington and seek directly or indirectly to mold public opinion and public policy. In some cases their propaganda activities cancel one another. In others, log-rolling is practiced, and the influence of small but active minority groups is large. The American Anti-Slavery Society ( 1833 ) was one of the most active and influential propagandist organizations in pre-Civil War days. The American Peace Society (1828) is one of the oldest of numerous organizations seeking to further the cause of peace, and is active today. The Anti-Saloon League of America, the American Legion, the American Civil Liberties Union, the National Civil Service Reform League, and the National Council for the Prevention of War are examples of persistent special-purpose propaganda organizations.

The World War injected the national government into the propaganda arena on an unprecedented scale. Since then the role of propaganda in the United States has been markedly affected by (I) the increasing use of propaganda by governmental agencies, national, state, and local; (2) the availability of new instruments of mass impression such as the radio and motion pictures; (3) refinements in technique accompanied by greater specialization, as illustrated by the rise of public-relations counselors and the use of more precise methods for charting changes in public opinion; (4) increased attention of business executives to problems of public relations and propaganda as distinct from those of advertising; (5) the rise of dictatorial propaganda machines and a more intensive competition of propagandas in the field of international relations; and (6) an increasing emphasis upon the specialized study of propaganda as a social phenomenon.

There have been many studies of the history of ideas; historical treatises describing the work of those who have propounded great philosophies and analyzing the nature of their doctrines. The student of propaganda is interested in this work, but more particularly in the questions: Why do these ideas spread? How may we account for the far-flung acceptance of some ideas and not of others? To 
answer these questions will bring us closer to an understanding of why public opinion is what it is.

In some respects the task of the student of propaganda and public opinion is like that of the biologist or the horticulturist. He is a student of societal evolution. He deals, however, with ideas and opinions rather than plants and animals. He wishes to find out, if he can, why ideas grow, multiply, and spread. One method of approach is to study the activities of individuals and organizations actively engaged in the propagation of ideas and doctrines.

There are many different approaches to the problem. We might study the genesis, growth, and spread of selected doctrines in terms of the activities of those engaged in their propagation. We might take as our starting point specific individuals or organizations and study the doctrines they are spreading. Or we could try to chart the course and spread of selected doctrines through the centuries or even focus attention upon the dominant pattern of ideas in particular places at particular times. What we are really interested in as students of propaganda and public opinion are the reasons why ideas and doctrines spread, and more especially the role played by human, active forces in the process.

Since the World War the word "propaganda" has acquired an invidious connotation, less frequently in the writings of serious students than in discussions by popular commentators. Professor Frederick E. Lumley, for example, in his book The Propaganda Menace, states that "Propaganda is promotion which is veiled in one way or another as to (I) its origin or sources, (2) the interests involved, (3) the methods employed, (4) the content spread, and (5) the results accruing to the victims-any one, any two, any three, any four, or all five." ${ }^{39}$ From his point of view all propaganda is bad. It is unsocial because it "dwarfs the critical faculties, engenders fear and suspicion, and produces intellectual slavery." He writes: "In sum, the results of propaganda correspond in many particulars with the results of a stalwart belief in the omnipresence of innumerable disembodied spirits. Indeed, propaganda may appropriately be described as the modern substitute for these powerful, mostly malignant and potently devastating powers. Or perhaps it would be more correct to say that propaganda makes the social order spooky, and thus makes society a vast, many-roomed, haunted house." 
If the word "propaganda" is to be restricted in meaning to the propagation of ideas and doctrines which are veiled as to origin, interests, methods, content, and results it may be that such propaganda produces the consequences Professor Lumley enumerates. The only way to test this conclusion is to investigate propaganda which does employ such methods. Personally, I am willing to admit that the consequences listed are bad, although to do so presupposes the existence of objective and absolute standards of goodness. No one can reasonably object if Professor Lumley wishes to confine his own studies to veiled propaganda, but forceful objections may be made to restricting the meaning of the word propaganda itself to ideas propagated by veiled methods. It is a question of perspective, a question whether students of propaganda wish to limit the scope of their interest to disseminators of ideas and doctrines which in their opinion are bad or prefer to focus attention upon the broader area of idea dissemination.

Obviously the morals of propaganda are prescribed by the standards of goodness and badness which we use to evaluate it. Are there such standards? To answer this question satisfactorily we would have to delve into philosophical discussions of exceptional perplexity. We would ultimately have to answer the question: What is the good life?

Within recent years we have witnessed the rise of authoritarian states with definitions of the good life so different from our own that it would be difficult for most of us to stamp their propaganda good. And yet who can say with assurance what is good and what is bad? We live in a world of conflicting ideologies and philosophical systems. All of them start with certain assumptions, certain premises incapable of absolute proof. The only certainty is that every listing of human values takes us back ultimately to a premise, an assumption, a mere opinion. The starting point for a pure science of propaganda is not a definition of moral values, but the selection of an object to study. After the study is completed, not before, is the appropriate time to evaluate in terms of moral, ethical, and social criteria.

In the fall of 1937 an Institute for Propaganda Analysis was organized as a "non-profit corporation for scientific research in methods used by propagandists in influencing public opinion." ${ }^{* 0}$ The 
charter of the Institute contains the following statement of its purposes:

To assist the public in detecting and analyzing propaganda by conducting scientific research and education in the methods by which public opinion is influenced, by the analysis of propaganda methods and devices, and by the distribution of reports thereon.

It shall not be within the purposes or powers of the corporation to engage in propaganda or otherwise attempt to influence legislation and the corporation shall not, either as one of its purposes or as a means of furthering any of its purposes, engage in propaganda or otherwise attempt to influence legislation.

The Institute defines propaganda as an "expression of opinion or action by individuals or groups deliberately designed to influence opinions or actions of other individuals or groups with reference to predetermined ends." So far as this definition is concerned there is no implication that propaganda is bad, no attempt to distinguish between good and bad propaganda. To the definition itself there is no ground for objection. It is simply another way of stating that the word propaganda refers to ideas, doctrines, and opinions which are propagated for a purpose. It is only when the Institute proceeds to identify, analyze, and appraise propaganda that it departs from its announced objectives. In reality the Institute confines its investigations to propaganda which it considers bad.

According to what standards does the Institute select the propaganda it wishes to study, propaganda which it considers bad? "Propaganda which concerns us most," it states, "is that which alters public opinion on matters of large social consequence often to the detriment of the majority of the people." And elsewhere it asserts that, "Socially desirable propaganda will not suffer from such examination, but the opposite type will be detected and revealed for what it is."

The principal basis used for selecting and distinguishing various types of propaganda is the Institute's conception of democracy. Propaganda which conforms to democratic principles is good. Other types are bad. The Institute lists four principles of democracy: (I) Political-freedom to vote on public issues; freedom to discuss those issues in public gatherings, in the press, radio, motion pictures, 
etc. (2) Economic-freedom to work and to participate in organizations and discussions in order to promote better working standards and higher living conditions for the people. (3) Social-freedom from oppression based on theories of superiority or inferiority. (4) Religious-freedom of worship, with separation of church and state.

There is no valid objection from the scientific point of view to the Institute's selection of certain types of propaganda for special study. All scientists have to select some subjects and exclude others. Various bases of selection will be used, such as the importance of the subject, whether or not it is interesting, and the feasibility of studying it. No one may reasonably object if the Institute arbitrarily selects for purposes of study propaganda which it considers undemocratic.

The principal difficulty with the Institute's approach to the study of propaganda is not that it has exercised its privilege of selection but that it has failed to proceed from that point without preconceived notions regarding what it wishes and expects to find. Instead of attempting to find out precisely why certain types of propaganda spread it merely tries to show that propagandists use certain devices or methods. It ignores the possibility that other and, from its point of view, good propagandists also use these devices, and the possibility that the propagandists selected may use other techniques equally important. In other words, instead of coming to grips with the phenomenon of propaganda the Institute simply tries to prove that "bad" propagandists use certain methods, thereby implying that only "subversive" advocates use them. Instead of trying to find out something the Institute is merely trying to prove something.

The Institute began its researches with the assumption that propagandists, especially "undemocratic" propagandists, used seven principal devices for propagating their ideas: name calling, glittering generalities, the transfer device, testimonials, plain folks device, card stacking, and the band-wagon technique. Instead of making a real contribution to our understanding of propaganda techniques its studies merely show that some propagandists do use these devices.

My criticism of the Institute's work is that it has too limited a perspective of the problem of propaganda. Instead of starting out to find why particular ideas spread, and exactly what methods are used to propagate them, the Institute seeks to bring the phenomenon of 
propaganda within the limits of a few devices which have caught its fancy.

Both Professor Lumley and the Institute for Propaganda Analysis focus attention on certain methods used to propagate ideas-methods which they regard as bad. Because some propagandists have used distortion, fabrication, name calling, and tricks of various sorts the word propaganda has acquired an invidious connotation in some circles. This has even led to definitions solely in terms of techniques. From this point of view a propagandist is a person who uses these "bad" techniques to propagate his ideas and doctrines. Even if the student avoids the use of ethical labels he may try to restrict the meaning of propaganda to ideas which are propagated in a specific manner.

Professor Doob defines propaganda as "the employment of nonlogical, or affective appeals in the public dissemination and modification of ideas, attitudes, and beliefs." ${ }^{+1} \mathrm{He}$ excludes from consideration propaganda that is "factually accurate and logically adequate." His perspective is broader than that of Professor Lumley and the Institute. But it is still restricted to the dissemination of ideas that are illogical and not factual. The business of propagating ideas, even from this broader perspective, retains an unsavory, unsocial connotation. The principal methods of the propagandist are said to be emotional and illogical.

With this limited perspective Professor Doob classifies propaganda methods under seven maior headings. In the first categorv he lists devices sometimes employed to make ideas stand out so that they will be perceived. These include a careful selection and use of all available channels of communication; the placing of ideas in as alluring and attractive surroundings as possible; repetition; and simplicity of expression.

In the second category he lists methods of direct and indirect suggestion. In some instances the propagandist reveals his aim; in others he conceals both his own identity and his goal. He may even use indirect suggestion for a time and then finally reveal his motives.

In the third category he cites a number of methods used to adapt appeals to the interests, attitudes, and beliefs which people already have, which are momentarily active, and which play a significant role in the life of the person. One common device is to vary the appeal. 
In the fourth category he considers various techniques for combatting antagonistic doctrines and ideas. One method is to ignore the antagonist and his opposing ideas, and attempt to create favorable attitudes by positive suggestion. Another is to use the method of direct frontal attack, employing the technique of negative suggestion to overcome unfavorable attitudes.

A fifth category comprises various devices for reducing the chances. of failure. The propagandist may seek to enhance the prestige of his cause by having prominent people endorse his ideas or by creating the impression that large numbers of people approve them. He may even distort, suppress, or even fabricate to accomplish his purposes.

Furthermore, he mentions a number of techniques used to transform momentary approval into firm conviction, such as repetition, varying the appeat, and reinforcing the initial acceptance of the idea with new arguments and new emotional appeals. First impressions are often lasting, and the propagandist exploits this principle.

Finally, to induce action, the propagandist often specifies clearly the course of action which he wishes to have taken. Sometimes he finds that mass appeals are not successfü, and confines his efforts at first to personal appeals, often directed at group leaders who may be better disseminators of ideas than he is.

What Professor Doob is really doing is breaking down the propagandist's methods into a sequence of immediate objectives and classifying propaganda techniques accordingly. He emphasizes, therefore, the necessity for attracting attention, adapting appeals to the interests of different groups, combatting unfavorable attitudes, strengthening favorable attitudes, and inducing action.

This approach is essentially psychological, and follows the traditional procedure of advertisers. Emphasis is placed upon the use of suggestion and emotional appeals. It is limited in perspective because it ignores appeals to reason, and the efficacy of logical and factual techniques. Although Professor Doob does call attention to a considerable number of techniques customarily employed to mold public opinion, his set of principles is an inadequate tool for use in exploring the broad field of idea dissemination.

Another well-known student of propaganda, Harold D. Lasswell, also defines propaganda largely in terms of method." For him propaganda is not simply the propagation of ideas and doctrines, but 
propagation of them by certain methods. He writes, "Not bombs nor bread, but words, pictures, songs, parades, and many similar devices are the typical means of making propaganda. Not the purpose. but the method distinguishes propaganda from the management of men by violence, boycott, bribery, and similar means of social control. Propaganda relies on symbols to attain its end: the manipulation of collective attitudes." He goes on to state that. "Anybody who uses 'representations' to influence collective responses is a propagandist.

Professor Lasswell's conception is, of course, much broader than that of Professor Lumley, who restricts the word "propaganda" to veiled promotion; more inclusive than that of the Institute for Propaganda Analysis, which limits its meaning to undemocratic doctrines propagated by means of seven "devices"; and broader even than the definition of Professor Doob who confines it to the propagation of ideas by means of illogical and emotional appeals. Lasswell restricts the meaning of the word to the propagation of ideas by one method, the "manipulation of significant symbols."

Every student of public opinion and propaganda ordinarily limits his field of investigation. It is not unscientific, for example, to select for purposes of scientific study propagandas the investigator considers "bad." Nor is there anything scientifically objectionable to focusing attention upon one or more specific methods of propaganda, such as the manipulation of symbols. Whether it is desirable to restrict the meaning of propaganda itself, however, to doctrines propagated by selected methods is another question. As students of public opinion we wish to know how opinions are formed, and we can never obtain a complete answer if we start out by defining public opinion in terms of selected methods of formation. Similarly, in the case of propaganda, our problem is to find out how and why certain ideas spread. Undoubtedly symbols and representations play an important role in the process, but not the whole role. Definitions should not be used to obstruct the vision of social scientists. It is preferable to select some particular propagandists or propagandistic organization and study comprehensively and objectively what is actually done to propagate ideas. Such a procedure is more realistic and probably more fruitful than simply selecting a particular method and then trying to find out who uses it, why they do, how, and 
under what circumstances. If the latter course is followed the investigator will discover a great deal about the particular method and its application, that is all.

To repeat, to propagandize is merely to propagate ideas and dectrines. Objectives, motives, and methods employed are numerous. Objectives may be specific as in an advertising campaign or general as in a worldwide philosophical, political, social, or religious reform movement. They may be socially commendable or reprehensible ac-b cording to the standards by which they are evaluated. Motives may be concealed or expressed, publicly approved or condemned. Methods used include the most refined techniques of logical argument, statistical presentation, and citing of authorities; as well as stunts, overt acts, and subtle types of suggestion designed to arouse the emotions. Is education propaganda? Professer Lasswell says no. "Education," he states, "is a process of transmitting skills and accepted attitudes. Propaganda is the transmission of attitudes that are recognized as controversial within a given community." Question! Accepted by whom? Such a distinction is obviously futile. If ideas are accepted it is difficult to see why there is any necessity for transmitting them, for propagating them. Education is something vastly more important than the propagation of accepted ideas. It is because certain ideas have not been accepted that we have our great educational systems. Moreover, it is by no means clear that all propaganda stems from controversy. Its genesis would seem to be the urge on the part of some individual or group to propagate ideas. One significant line of inquiry is to discover, if possible, the reason for this urge.

Everett Dean Martin undertakes to distinguish education and propaganda as follows: ${ }^{43}$

Although the educator and the propagandist are both concerned with the dissemination of information, they have nothing else in common. They use contrary methods and they strive for opposite goals. The propagandist is interested in what people think; the educator in how they think. The propagandist has a definite aim. He strives to convert, to sell, to secure consent, to prove a case, to support one side of an issue. He is striving for an effect. He wishes people to come to a conclusion; to accept his case and to close their minds and act. The educator strives. for the open mind. He has no case to prove which may not later . 
be reversed. He is willing to reconsider, to be experimental, to hold his conclusion tentatively.

But is this a distinction with a real difference? Is it not true that the person who is instructing us how to think as well as he who tells us what to think is propagating ideas, doctrines, principles? In the one case the ideas propagated may be the tenets of Fascism or Communism; in the other the principles of logic, the open mind, liberalism. Moreover, do educators and propagandists use contrary methods? In propagating the "art of straight thinking" the teacher frequently uses many of the devices and tricks of the propagandist. He uses suggestion, authorities, emotional appeals, visual appeals, devices to gain our attention and inspire us to act. The teacher, the real educator, has quite as definite an aim as any other type of propagandist. He strives to convert, to sell, to secure consent, to prove a case, to gain an effect, to induce us to conclude that the way to truth is not revelation, nor faith, but reason, the use of one's mind, the weighing of evidence, the suppression of emotions; straight thinking. What really distinguishes the educator from other types of propagandists is the content of his propaganda.

Professor Carl Friedrich virtually comes to this conclusion, although he hesitates to state definitely that education is simply one type of propaganda. ${ }^{44}$ He admits that education and propaganda are closely related, that both undertake to bring about a change in human attitudes. But, he states: "Propaganda always aims at getting people either to do or not to do some very particular thing. Education, on the other hand, is fundamentally concerned with molding and developing a human being in terms of an ideal, as far as his nature allows it." And again, "All these efforts to mold human beings according to some ideal, according to some standard of what is good, beautiful, and just, constitute genuine education."

Professor Friedrich has really narrowed the distinction to this: the propagation of a comprehensive philosophy of life is education; the propagation of less inclusive ideas, doctrines, and principles is propa, ganda. But how may we distinguish between the propagation of a world view and the propagation of segments of it? It would seem that Professor Friedrich's argument really leads to the conclusion that education is one type of propaganda. And this result is not so 
alarming after all. We may summarize the relationship between the two as follows:

I. To propagandize is to propagate ideas and doctrines, to attempt deliberately to influence the minds of other people,

2. Education is merely one type of propaganda. To educate is to instill certain attitudes into the minds of others, a philosophy, if you will, of man's mind and how to use it.

To say that the educator is not attempting to influence "the opinions and actions of other people toward a predetermined end" is a statement contrary to fact. Every educator is a philosopher of education itself, advocating educational ideals which he is deliberately and dogmatically seeking to inculcate in the minds of students. In order to emphasize the propagandistic character of education we need only review some of these ideals.

I. Social progress is essentially a matter of individual growth, development, and improvement. It is not so much a question of "what is good for society" as "what is good for the individual."

2. Individual, and therewith social, progress depends upon man's capacity to use his mind-upon his reasoning process, rather than upon blind faith or revelation.

3. The educator advocates, among other things, training in logical process of thought; careful testing of assumptions; respect for scholarship and objectivity; modesty and tolerance.

The educator need not cringe when confronted with the label propaganda. His objective approach to the study of current social problems is merely another evidence that he practices what he preaches. 


\section{The Art of Propaganda}

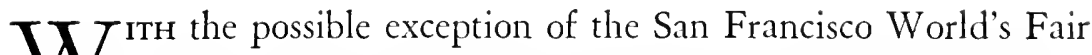
$W$ the New York World's Fair of 1939 is probably the masterpiece of the modern art of propaganda. Not one propagandist, but thousands, are cooperating to promote "the greatest show on earth." They are using every technique and strategy available to capture and captivate public opinion. Incidentally this gigantic propaganda enterprise gives us a glimpse of the art of propaganda in the World of Tomorrow.

The Fair corporation, operating under the legal status of an educational institution, made its official debut on September 23, $1935 .^{45}$ Broadly speaking, the objectives of its propaganda campaign are twofold: ( $\mathrm{I}$ ) to induce people to attend the fair and pay their admission fees; (2) to propagate the doctrine of the American Way of Life as of 1939. For the sake of convenience we may consider the propaganda techniques of the New York World's Fair of 1939 under four headings: (1) the strategy of publicity, (2) the strategy of organization, (3) the strategy of argument, and (4) the strategy of persuasion.

Propaganda, if it is to grow and spread, must be perceived. Regardless of its content it must be brought to the attention of the public. Hence the emphasis which is placed upon the' strategy of publicity - the effort to use to advantage all available instruments of opinion dissemination. The facilities for doing this are much more numerous and effective today than ever before. They include the press, the radio, motion pictures, theatres, the educational system, art, exhibits, the pulpit, and countless others. The World's Fair corporation has been exceptionally successful in exploiting the channets of communication and doing it free of charge for the most part.

Assisting Grover Whalen the corporation has a large staff of specialists directing the more important phases of its publicity campaign. To this number should be added many specialists employed by various groups and organizations participating in the Fair. Every 
conceivable medium is employed to transmit the Fair's message. There is a department of the press organized along the lines of a newspaper city desk with an expert staff of editors and subeditors. A special foreign editor services the great national press organs of five continents. Press releases are translated into the leading languages of the world. The department has a paid clipping service in practically every country. And it has been estimated that the grand total of international newspaper publicity alone will fill an entire 24-page newspaper every weekday for a year.

All in all, the press department serves directly some 2,o0o daily papers in the United States, 3,00o biweeklies, 300 foreign-language papers, and I,500 papers abroad. A squad of photographic editors have disseminated thousands of different pictures of the Fair. Teletype machines are used to broadcast publicity in the New York area. Probably no press bureau in the country has a more efficient mat and plate service than this dynamic department of the World's Fair.

A feature publicity bureau services more than I,700 magazines of every description and prepares articles which serve as speeches for members of national and local advisory committees. A radio division sponsors international and domestic broadcasts, including the "Salute of Nations" program which links together several hundred broadcasting stations throughout the world. The bureau of newsreels projects and distributes hundreds of subjects over the newsreel circuits of the country, a number exceeding that of any other project in the history of newsreels. A speakers' bureau provides speakers and lecturers for all sorts of occasions.

These illustrations suffice to give some indication of the scope and nature of World's Fair publicity via the more familiar channels of communication. Except for salaries, office expenses, and a few incidentals, this parade of publicity is obtained free of charge. These media by no means exhaust the possibilities, however, as the experience of the Fair shows. Special mention should be made of the use of "collateral" advertising, supplementary publicity donated by individuals and groups cooperating directly or indirectly in the enterprise.

The American Sales Book Company prints from 12,000,000 to 15,000,000 business forms daily, stamped with the Fair emblem. The American Sugar Refining Company publicizes the Fair on the wrap- 
pers of 15,000,00o sugar tablets distributed to restaurants throughout the United States. The State of New York provides space on the license tags of one-tenth of the automobiles of the country for the Fair's label. Colgate-Palmolive-Peet distributes to leading New York hotels 500,000 bars of soap with wrappers featuring the Fair. The Electric Utilities Exhibit Corporation through its local subsidiaries uses 2,000,000 bill inserts every month, 300 correspondence stickers, 3,000 window stickers, 10,000 counter cards, 750,000 booklets to glorify the Fair. A comparable campaign is being carried on by the members of the American Gas Association. The American Telephone and Telegraph Company inserts Fair advertising in its monthly bills to I,500,000 subscribers. Newspapers publish World's Fair editions. More than 450 banks and savings and loan associations throughout the country are sponsoring World's Fair savings clubs. The Childs restaurant chain prepares handsomely printed World's Fair menus.

Reduced to its essentials, therefore, the strategy of publicity is the technique of using to the maximum every available channel of communication, and doing so as cheaply as possible. The number of such channels is almost unlimited, and only a novice will think of communication channels solely in terms of newspapers, radio, and motion pictures. He will draw upon his imagination to find others as effective, cheap, and adaptable as license tags, business forms, and soap wrappers.

Without regard to the nature of the cause being propagated, the strategy of publicity is an essential feature of every propaganda campaign. Political parties, business corporations, trade unions, professional groups, governmental agencies, educational institutions, religious denominations-all of them are energetically striving to increase the number and usefulness of their contacts with the public. There is no mystery about this. The list of known channels is a long one and is being added to constantly. The strategy is to take them one by one and find out be done to make them available as cheaply as possible. Each medium has, of course, its own special usefulness, and the message of the propagandist must be adapted to that use and the public served. The situation in a democracy, so far as channels of communication are concerned, differs greatly from that in dictatorships. In Germany, Italy, and Russia there is no prob- 
lem or difficulty about using or controlling them. The question is, how can they be used to the best advantage? In the United States, and democracies generally, however, the propagandist must display considerable ingenuity to gain access to them.

Propagandists also realize the importance of the strategy of organization, the necessity for creating an organization adapted to the purposes of the campaign-an organization which will bind adherents together, provide a hierarchy of leaders and subleaders, define responsibility, maintain interest in the cause, and cement allegiance.

There are many ways of binding a new convert to the cause once he has been won over. One method is to induce him to take a financial stake in the enterprise, either in the form of an investment, dues, subsidies, insurance premiums, or benefit payments of one kind or another. Trade unions, business associations, fraternal groups, corporations, and political parties do this sort of thing.

Another technique is to give as many members as possible an official position in the organization, some definite responsibility which ties them physically and mentally to the cause. To possess an offce, however humble, is often enough to assure continued allegiance. At any rate it is important to jdentify the personal interests of every member with the abjectives of the campaign. He must be made to see that the enterprise not only serves a great social purpose but also satisfies his own particular desires. The widespread appeal of the World's Fair is due in no small part to the fact that within the arena on Flushing meadows there is something, somewhere, to interest and satisfy the tastes of practically everyone. Care has been taken to provide stimuli for the artistically minded, the technically minded, the sexually inclined, as well as those who wish to learn, to be thrilled, amused, and duped.

In contrast to many political, economic, and social propaganda campaigns the New York World's Fair of 1939 has a more or less definitely fixed time limit. It is really a short-run affair, and its sponsors are more interested in immcdiate results than long-time effects. For that reason they have not devoted as much attention to the strategy of organization as, for example, many political parties, business associations, trade unions, religious denominations, and the like. If one wishes to study the strategy of organization intensively he should examine the structure of such organizations as the $\mathrm{Na}$ - 
tional Socialist Party, the American Federation of Labor, the Chamber of Commerce of the United States, or some of our older and more permanent religious denominations.

The promoters of the Fair have not been wholly unmindful of organization techniques, however. They have, for example, organized an elaborate network of advisory committees over the country, composed of prominent leaders in all walks of life. There are committees of women, business men, boys and girls; committees representative of different racial minorities, sectional groups, and business interests. Many individual exhibitors have their own specialized advisory committees. In addition to national advisory bodies, there are innumerable state and local committees. Each state has its committee of one hundred. It has been estimated that more than Io,000 persons throughout the country are members of various advisory committees.

The propaganda value of such committees should not be underrated. They are composed of leaders of thought and action, and it is well known that the way to the minds of the masses is through their leaders. These committees serve as channels through which Fair propaganda may be disseminated as well as instruments through which Fair officials can keep in touch with public opinion. Their members constitute a host of voluntary propagandists, and the advisory-committee technique is used in almost every propaganda campaign. It was used by George Creel in his campaign to win public support in this country for American participation in the World War. It is used by chambers of commerce, political parties, religious organizations, by almost every type of propaganda group. The success of Hitler is due in no small part to his skill in enlisting the support of group leaders and then cementing their allegiance by placing them in positions of responsibility throughout his nationwide network of group formations.

Moreover, the creation of advisory committees may add prestige to the undertaking as a whole. Prestige is important for any cause, and can be enhanced by identifying with it persons, such as business, educational, and political leaders, who already command respect. The list of names on the advisory committees of the New York World's Fair reads like a Who's Who of American teaders.

Another basic strategy of propaganda may be labeled the strategy of argument No propagandist can rely entirely on publicity and 
organization. He must be able to rationalize his cause. People do not contribute a quarter of a billion dollars to such an enterprise as the New York World's Fair unless they are convinced of its concrete value to them. The masses may be swayed by emotional appeals, but not hard-headed business men, calculating politicians, and many so-called intellectuals. Leaders such as these must be convinced by cogent arguments in the form of lawyer's briefs, preacher's exegeses, economist's statistics, or philosopher's systems. Parties, trade associations, labor unions, all of them earnestly search for rhetoricians, lawyers, philosophers, economists, and historians to do this job.

One of the most important propaganda departments of the New York World's Fair of 1939 is the department of library and research. Most propaganda groups have similar departments. They are absolutely necessary. The job of this department is to collect facts, statistics, and basic information of all kinds. The head of it is a professor of history at Yale University. With the help of a research staff he collects material for speeches by Fair officials and often writes them. He has prepared more than 67 authoritative information bulletins about the Fair and keeps them up to date. He has published a series of about 20 books which would be a credit to any research organization. Among the more important are a 250-page Official Guide Book; a volume entitled New York: The City Washington Knew; and such studies as Going to the Fair and The Fairs of the Past and the Fairs of Tomorrow.

This type of material is very different from the usual newspaper ballyhoo. It corresponds to the kind of research work done by educational institutions. These studies may appeal to the masses, but their primary function is to sell the Fair idea to the more serious minded, to implement Grover Whalen and his aides in inducing government officials to exhibit at the Fair, business men to invest millions there, and group leaders in all walks of life to participate. Facts, statistics, cogent reasoning buttressed by historical evidencethese count for more in dealing with group leaders than what is usually called mass appeals.

The disposition of many writers on the subject of propaganda to think of it solely in terms of emotional appeals tends to limit our perspective of the whole phenomenon. Rational appeals play quite 
as important a part in modern propaganda campaigns as irrational. Fortunate indeed is the propagandist who has at his disposal such masterpieces of argument as Karl Marx's treatise Capital, Locke's Treatise on Government, or Thomas Paine's Common Sense. Fortunate indeed is the party or pressure group that can command the argumentative prowess of the modern prototype of John Marshall, Thomas Hobbes, John Wesley, John C. Calhoun, George Bancroft, or Woodrow Wilson. The strategy of argument is illustrated again and again in the books, pamphlets, articles, editorials, and speeches which flood the country during an election year. From the point of view of its convincingness, much of this material is poor in quality, whether measured by legal standards of brief-making, statistical presentation, canons of logic, or fundamental philosophical systems.

Graham Wallas in his classic work, Human Nature in Politics, forcibly recalled to the minds of political scientists the fact that man's opinions are not solely the product of rational processes of thought, and he inspired a new interest in the emotional basis of political and social behavior. All propagandists try to supplement rationalizations of objectives with emotional appeals, The findings of psychologists have emphasized the role played by emotions, interests, and drives in the opinion-forming process. Whether or not instincts, in the sense of inherited tendencies to react to stimuli in specific ways, exist, politicians, fund-raisers, and advertisers realize that certain types of habitual response are characteristic of large masses of people. The propagandist seeks to arouse these habitual responses and relate them to the ideas which he is propagandizing. We call this effort to arouse emotional responses the strategy of persuasion.

It is extremely difficult, if not impossible, to define the word "emotion" precisely and to differentiate it clearly from what we call "reason." Emotion. and reason, persuasion and argument function together in a puzzling way in the opinion-forming process. Thought and feeling are so mysteriously related that any attempt to separate them is bound to create an artificial dichotomy. Whatever the relation of emotion to mind, propagandists know that there is a close relation between emotion and will, and that emotions when aroused to a high degree of intensity hinder analytical processes of thought 
and often produce the desired response without the need for argument.

It is for the sake of convenience only that we distinguish the strategy of argument from the strategy of persuasion. The strategy of persuasion comprises those techniques which are primarily concerned with stimulating the senses to produce favorable responses. Often such techniques serve as short cuts to results that would not be reached if reflective processes were invoked. The distinguishing feature of the strategy of persuasion, therefore, is the attempt to bring about favorable responses without bringing into play serious mental activity.

The New York World's Fair of 1939 has a number of departments or bureaus engaged in this business of arousing the emotions. On the Fair grounds themselves exhibitors vie with one another to produce the responses desired. The task is twofold: to project emotional stimuli to the far corners of the earth and induce people to attend the Fair; and, secondly, to produce specific emotional reactions after they get there. The strategy of publicity is concerned with the projection of stimuli; the strategy of persuasion with the content and character of the stimuli themselves.

Efforts are made to arouse curiosity, inspire patriotism, produce a sense of awe and amazement, create a feeling of eagerness and impatience, amuse, enthuse, excite. To attract attention and arouse one or more of these sensations innumerable events are manufactured which have national and international news value. Mention may be made of a few of the more dramatic. A preview and motorcade was staged in April,.I938, a year before the opening of the Fair. One of the directors of this spectacle described it as "the greatest spectacle ever witnessed by a city which has grown accustomed to lavish and skillful entertainment" and as "probably the greatest and most ambitious promotional project ever attempted" (sic). The motor parade included more than ioo large floats, 48 goodwill automobiles which were sent with goodwill messages to the capitals of every State in the Union, the massing of flags and floats of 6o foreign nations, and an almost endless procession of human beings. Other events on a comparable scale were the Dawn of a New Day celebration on January I, I939; the I5-hour program of events marking the opening of the exposition on April 30 ; George Washington's inau- 
gural journey from Mount Vernon to New York; and the royal visit of England's King and Queen on June 10.

In addition to pageants, parades, and special events of all kinds sponsored by the Fair directly, special arrangements are made for assisting exhibitors and other groups to stage special events of their own. Feature days for states, counties, and cities; foreign days; school, youth, art, health, and commercial "days" succeed each other with amazing rapidity. Approximately $\mathrm{I}, 000$ of them were crowded into a period of six months. What each exhibitor does on a small scale, the Fair corporation magnified to gigantic proportions.

Propagandists know that everybody likes to see a fight. Newspaper publishers realize the influence of contests in increasing newspaper circulation. Although the Fair corporation itself does not sponsor such contests, it cooperates with several thousand business concerns in arranging them. One notable illustration is the "Typical American Boy Competition" sponsored by the Rockefeller interests at Radio City.

Extensive use is made of symbols and slogans, those short cuts to response. Representations of the trylon and the perisphere have been broadcast throughout the length and breadth of the United States and the world. They are already serious competitors of the swastika, the British lion, the Republican elephant, and the American eagle. Apparently no one knows what they really signify, but this is a source of strength rather than weakness. The symbols arouse curiosity and, for that very reason, are indications of good showmanship.

The promoters of the Fair also realize the propaganda value of an "impression of magnitude." They have emphasized from the beginning that the New York World's Fair of $\mathbf{1 9 3 9}$ is the greatest exposition ever held; that many times as many people will attend it as have ever attended a world's fair before; that at least four times as much money has been spent on it as on any previous fair; and that from every angle it is the "greatest show on earth."

Every effort is made to produce a "band-wagon" effect, a universal impression that everybody is going to the Fair and that you and I will be out of the swim if we fail to go. Attendance figures are published and broadcast daily. The attendance of the great and the near great is publicized far and wide.

Propagandists also realize the importance of timing their appeals 
properly and relating them to slearly defined objectives. Although repetition has its uses there is always the danger of overdoing it. Curiously enough this has been a real problem for promoters of the New York World's Fair. They have found it necessary to schedule and time events in such a way that emotional responses would not be dulled, but would grow in intensity to reach the proper climaxes.

A major difficulty is the use of the sex appeal. The strength of this emotion is fully appreciated by propagandists, and Grover Whalen's assistants were fully aware of the drawing power of such exhibitions as the Sally Rand show. At first they tried to avoid undue emotional appeals of this sort. An effort was made to differentiate the emotional appeals of the amusement area from those of the remaining 2,600 acres of the fair. Finally on February 16, I939, Eleanor Holm and her mermaids were allowed to dedicate Rose's Marine Amphitheatre, and gradually the bars were let down. On June 27, 1939, the press of the country reported that, "The name, flag, and crest of Southern Rhodesia were removed yesterday from its Victoria Falls exhibit in the amusement area of the World's Fair in accordance with peremptory cabled instructions from the government of Southern Rhodesia which objects to the 'depraved and obscene' shows that surround the exhibit."

No technique of persuasion has been overlooked by those associated with the New York enterprise. In the language of the Institute of Propaganda Analysis there are innumerable examples of the "band-wagon device," the "transfer device," "glittering generalities," "card-stacking," "testimonials," and so on. And we can run down the list of Professor Doob's principles to find that World's Fair propagandists make their "stimulus situation stand out" by arousing auxiliary attitudes; repeat the stimulus situation, and simplify it. They practice "revealed, delayed revealed, and concealed" types of propaganda. They arouse related attitudes which are dominant and central. They vary the stimulus situation, employ stereotypes, use the names of prominent persons to give their enterprise prestige, and seek to produce an impression of universality. These and many other techniques of suggestion are employed.

Most discussions of the art of propaganda begin with an enumeration of a list of so-called principles. I believe that the use of the word "principle" in this connection is misleading. It gives the impression 
that there exists a body of scientific laws governing the subject which anyone can learn and apply successfully.

Some years ago Frank Kent wrote a book called Political Behavior with a subtitle that reads, The Heretofore Unwritten Laws, Customs, and Principles of Politics as Practiced in the United States. ${ }^{46}$ I wish to cite a few of these rules or principles listed.

Rule I. Give them "Hokum." For the candidate without the imagination or initiative necessary to supply an original brand of hokum for himself, there is always the Bible, the Constitution, and the Flag to fall back upon.

Rule 2. Give them a good show. As a political asset the ability to dramatize your issue or yourself is hard to beat. It is worth any amount of argument, statistics, facts.

Rule 3. Probably the most important single accomplishment for the politically ambitious, the most effective asset they can possibly acquire, is the fine art of seeming to say something without doing so.

Rule 4. Never handle a hot poker. In other words, the thing above all others for a candidate to avoid is to appear ridiculous.

Rule 5. You can't win on a Shoe String. Success in any campaign where there is a real fight depends very largely upon having available enough money to take care of what the late John Walter Smith of Maryland used to refer to on the Eastern Shore as "current expenses."

Rule 6. You Must Play the Game with the Gang, or as Boies Penrose once explained it, you must stand by your own damned rascals.

Rule 7. This is what may be called "Name and Face stuff"-it is not a question so much of getting your views and opinions on the issues before the people, though that is of course desirable, but the big thing and the vital thing, however, is to get your name and face familiar to the voters.

Rule 8. Don't worry about the Women-if in the eight years they have had complete political equality with men any one in politics has discovered a key to the woman vote-a sure way of lining it up-they have kept it a profound secret. And that is because there is no such thing. As a matter of fact there is absolutely no rule for dealing with women in politics which will not work just as well half the time if reversed.

Rule 9. When in doubt do right. 
Most people will agree that this analysis of political propaganda is shrewd and displays considerable insight into the psychological processes of political behavior. It describes what is frequently done. The difficulty is that if you or I try to practice these principles we may come to grief. Instead of winning an election we may lose it, partly because Mr. Kent's analysis does not tell the whole story, and partly because he does not state precisely when and how to apply the principles listed to obtain the desired effect. In other words, these so-called principles are not principles at all in the scientific sense of the term.

We are told to "Give them Hokum." But who is "them," and under what conditions will giving them "Hokum" produce the particular changes in attitudes and opinions we wish? If we try to apply these principles with faculty members or hard-headed business men we may suffer something worse than political defeat.

Many others have attempted to reduce the art of propaganda to a science. In 1935 Professor Leonard W. Doob published a book entitled Propaganda-Its Psychology and Technique. He undertook to give precision to the art by reducing the techniques of propaganda to a set of eight basic principles and about thirty-six corollaries. This is a useful study. It does give descriptive generalizations regarding propaganda practices of one sort or another. But these so-called principles do not indicate precisely when and under what conditions they apply.

Let us take, for example, principle $4 \mathrm{~b}$ labeled the "Principle of Related Central Attitudes." It states that "The propagandist arouses related attitudes that are central attitudes." Many illustrations of this practice could be cited. The difficulty is that we are not told when and under what conditions this particular maneuver is employed and what results accrue under specific conditions.

We have not, therefore, a science of propaganda in the sense of a body of principles which state under what conditions the use of a particular technique for propagating a doctrine will produce a predictable result. We have series of statements like these: ${ }^{47}$

Propagandists persistently appeal to the emotions of their subjects.

The propagandist exaggerates in the interest of his cause.

The propagandist distorts by selection. 
One of the oldest devices of the manipulator of public opinion is the distraction of attention by the use of the "red-herring" technique.

The propagandist eternally repeats his assertions.

The propagandist's rule is to avoid argument.

The contemporary propagandist can and does tap all the accumulated lore and science regarding the most efficacious methods of attracting attention.

The propagandist must adapt his methods and the content of his appeals to the common social attitudes of his subjects.

The propagandist must know the prevailing attitudes of his subjects.

The propagandist must have a thorough knowledge of the symbols whereby attitudes are expressed.

The propagandist must be simple, clear, and precise.

The propagandist uses all the media of communication to which he can obtain access and which are adapted to his appeals in a particular campaign.

The propagandist recognizes the importance of impressing upon the young their arguments, suggestions, and partial information.

We might continue indefinitely stating what propagandists do and have done. There are quantities of books describing the activities of particular propagandists. These generalized accounts vary all the way from descriptive classifications based on one campaign to classifications derived from a host of propaganda undertakings. In the religious field there are countless treatises describing the techniques of religious denominations, missionary societies, and individual religious leaders. Political writers from Plato to Lenin and Hitler have tried to generalize from their own experience and the experiences of others. Business groups, labor organizations, professional associations, and pressure groups generally have formulated rules to guide them in promoting their causes. Possibly no group of specialists has devoted more attention to the subject of propaganda technique than commercial advertisers, although fund raisers, press agents, journalists, public-relations counsel, lawyers, psychologists, and teachers of public speaking should not be overlooked.

The point I wish to stress is this, practically all lists of "principles" are nothing more nor less than descriptive statements of what propa- 
gandists do. Such lists cannot be complete. Propaganda practices cannot be reduced to a list of "seven devices" or a set of "thirty-six principles." It is important for us to remember that a description of something is not necessarily a scientific principle. The practical value of descriptive propaganda studies should not be underestimated, however. Their value to us personally increases as the specific practices are described in terms of situations and under conditions which approximate those we confront. The validity of such generalizations depends on their taking account of the total situation.

One reason why it is so difficult to determine the precise effect of particular propaganda appeals and techniques is that public opinion is molded, not by propaganda alone, but by the combined influence of a great many different factors. The only way that scientific principles can be deduced is by ascertaining what occurs when a selected influence or method is employed, all other factors remaining the same. Such experiments have been tried and with some success, but the body of truly scientific principles increases in number very slowly. The science of propaganda is in a very rudimentary state. Propaganda is essentially an art. Most of the literature today on the subject is primarily descriptive. Our knowledge of the practice of propaganda, however, as distinct from the science of propaganda, rapidly expands. Students are aware, not of "seven devices" to win friends and influence people, but one thousand times seven. The problem is to know when and how to use them, that is, to know precisely under what conditions they will produce the results de= sired. By increasing our knowledge about this we shall be transforming the art of propaganda inte a science. 


\section{Propaganda and Dictatorship}

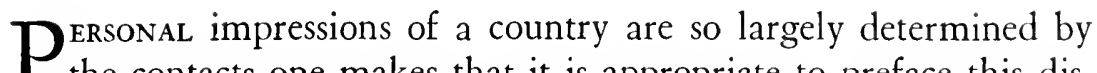
P the contacts one makes that it is appropriate to preface this discussion with some mention of the scope and nature of personal experiences during my visits to Germany in 193I-32 and again in 1937 . In 1931-32, as a Fellow of the Social Science Research Council, I spent a year in Germany with my family studying the influence of economic groups on the public policies of that country. In Berlin, Frankfort, Stuttgart, Munich, and other cities, I interviewed the officials of important business federations, trade unions, and agricultural associations; studied the organization, activities, and policies of these groups; and investigated the impact of their pressure upon legislation and administration. Incidentally these studies brought me into contact with most of the political parties, including the National Socialists. In December, I93I, with the help of Mr. Hanfstaengl I obtained a personal interview with Hitler in his room at the Hotel Kaiserhof.

The principal purpose of my visit to Germany during the summer of 1937 as a Guggenheim Fellow was to retrace my steps and find out what effect the rise of National Socialism really had upon the functioning of these economic pressure groups. I found that old trade union federations had disappeared and that the labor forces had been amalgamated in a superorganization of the working forces of the nation, the Labor Front. I found that agricultural associations had been superseded by an all-inclusive Nazi agency, the Food Estate. Marked changes had also taken place in the business formations of the country, although many officials of the Reichsgruppe Industrie were the same men who had been at the head of the old Federation of German Industry. The headquarters of the old Federation was the central office of the new.

A few weeks' study of these newer formations revealed that the phenomenon of pressure-group activity, as it existed in Germany in I93I-32 and as we are familiar with it in this country, no longer 
existed. Germany was no longer a land of competing pressure groups but a land of political pressure. The new organizations, instead of being channels through which special interests made their influence felt upon government, were now the instruments by which government exerted pressure upon these interests. That being so my interest centered upon this phenomenon of government and political pressure. I tried to find the source of it, the way it operated, and the effects.

For several weeks I explored Dr. Goebbels' Ministry of Propaganda and Popular Enlightenment, interviewing the officials of the eleven divisions into which this amazing administrative branch of government is divided. I spent considerable time in the official library of this Ministry, a marvelous collection of materials for students of propaganda. From the Ministry of Propaganda my search took me back to the Labor Front, the Agricultural Estate, and the business formations which served as propaganda channels for the Ministry. I interviewed officials in charge of the German radio, motion pictures, the stage, art, literature, and the press-all instruments of propaganda effectively mobilized under the control of the Ministry. I attended the Nazi Party Rally and the Harvest Festival of the Peasants, outstanding examples of the modern art of civic education and propaganda. I witnessed the mammoth anniversary celebration of the founding of Berlin and Hitler's reception of Mussolini.

The work of the Ministry of Propaganda, however, proved to be only a part of the national crusade to win the people of Germany to National Socialism. It is primarily concerned with the minds of the masses, the opinions of adults. No less important is the work going on in the schools and among the youth of Germany. I spent several days at the headquarters of the Hitler Youth organization, an all-inclusive formation which has taken the place of a multiplicity of youth groups that existed at the time Hitler came into power in 1932. Today it has a membership of more than 7,000,000 boys and girls between the ages of ten and eighteen. I visited public and private schools, labor camps, leadership schools, and one of those unique castles where the cream of the young men of Germany undergo a three or four years' course of training to prepare them for the highest positions in the social, economic, and political life of the state.

In many respects Nazi propaganda is like all other propaganda- 
political, economic, social, and religious. Propaganda is characteristic of the age in which we live, an era of competing ideologies. The more closely one studies the Nazi propaganda machine the more conspicuous become the similarities of it to such worldwide propaganda efforts as those of the Roman Catholic Church and the Communist party. From these two institutions National Socialists have borrowed many ideas regarding organization and method, but not, I should hasten to add, regarding content.

In important respects, however, the Nazi propaganda campaign is unique, and I should like to call particular attention to four respects in which it may be differentiated from others.

In the first place there are the doctrines of National Socialism. A fundamental tenet of National Socialism is the "race idea"-the notion that the world is populated by distinct races and peoples, differing in kind if not in quality; that life is essentially a struggle for survival among them; and that to be successful in this struggle for survival a race or a people must be strong. Most of the specific governmental measures taken by the German government in recent years are reflections of this racial outlook on life. The persecution of Jews stems from the belief that Jews belong to a different race, and that the survival of the German people is possible only if Jews are vanquished. The attack on the Christian Church is justified, according to Nazis, because the Church preaches the doctrine of the brotherhood of man and denies the inevitability of race conflict as a condition of survival. The former attacks on Communists were rationalized by arguing that Communism ignores the race idea, emphasizes the doctrine of class struggle, and spreads beliefs which undermine the unity and strength of the German people.

The race idea, and its corollary the notion of race conflict, constitute the basis for internal policies of the German government designed to strengthen the German people physically, morally, and psychologically. The emphasis upon physical training, population policy, eugenics measures, the encouragement of large families-all are intended to strengthen the German people quantitatively and qualitatively so that they may survive in this inevitable race struggle. The Four-Year Plan, the armament program, the foreign-trade policies, the desire for colonies and more territory aim to enlarge the national resources of the German people. The creation of a Ministry 
of Propaganda and a Reich Chamber of Culture, the comprehensive system of civic education, and the minute regulation of expressions of opinion serve to strengthen the German people by unifying their wills.

The basic difference between Nazi ideology and other philosophies of life, especially the Christian, is this race conflict view, this absence of cosmopolitanism, an unwillingness to accept Christian beliefs regarding the brotherhood of man, a refusal to admit that the world is so large and fruitful that all types of peoples can live together peaceably. It is one of the most serious attacks on Christianity for centuries. Ordinarily it is commendable to make a nation fit physically, materially, and psychologically. But when this is done without regard for the rights of other peoples it violates the fundamentals of Christian ethics.

In the second place, Nazi propaganda is exceptional because of its worldwide character. Other movements have had and do have worldwide ambitions. This is true of religious movements, many political organizations such as the Communists and numerous social, economic, and humanitarian undertakings. By itself this aspect of Nazi propaganda does not call for special emphasis; but in relation to other aspects it assumes great importance. The National Socialist party is not a party in the American sense of the word. It is an Order, composed of specially selected and carefully trained converts, scattered throughout the world, and bound together by mutual loyalty to one leader. Membership in the National Socialist party is now limited to those who, as members of the Hitler Youth, and during their service in labor camps and in the army, demonstrate physical, mental, and moral capacities of leadership. To be admitted the applicant must subscribe to the following dogma:

I. The Leader is always right.

2. Never violate discipline.

3. Never waste time in idle chatter, nor in self-gratifying criticism, but take hold and help.

4. Be proud but not arrogant.

5. The program is your dogma, it demands your complete surrender to the cause.

6 . You are a representative of the party, govern your appearance and behavior accordingly. 
7. Loyalty and unselfishness are the first commandments.

8. As a true socialist you must be a real comrade.

9. Do to your comrades as you would have them do to you.

Io. In battle be steadfast and discreet.

II. Courage is not recklessness.

I2. Whatever serves the interest of the movement, and through it Germany and the German people is right.

As Dr. Ley stated in 1937, "Upon admission to the Order the man belongs to the party, body and soul. The party gives him everything, if, in return, he gives all that he has to the party."

The National Socialist party is more closely analogous to the Masonic Order, the Catholic Church, and the Communist Internationale than to our own Republican and Democratic parties. It comprises an élite which speaks for and acts for the German people.

There are members of the National Socialist party in every country of the world. In the United States practically all official representatives of the German government are members-the Ambassador and his diplomatic staff, including military and commercial attachés, as well as German consular agents in scores of American cities. Owing to the totalitarian character of control exercised by the Nazi party over all phases of life in Germany, most German citizens coming to the United States are also National Socialistsjournalists, business men, representatives of professional and labor organizations. The secretive character of the Order makes it difficult to determine precisely the number of party members in a particular country. To make certain that all German citizens, who for one reason or another visit foreign countries, shall be exemplary representatives of National Socialism the party has established a special school in Berlin for this purpose.

What do Nazi party members in foreign countries do? It is clear that they do what they are told to do by their superiors in Germany. The scope and nature of their activities depend upon the objectives and strategies of the propaganda campaign at the moment. In general they seek to promote favorable attitudes toward National Socialism, curtail criticism of German policies and activities, and prevent government action by foreign countries that will obstruct the carrying out of these policies. Members are encouraged to take an active part in the political, economic, and social life of the country in which 
they reside; to become leaders in organized community activities. The aim at first may be to extend the cultural area of the German Reich merely as a prelude to extending German population and political areas. The ultimate aim is always to strengthen the German people morally, physically, materially, and psychologically; the better to fit them for survival in "the inevitable struggle of peoples and races." The tactics of the moment are only means to this end.

A third outstanding feature of the Nazi propaganda movement is the thoroughness and efficiency with which it is organized. The head of the organization is the Leader, and the major strategies as well as the minor tactics of the campaign are determined by Hitler with the advice and counsel of his general staff--the supreme council of the party. It is through this council that Hitler coordinates the campaign.

It is essential to keep in mind the respective roles of party, official agencies of government and unofficial agencies of government. The party has at least four important functions to perform: (I) It serves as the general staff to formulate policies and devise strategies. (2) It supplies the active leadership, not only for official agencies of government, but in all walks of life. (3) It serves to unify and integrate propaganda activities throughout the matrix of group formations. (4) Wherever the party has control over official agencies of government, it directs their activities. Where it does not, its principal efforts are directed to obtaining this control.

In Germany official agencies of government are in the hands of the party and are used as instruments of propaganda. Ministries translate the wishes of the party into legal terminology and supervise the execution of policies. The Foreign Office, with representatives in practically every country of the world, translates the aims of the party into treaties and agreements and supervises their execution. As the dean of cabinet departments, representatives of the Foreign Office abroad have general supervision over the propaganda activities of other departments and agencies within the country to which they are accredited.

Similarly the Ministries of War, Navy, Air, Commerce, Agriculture, and Welfare translate relevant policies into legal terms and supervise the carrying out of programs. Each of them has represen- 
tatives abroad, attached, as a rule, to the particular German Embassy or Consular office.

The Ministry of Education functions in a corresponding manner with respect to the public-school system of Germany. Through it the National Socialist party brings the formal education of young people into tune with its general policies. Profound changes have been and are taking place in Germany's educational system; changes in organization, in methods of instruction, in personnel, and in objectives.

Public schools are extremely important channels of propaganda in any country. In Germany all schools are now under the centralized supervision of the party through the Ministry of Education. Moreover, all youth organizations have been dissolved or amalgamated with the Hitler Youth, an inclusive association of more than $7,000,000$ young people between the ages of ten and eighteen. From now on, all boys and girls will be subjected to a uniform, highly integrated program of civic training within the framework of $\mathrm{Na}$ tional Socialist philosophy.

Changes in the organization of the German public-school system were introduced to simplify its structure and bring about a greater degree of centralized control, standardization, and uniformity. Virtually all private schools were abolished, and many types of public schools were eliminated. The period of secondary education was shortened from nine to eight years. In general, educational opportunities have been equalized and plans adopted for doing a better job in selecting and differentiating the studies of qualified students.

One of the difficult problems encountered in trying to unify the public-school system was to provide teachers imbued with the spirit and aims of National Socialism. The public-school teachers of Germany constitute a veritable army of propagandists. All members of the teaching profession in both primary and secondary schools must now be members of the National Socialist Association of Teachers. This Association is a channel through which teachers are indoctrinated and an agency of control and supervision.

The philosophy of National Socialist education is anti-intellectualistic, anti-individualistic, and anti-cosmopolitan. One of the principal defects of pre-National Socialist education, according to the Nazis, was overemphasis upon purely intellectual training-the love of knowledge for its own sake. To remedy this defect, relatively more 
emphasis is now being given to physical training and character building and less to intellectual exercises. The ability to memorize facts, perform intellectual feats of rationalization, are of less importance, from the National Socialist point of view, than to live in everyday life the ideals of National Socialism. The ideal Nazi teacher is not the savant, the drill master, or the intellectual genius who dominates his classroom because of his erudition, but the leader who, by his example, his physical fitness, his devotion to National Socialism, as well as his intellectual capacities inspires students to lead the life of true National Socialists. Wherever possible the work of the classroom is made a part of the life of the community.

Closely related to the Nazi attack on intellectualism is the attack on individualism. One of the primary tasks of the Nazi educational system is to make the student community-conscious, to make him feel that he is a part of the community and that community welfare comes before personal welfare. The idea of community is fourfold. It is first of all a community of blood, hence the emphasis upon the study of biology, eugenics, and ethnology. It is also a community bound together by fate and century-old struggles, hence the emphasis upon German history. It is also a community of work, which is exemplified by community work projects in which all pupils take part. And finally it is a community of opinion.

The National Socialist teachings with respect to cosmopolitanism offer the most glaring contrasts to our own liberal ideology. National Socialism rejects the idea of an inclusive humanitarianism. The community whose welfare it places above that of the individual's is not the peoples of the world irrespective of race and color, but a particular people alleged to be bound together by blood, destiny, work, and culture. There is no place in their teachings for internationalism, for universally applicable Christian ethics. Liberals may be willing to applaud the zealous efforts of educational leaders in Nazi Germany to improve the physical well-being of young people, to develop their character, and to produce well-rounded personalities. They may even support the attacks on individualism and selfcentered intellectualism. But the great gulf separating National Socialism and liberalism is the difference that exists between efforts to improve the lot of humanity in general, and those confined to strengthening and glorifying one people at the expense of others. 
Although all government agencies and ministries in Germany serve as propaganda instruments for the National Socialist party in its efforts to make the German people strong psychologically, the Ministry of Propaganda occupies a unique and key position among them. Its significance lies in the fact that to it has been assigned complete control over the channels of communication, channels which all other agencies of government as well as private groups and individuals must use. The ministry consists of eleven principal divisions. One of these is purely administrative, concerned with departmental finances, personnel, and legal questions.

Division 7 deals with German propaganda abroad and is actively engaged in creating favorable attitudes toward Germany in foreign countries, in silencing opposition, in presenting Germany's point of view, and in fostering better relations with other countries. It has a staff of specialists supervising Nazi propaganda throughout the world. It maps general campaigns and integrates the foreign propaganda work of other departments of government and that of private agencies. It has agents in most foreign countries. With the help of assistants and officials in the country to which they are assigned these agents make careful reports of the state of public opinion, follow closely the statements and writings of individuals regarding Germany, disseminate information about Germany, and promote friendly relations among economic, social, cultural, youth, religious, and other types of groups with similar groups in Germany.

The technique of National Socialist propaganda abroad is frequently misunderstood. It is important to remember that methods vary from country to country to meet the particular public-opinion situation. The same methods will not necessarily be followed in China, in South America, and in the United States. National Socialists have learned much from Communists, from the Catholic Church, and from World War experiences with propaganda.

One method frequently employed is to encourage criticisms and doubts regarding the efficacy and future of the existing system of government; promote cleavages and differences of opinion; and establish rather tenuous arrangements with dissident and rebellious groups. Another method of weakening the unity and strength of foreign countries is to promote factionalism and disagreements over matters of purely domestic policy. Often attempts are made to organ- 
ize Germans and German sympathizers in foreign countries, not necessarily into National Socialist organizations, but into any kind of association through which members can be reached easily and quickly. In short, Nazis follow the Communist method of boring from within, and the traditional device of dividing and conquering.

Another method which has proved very effective is to promote closer ties between non-political organizations in Germany and corresponding groups in other countries. Women's organizations in Germany, for example, seek to establish friendly relations with similar organizations in other countries, often creating an international organization for this purpose if none exists. This procedure is also followed with respect to youth organizations, sport leagues, and associations in the professional field.

Division I I of the Propaganda Ministry supervises cultural propaganda for mass organizations, especially the propaganda work of that huge leisure-time organization of German workers, Strength through Joy, and its international affiliate, Joy and Work. All members of the German Labor Front, about 20,000,000, are also members of the Strength through Joy. When Hitler destroyed the trade unions and employer associations and undertook to weld the working forces of Germany into one mammoth labor organization, he faced the difficult problem of overcoming the class conflict tradition which had been instilled into the minds of the laboring classes by Marxists for decades. Strength through Joy is the instrument for eradicating this tradition. It seeks to break down the barriers between employer and employee by diverting the minds of employees particularly from the class-struggle idea, by occupying their leisure time, and by assisting the workers to do the things they have always wanted to do. Special theatres have been established to provide entertainment for workers at low prices. Evening courses are instituted at very low prices. Attractive excursions are organized. Facilities for sport have been enlarged. And a vigorous campaign to improve working conditions has been launched. There are many commendable aspects of this campaign from the liberal point of view. Nevertheless its underlying purpose is propagandistic, to replace Marxian ideology with the philosophy of National Socialism.

Except for one other division all remaining sections of the Propaganda Ministry deal with channels of communication. This is di- 
vision 2, which is in a class by itself. Much of the actual propaganda work in Germany is not carried on directly by the Ministry. The Ministry determines policies, prescribes general rules, legislates when necessary, integrates, supervises, and controls. But it usually leaves to other agencies the preparation and distribution of propaganda material. This is true, for example, of Division II, which supervises the organization Strength through Joy.

There are some propaganda undertakings, however, of such widespread public importance that they cannot wisely be left to other agencies. Division 2 was created to deal with these. It is subdivided into twelve bureaus dealing with important national exhibitions, questions of foreign policy, state celebrations and festivals, counterpropaganda, public health, economic questions, agrarian policies, transportation and travel, national symbols, German minorities abroad.

As previously indicated, seven of the eleven divisions of the Ministry deal with channels of communication; the radio, press, motion pictures, theatres, literature, art, and music. Each functions in close relationship with a corresponding division of the German Chamber of Culture, an institution created in September, 1933, as a superfederation of associations in the communication field. It is the function of the Propaganda Ministry to determine in the final analysis the law governing these several fields, pass upon proposed legislation, supervise activities, and in general assume the role of general staff. It is the function of the Chamber of Culture to execute policies and to enforce legislation.

Enough has been said to indicate the thoroughness with which National Socialists have organized their propaganda activities. The functional organization of the central headquarters of the Ministry of Propaganda serves as the model for the work of the Ministry in the various geographical subdivisions of the Reich. Through its various divisions Berlin maintains close contact with the propaganda offices of all semi-official and unofficial associations throughout the country. Most of the active propaganda work, in the sense of direct appeals to the masses for support, is done by these unofficial or semiofficial organizations, all of which are directly responsible to some agency of government and indirectly to the party. The Food Estate 
in the sphere of agricultural policy; the Labor Front in the field of labor policy are illustrations.

Nazi propaganda is set apart, therefore, from other attempts to propagate doctrines by its philosophy, by its worldwide character, and by the thoroughness with which it is organized. It is also distinctive because of the resources at its disposal. It has the full power of the state behind it. We do not know how much of Germany's national income is allocated to the Ministry of Propaganda. Whatever this sum is, and it is probably considerable, it constitutes only a part, and proportionally a small part, of the total used by the $\mathrm{Na}$ tional Socialist party to spread the gospel. For the Ministry of Propaganda is only one branch of a propaganda machine which includes all other departments of government as well as numerous unofficial organizations. Nazi propaganda is so inextricably bound up with the activities of the totalitarian state as a whole that it is proper to say that it is being supported by all the resources of the state. No organized movement, unless it is Communism or Fascism, has such resources, or has had, unless we include the cause of democracy during the World War, or Catholicism and Mohammedanism at certain periods in their history.

Are the methods employed by the National Socialists unusual? I do not find them so. The discussions of propaganda in Hitler's Mein Kampf and in the writings of Dr. Goebbels are very familiar to any student of World War propaganda, Communist propaganda, commercial advertising, or for that matter the propaganda of political, economic, religious, and special-purpose groups generally. In his writings Hitler has stressed the importance of the spoken as contrasted to the written word; the necessity for simplifying appeals, and adapting them to the mentality of the masses. He distinguishes between the role of the agitator, the organizer, and the leader in a propaganda campaign. And all National Socialists repeat the obvious fact that propaganda is only a means to an end, and that it is to be evaluated accordingly.

No, there is really nothing new in the art or science of Nazi propaganda. National Socialists have simply profited from their experiences during the World War, studied closely the techniques of Communists and Roman Catholics, and taken a few lessons from business and commercial advertisers in this country. The distinctive 
features of Nazi propaganda are the doctrines themselves, the worldwide scale of operations, the resources available, and the disciplinary efficiency of the organization. The degree of success of Nazi propaganda to date is due in large part to these features, and the fact that the movement has had a vigorous and exceptional leadership in an environment inviting such leadership.

The spread of dictatorial propaganda provokes a number of questions of special importance to American citizens. Should official steps be taken by the United States to outlaw such propaganda? If dictatorial propaganda is permitted in the United States may it not undermine and endanger the very existence of democracy itself? What is the proper relation of government to propaganda in a democracy?

National Socialists look upon the government of a state as merely an instrument to be controlled and used for the purpose of propagandizing the Nazi faith. Many liberals subscribe to much the same point of view and wish to use the government as a tool for propagating their conception of liberalism.

It may be that, because of the growing intensity of race, class, and ideological conflicts, all governments will ultimately become merely instruments for propagating the views of whatever groups control them at a given time. When this occurs the national, territorial state will lose much of its significance as a sovereign body and international relations will become a struggle between worldwide ideological groups rather than a contest between states in the traditional sense. This will be similar to the situation before the rise of our western state system. The conflict between church and state during the Middle Ages will be finding its counterpart in the new struggle between democratic and authoritarian ideologies.

Liberals like to think of the state and its government as being above the multiplicity of competing groups within it. Their function is, so the argument runs, to serve as neutral, balancing agents, reconciling the conflicting aspirations of competing groups. Government is the arbiter of social justice. It prescribes and enforces rules governing intergroup activities. According to this view all groups should be allowed the maximum degree of freedom to propagandize, consistent with the rights of others. Government in a democratic state, instead of being an instrument for propagandizing causes, should be a continuing agency for balancing the interests of conflicting par- 
ties, a continuous process of legislation, administration, and adjudication.

This ideal of a neutral government, exercising the function of arbiter, can be achieved, however, only if contending groups are subject to the jurisdiction of the government and can be forced to abide by the decisions of the arbiter. The rise of international groups, intent on seizing control of governments with territorially limited jurisdictions and using them for their own ends, now poses the question whether such governments can continue to function in accordance with the liberal ideal.

So long as competitive propaganda in the United States emanated solely from groups over which the American government had jurisdiction, and with respect to which the government of the United States could function as arbiter, the democratic ideal was workable. But the advent of worldwide, dictatorial propaganda, backed by hitherto unprecedented resources, places the problem in a new light.

One answer, and the ideal answer according to many, would be an international government with sufficient authority to control the activities of other international organizations. The existence of such a government to reconcile differences and enforce decisions is probably the best guarantee of the preservation of the democratic ideal of freedom. The failure of the League of Nations, due in part to the unwillingness of the United States to support it, has seemingly blinded the world to the realities of the present situation, and probably postponed action along these lines for some time to come. The best guarantee of freedom and the preservation of liberalism, however, is the existence of such a government with sufficient jurisdiction and force to adjudicate conflicts between groups whose operations are international in scope.

Before the rise of Communism, Fascism, and National Socialism, worldwide organizations with enormous resources at their disposal for competing in our own propaganda arena did not exist. To be sure there were some representatives of international groups in our midst; members of religious organizations, international chambers of commerce, international labor organizations, and the like. But none of them possessed the resources, the organized efficiency, or the determination of Fascist and Communist groups. There was no 
reason to suppose that individual state governments could not enforce compliance with whatever rules they prescribed.

One thing liberals can do under present circumstances is to rely, not on government in the abstract, but on an organization of their own. To meet the ideological attacks of other groups they can formulate a program equally persuasive. To combat worldwide organizations such as the National Socialist party they too can organize on a worldwide basis. They can match the efficiency of National Socialists, Communists, and Fascists with an equally efficient organization of their own. And they should be able to obtain sufficient resources to carry on an effective campaign to keep governments in democratic hands. An international league of the surviving liberal parties throughout the world is indicated.

Ultimately the world will have some form of international government, capable of preserving law and order in a world torn by racial, class, and economic conflicts of all kinds. The present system of independent national units is inadequate. Liberals who look to their state governments, to a relatively small group of elected officials, alone, to protect liberalism are almost certain to discover, sooner or later, that stronger forces dominate the situation. These forces are international groups, cutting across state lines, controlling the opinions of those that control the opinions of public officials.

The effective antidote to dictatorial propaganda, therefore, is an international order of liberals, efficiently organized, inspiringly led, with adequate resources, and a positive program for setting up the international machinery needed to guarantee the reign of law in the international field. The onslaught of dictatorial propaganda cannot be met without a positive program. A worldwide campaign cannot be successfully countered with scattered, isolated, local agitation. A supremely efficient organization, cohesive and disciplined, cannot be challenged without an equally efficient one.

This answer to the problem will probably sound more realistic among the liberals in Europe than it does here. The United States is fortunately somewhat removed from any immediate or serious threat to its democratic way of life. The people of the United States have not been called upon to make the sacrifices that other countries have. The force of dictatorial propaganda has not been felt to such an extent. Liberal leaders have been unusually alert. If, how- 
ever, we wish to face the problem of dictatorial propaganda and sincerely wish to make a liberal contribution to the improvement of international relations, I believe we shall have to display some of the same energy and vitality that characterizes the dictators in mobilizing public opinion behind a positive solution of concrete problems, a solution that we believe is just and right. 


\section{Propaganda and Democracy}

$T^{H E}$ United States has the greatest propaganda density of any 1 country in the world. By propaganda density I mean the ratio of the volume of propaganda to size of population; the quantity of ideas projected by means of various kinds of symbols divided by the census figures for population. Now I am not asking you to believe that I have ever made such calculations. In fact, I do not know that they can be made. I am merely trying to stress the point that there is more propaganda in this country even than in such propagandaruled countries as Germany, Russia, or Italy. Democracies believe in propaganda, believe in having lots of it with plenty of variety. Dictatorships believe in it too, but prefer to have only one kind.

There is really no difficulty about detecting propaganda. Newspapers, magazines, books, pamphlets, motion pictures, radio broadcasts, lecture platforms, art galleries, billboards, mail boxes, and libraries are overrunning with it. Propagandists want us to detect it. Those who cooperated in that gigantic enterprise known as the New York World's Fair of 1939, for example, spent at least a quarter of a billion dollars to have their propaganda detected. And I presume that the San Francisco World's Fair spent comparable sums for the same purpose. No, the difficulty is not to detect propaganda, but to evaluate it-to find out who are doing the propagandizing, what their motives are, and to decide, if we can, which propaganda to accept.

The fact that a propagandist uses such devices as "name calling," "glittering generalities," "transfer," "testimonial," "plain-folks," "card stacking," and the "band-wagon" device does not prove that the cause he seeks to promote is socially menacing. No person trying to disseminate ideas can avoid the use of some of these devices.

Take name calling, for example. What harm is done if I call a person a "sap" if he is a sap and you and I know that he is? Nouns like "sap," "gangster," "nut," are names of things or persons, and I do not believe that there is any particular social menace in using 
them. Of course if you call me a sap and the fact of the matter is I am not a sap, that is something different. You have perpetrated a personal and social wrong. I am all for greater precision in our thinking and speaking. I realize that our poor old language is often an imperfect tool for transmitting ideas. But I suspect we shall go on for a long time, all of us, using word symbols-nouns, adjectives, and adverbs-calling names if you like.

Scientists have invented a machine known as a lie detector. I have operated one. You know how it works. The supposed culprit is attached to the machine and then asked a series of questions more or less related to the subject matter of the supposed falsification. As the answers are given this "infernal" machine is supposed to register changes in blood pressure and respiration, and these changes presumably indicate whether he is telling the truth or not. If it is true that scientists have finally discovered a mechanical device for distinguishing truth from falsehood I submit that we have something there. Students of propaganda will be elated to know that at last we are on the way toward a solution of the great problem of propaganda, the problem of separating the good from the bad. We all agree, I am sure, that truthful propaganda is good and false propaganda is bad. But hitherto we have been puzzled to know which is which. Possibly the manufacturers of lie detectors have the answer. But are they telling the truth?

Why do those who believe in democracy favor the practice of allowing each and every person to express his opinions freely, to propagate any ideas he wants to? Or do they favor the practice? Have they any reservations?

Fascists and liberals agree that in the final analysis public opinion should be the deciding authority in questions of public policy. They accept Hume's dictum that "It is on opinion only that governments are founded." And they also agree that opinion is, to a considerable extent, the product of propaganda-the conscious, deliberate attempt by persons and groups to propagate ideas and doctrines and to mold the minds of other people. It should always be remembered, however, that public opinion is not an ultimate cause. We cannot say, "In the beginning was public opinion." Public opinion is only one link in an endless chain of social causation. It may be true that 
"It is only on opinion that government is founded," but the more important question is, on what is opinion itself founded?

The fundamental difference between the role of propaganda and public opinion in dictatorships and democracies is not that public opinion rules in the latter and not in the former, but that propaganda freedom is supposed to exist in one and not in the other. Liberals believe that "rule by public opinion," a condition which is inevitable under any form of government, will work better if citizens are given an opportunity to weigh the relative merits of different points of view before they make decisions, than it will if they are subjected blindly to only one. It is the role of propaganda, therefore, not the role of public opinion, that differentiates dictatorship from democracy.

In a democracy it is for the masses to determine what is and what is not good for them; what is true and what is false; what is in the public interest and what is not. Public opinion is, and must of necessity be, the ultimate standard of values, the court of last resort.

The true function of the propagandist is to help citizens make wise and intelligent decisions. The sad fact is that many propagandists do not. The situation is not quite so unfortunate in a democracy as it is in a dictatorship, however, because there is safety in numbers. If a dictator misleads his people the result may be catastrophic. If a few leaders of opinion in a democracy do this, the harmful consequences may be checked by the activities of other propagandists.

The democratic theory of propaganda states that if individuals and groups are allowed to propagandize freely the best opinions will survive. Unfortunately, however, this does not always happen. And I want to specify a few of the reasons why.

In the first place many propagandists are unable to present their views to any considerable number of people. In other words, perfect freedom of propaganda does not exist. The democratic theory will not work, and never was presumed to work, if the competitive race for the support of public opinion is not open to all comers on an equal basis. The best man cannot win a race if he is not allowed to enter it, or if he enters it handicapped by deficiencies that have no relation whatever to the purpose of the race. The purpose of the race for public opinion is to find out which, among many ideas, is best, 
not in terms of the amount of money spent in its behalf, or the amount of physical force at its command, but in terms of its appeal to the rational mind of man. The purpose of the competition is not to determine which idea is the most sensational, funniest, most stirring, or can get the most publicity in terms of newspaper space and radio time. Any idea which cannot compete successfully because its supporters are unable to mobilize sufficient evidence and logic behind it deserves to lose. This is the supreme test. In other words, democratic theory assumes that the competitive race for public opinion will be surrounded by conditions, practices, and rules that will insure victory to the more rational rather than the less rational ideas. But what is the situation?

Many propagandists are financially unable to use the channels of mass communication for spreading their ideas. An alarming trend of recent years has been the progressive centralization of control over these instruments of mass impression-newspapers, radio, motion pictures. Not only that, but many would-be propagandists cannot reach the masses because they do not know how to do so. They have beliefs and ideas which may be very sound and if presented to the masses with the skill other propagandists employ would gain wide acceptance. They may even have the financial resources needed, but lack the capacity for presenting their ideas to the masses in terms they will understand. It is not the lack of skill in dramatizing ideas or arousing emotions to which I refer, but skill in mobilizing facts, interpreting facts, and elucidating the logic of the case.

Propagandists often fail to assist the masses in reaching intelligent decisions on matters of public policy not because of inability but because they simply have no intention of doing so. This type of propagandist deliberately tries to confuse us; consciously undertakes to distort, to fabricate, and to produce emotional rather than rational responses to his appeals. This is the kind of propagandist who arouses the ire of so many popular commentators on the subject, and properly so. He uses all sorts of wiles to divert our attention from the real merits, the true logic of the case he is trying to promote. $\mathrm{He}$ never tells us who he is or what his real motives are. He tries to make us emotionally drunk with excitement during parades and mass celebrations. He tries to gain prestige for his cause by artificial means. He draws red herrings across our thinking paths. Instead of 
trying to make it easy for us to analyze his case logically he resorts to all sorts of logical fallacies and artful devices to mislead us. The crusade of the Institute of Propaganda Analysis and similar efforts to expose this kind of propaganda are commendable. In many cases such exposures are sufficient to cure the evil. But this is not always true.

As in the field of business competition so in the arena of competitive propaganda it may be necessary to formulate and enforce rules of fair competition. We may be compelled to do this if the democratic thesis is ever to work as it should. There are some methods of propaganda which are so obviously hindrances to clear thinking that they should be outlawed. Private institutions such as the Institute of Propaganda Analysis, with limited funds at their disposal and no official authority, are tremendously handicapped in their efforts merely to expose these practices. Publicizing unfair practices is good as far as it goes, but does it go far enough?

There is need for a federal commission, comparable in some respects to the Federal Trade Commission or the Securities Exchange Commission, to make periodic audits of unfair propaganda practices. Such a commission should be adequately financed and competently staffed. Among other things it would undertake to define the meaning of "unfair competitive practices"; entertain complaints regarding their violation; investigate the validity of the complaints; and prescribe remedies.

I wish to lay special emphasis upon the need for an official, continuing body of this sort. One illustration will suffice, perhaps, to show how useful it could be in helping citizens reach more rational decisions on matters of public policy. Several years ago Congress passed legislation providing for the compulsory registration of all representatives and agents of foreign principals engaged in propaganda activities in this country. These propagandists were compelled by law to register with the Department of State and fill out special information blanks.

Now this is splendid as far as it goes. Any citizen may examine the registration lists and obtain a limited amount of information regarding these propagandists, such as place of residence, who their principals are, and what salaries they receive. The important question is, however, what are these people doing and how are they 
doing it? This legislation should have paved the way for a continuing survey of foreign propaganda in this country. In view of the prevailing international tensions in Europe and other parts of the world it is obvious that potential belligerents are doing all they can to win the support of American public opinion. But what are they doing? What are the Nazis doing? What is the British Council doing? What is Japan doing?

Spasmodic congressional investigations of propaganda and lobbying are economically wasteful and in many cases socially worthless. Such committees are forced to devote too much time to getting under way, making historical surveys, and assembling existing data. A permanent commission, on the other hand, would have much of the needed material available at all times. It would certainly have an up-to-date library of information regarding all the important groups seeking to mold public opinion in the United States and would be in a position to make timely reports of their activities. And even more important, it would have a staff of trained,research workers and investigators, continually enlarging the scope of their knowledge of propaganda activities in specific fields.

One of the outstanding shortcomings of our present system of exposing propaganda practices, particularly unfair practices, by means of congressional investigations and private institutions is the inevitable untimeliness of the reports they issue. Congressional investigations, for example, in many cases coming several years after the event lose much of their usefulness. Most congressional investigations of propaganda and lobbying are of this kind. Historical studies of this sort have their value, of course, but as instruments for helping the public to arrive at intelligent decisions on current questions of public policy they are lamentably deficient.

I have just been reading a recent bulletin of the Institute for Propaganda Analysis entitled Britain Woos America. Owing to lack of funds, I suppose, it is necessarily superficial and based largely on secondary sources. This is an interesting and important subject. But it is equally important for American citizens to know not only what Great Britain is doing, but also what France, Germany, Italy, Japan, Russia, and other countries are doing. What influence, if any, are they exerting on our newspapers, radio, and motion pictures? What ideas are being disseminated? What methods are employed? Are 
unfair practices used? What influences are being brought to bear upon our own public officials and leaders in other spheres of life? Within the past few years we have had a number of excellent studies of World War propaganda. I think at once of the studies by Lasswell, Bruntz, and Peterson. What we really need, however, are equally penetrating analyses of propaganda designed to involve us in the present European war.

Most of us would agree, I think, that information of this kind would be very helpful and would serve to clarify public thinking on public issues. And I think we will also agree that the task of getting this information is one that only a governmental agency, adequately financed, competently'staffed, and with substantial authority, can perform. Hence my plea for a permanent government commission to do the job. I realize that many interests will oppose this suggestion, especially those that do not wish to have their activities exposed. But I do believe that we have reached a point where organized attempts to influence public opinion on matters of public policy have become activities vested with the public interest! The democratic thesis simply will not work unless the race for public-opinion support is brought out into the open and is subjected to certain rules of the game.

I know that there are some who will ask, and ask sincerely, what are unfair propaganda practices? How can we define them? The same kind of question was asked when the Federal Trade Commission was established and efforts were made to raise the level of competitive business practices. The way to proceed is not to start with the most doubtful cases imaginable and try to draw the narrowest line possible between fair and unfair practices. Let us start with the obvious cases, instances of unequivocal distortion and misrepresentation. In general, an unfair competitive practice might be defined as trying to influence public opinion by methods which obstruct rather than promote clear, rational thinking. This is admittedly a general and rather abstract principle, but it is a starting point. Refinements will come with the consideration of specific instances. This is the way the English common law developed, and it is the way a common law of unfair competitive practices in the propaganda arena can develop. Debatable questions will arise. Many five to four decisions will have to be accepted. But I believe that experience will show more 
general agreement on what are and what are not unfair propaganda practices than many of us suppose.

Responsibility for the failure of propagandists to perform their function as they should is not attributable solely to their own doings or misdoings. At the same time that efforts are made to raise the level of competitive propaganda and outlaw unfair practices, there is much that can be done to assist the public directly in arriving at more intelligent decisions.

Liberals believe in the efficacy of reason. They realize that men think with their emotions as well as their minds, and that democratic theorists of the early nineteenth century probably overemphasized the reasoning, rational capacities of the average man. But man is, nevertheless, a reasoning as well as a feeling being. I suspect that early democratic theorists were more fully aware of man's emotional disposition than we suppose. But they were optimistic enough to believe that the most flagrant abuses of emotionalism could be "educated" out of a people. Hence the emphasis upon general education and a nationwide public-school system. However imperfect man's reasoning powers are, and however difficult it is to improve them, early liberals believed that man's reason was about the best tool he had for use in his search for truth. As one writer has stated: "Reason is untrustworthy, but as it happens to be the only thing by which we can test authority, intuition, instinct, or other alternative guides of conduct, and choose between good and bad, we should cultivate assiduously this tender, weakly, but indispensable plant." ${ }^{3}$

Education is propaganda. A liberal education is an experience with a philosophy of education. The educator is propagandizing a philosophy of education-his views regarding the place of the mind in the general scheme of things. Some educators obviously forget this. They try to propagate some particular economic philosophy or social and political gospel. Frequently they become, unconsciously perhaps, the tools of other propagandists. But these gospels are not philosophies of education. They are economic, political, and social dogmas.

The educator insists that there is a definite social value in logical thinking. Is this an opinion or a fact? It seems so obvious to us that we often forget there are those who challenge the statement. Some Fascists, for example, deny the efficacy of logic. Germans are taught to think with their blood, whatever that means. The art of straight 
thinking is really the art of logical thinking. In our public-school systems, particularly our elementary and secondary schools, we seem to ignore this fact. Why should courses in logic be reserved for the exclusive use of university and graduate students? Would it not be feasible and eminently worth while to teach the fundamental principles of logical analysis throughout our entire educational system? What better safeguard is there to the onslaughts of illogical and irrational propaganda appeals?

The Institute of Propaganda Analysis has done a splendid piece of work in popularizing a few of the devices that propagandists sometimes use to muddle our thinking. Its efforts show that a real need for more instruction of this kind exists. But the strategies and tricks of argument and persuasion have been known to logicians for centuries. The Institute's "seven devices" are only a few of the tricks in the kit of propagandists.

In the face of the growing number of propagandists and the increasing volume of propaganda it is imperative, I believe, that students in elementary schools, in secondary schools, and throughout our educational system be given a more thorough training in logical analysis. They should learn how to use these basic principles to clarify their own thinking as well as to detect fallacies in the thinking of others. This may necessitate some rewriting of textbooks on logic to adapt them to the understanding of students at different levels in the educational system.

Of course logic, by itself, will not necessarily show the way to truth. Logic always starts with a premise, and that premise is only one step in an endless search for truth. But liberals believe that logic does provide one of the best criteria we have for channeling thought processes. I would place instruction in logic, therefore, among the more important needs of the American public today.

Something should also be said, however, about information and facts. It is sometimes asserted that the best antidote to propaganda is fact. If this statement means that the best antidote to false propaganda is true propaganda, it does not advance us very far. It only begs the question, for what is truth and what is falsity? We simply revert to this great imponderable. The difficulty is that facts do not speak for themselves. It is reasoning from the facts that counts. It is a fact that there are so many unemployed in the country; that the 
federal government is spending so much for relief; and that Hitler demands the return of German colonies lost as a result of the World War. But so what? What do these facts mean? Where do we go from here? It is because of the meaninglessness of isolated facts that I emphasize the importance of reason, of logic, as a tool for combining facts and premises to reach a conclusion. Fact-finding is the characteristic work-way of scholarship today. The quantity of available facts is a bit appalling. Perhaps we have given too much attention to fact-finding; too little to fact-interpretation.

I hope I have not given the impression that I have the answers to all questions raised during the course of this lecture. I have tried to show that propaganda has a real and a vital function to perform in democratic society, and I have tried to explain what that function is. It must be clear that, even in democratic theory, propaganda freedom will serve the interests of democracy only under certain conditions. Many of those conditions do not exist. Without attempting to offer a comprehensive panacea I have presented two very concrete proposals for improving the situation. In the first place I favor the establishment of a federal commission to formulate and enforce rules governing methods, not content, in the propaganda arena. Secondly, I believe that a greater effort should be made to explain, and train students in the use of, the basic principles of logical analysis. 


\section{Public Opinion and Social Control}

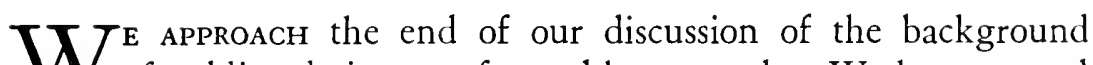
of public relations confronted by a paradox. We have argued that public relations is a term which refers to those aspects of our personal and corporate behavior having widespread social implications. We have said that the basic problem of public relations is to bring these relations into conformity with the public interest. And we have asserted that public opinion provides, in the last analysis, the best definition available of what that public interest is.

We have also noted that public opinion is not a static, inflexible standard. It is itself the end product of innumerable influences that direct and mold it. In a democracy particularly, public opinion is subject to an incessant battle of competing propagandas. As individuals and organizations we mold it as well as follow it. We use it as a standard of corporate behavior and simultaneously try to make it conform to our wishes.

Under these circumstances we have before us two major responsibilities. We have the duty of providing ways and means for adjusting those aspects of our personal and corporate conduct which have widespread implications to public opinion's concept of the public interest. To do this we must be alert to study and analyze our relations with the public and adjust them to public-opinion trends.

This process of adjustment may call for two very distinct types of approach. Public dissatisfaction with our conduct may have a valid basis in fact. It may call for a substantial modification of personal and corporate practices. It is extremely shortsighted to assume that misunderstanding is always the cause of public disfavor. Intergroup tensions may be due to, and often are the result of, real insight and possibly thorough understanding. The cause of our difficulty may be too much understanding rather than too little. The causes of public distrust may not be imaginary and fanciful.

At a recent meeting of the McGraw-Hill Public Relations Forum the question was asked: Why have the most disastrous strikes oc- 
curred in plants supposedly having the best programs of public relations? The answer is, assuming that these "best programs of public relations" are primarily informational in character, that management has taken it for granted that the causes of unrest are imaginary rather than real. A careful study of corporate behavior and practice in terms of their actual effects upon employees might show that the source of the difficulty was not lack of information or understanding on the part of employees but the natural consequences of corporate practices themselves.

Very often, however, the process of adjustment calls for an entirely different type of approach. Lack of adjustment may stem from a failure to understand exactly what the real implications of corporate behavior are. It is in cases of this kind that informational programs like those of General Motors, the American Telephone and Telegraph Company, United States Steel, and many other corporations have value. They give employees and the public a clearer picture of corporate activities and motives than they would ordinarily have, provided that they are honestly and intelligently executed.

But I cannot stress too emphatically the need for searching analyses of the total situation in each case to the end that real causes are differentiated from the mythical.

Our responsibilities do not end, however, once we have brought our relations with the public into line with public opinion. We have a duty as citizens and members of a national community to assist in making that public opinion what we think it ought to be. As one writer has stated: "The basic problem of public opinion is not to find out what it is but to make it what it ought to be."

Democratic theory has some very definite things to say about the place of opinion leadership in a democracy. In company with authoritarians, liberals recognize the importance and power of public opinion-the fact that all governments, all institutions, all laws, customs, morals, and standards of right and wrong derive their authority from public opinion.

Moreover, both liberals and authoritarians realize that public opinion does not have a spontaneous origin, but is merely one link in an endless chain of social causation. The real point of difference between the democratic and authoritarian point of view is that the former believes that the best way to improve the quality of public 
opinion is to provide an arena in which the maximum opportunity exists for presenting different points of view, whereas the latter maintains that the best way to achieve popular enlightenment is to rest responsibility of leadership in a small group of supposedly wise men.

Propaganda-the conscious dissemination of ideas and doctrineshas, therefore, a definite but distinct role to play in both theories. Liberals believe that improvements in the quality of public opinion are much more likely to occur when the masses are confronted with a multiplicity of competing propagandas than when they are subjected to only one. Democratic principles, like all principles, apply only under certain conditions, however. What are these conditions?

We have entered a new era in the life of democracy, an era characterized by a shrewder, a more intense, and a more ominous struggle for control over the minds of men. Business executives and group leaders, as well as governments, are awake to the importance of public opinion. Large corporations are revising public-relations policies, studying their publics, and improving their methods of dealing with these publics. Trade and professional associations, labor unions and pressure groups generally, are taking stock of existing practices and devising more refined methods for securing public support. Official agencies of government stress the importance of leading as well as reflecting public opinion.

What happens to us, however, when innumerable groups suddenly begin to realize the importance of public opinion and launch out upon courses of competitive propaganda officered by specialists? The answer is obvious. There occurs a race not unlike the international armaments race; a race for superiority in weapons of aggressive propaganda which may be as disastrous as the race for battleship supremacy. Group A modernizes its "public-relations" work. Group B follows suit. Group A increases its appropriation for advertising and publicity. Group B does likewise. Group A manufactures news, stages demonstrations, produces motion pictures, and purchases time over broadcasting networks. Group B "sees" them and raises the ante. Propaganda begets propaganda. Competition for opinion control becomes intense. Larger and larger sums of money are devoted to this purpose. And what results? What must necessarily be the ultimate social consequence in terms of national well-being? 
As I see it, the proper function of the propagandist is to assist us all in reaching rational conclusions on important matters of our public policy. Propagandists have a duty to perform for their clients, to be sure, but they also have a public service to render since they are affected with a public interest. Under our democratic system they are responsible for opinion leadership.

This social responsibility is as definite as the social responsibility of the lawyer and seems today perhaps even more vital. In this race of competing propagandas, group leaders sometimes overlook the fact that, from any social point of view, the important thing is not the success of their own enterprise, but rather their contribution to the enlightened thinking of all Americans. The real success of a propaganda campaign cannot be measured by column inches of newspaper publicity, amount of fan mail, number of telegrams received, or increases in sales. The social success of propaganda must be measured by the yardstick of popular enlightenment. The democratic thesis simply will not work unless the plane of competitive propaganda can be maintained at a high level; unless propagandists are true to their social responsibilities and seek to enlighten rather than befuddle their fellow men.

Pressure groups identify their interests with the public interest. This identification cannot be substantiated simply by a stroke of the pen or by waving a wand. The public interest is always an interest in a wiser and more rational decision on matters of general public significance. The competence of the public to decide wisely depends largely on the degree to which pressure groups enlighten the public mind; not upon the extent to which they arouse animal instincts. In a dictatorship where responsibility for opinion leadership is centralized and monopolized in a supposed élite, the social effect of irrational appeals may not be quite so disastrous. But in a democracy, where opinion leadership is decentralized, and where the individual is himself compelled to choose, we must establish and maintain the best standards of competitive propaganda and be ourselves responsible for what we have done. This is the first condition essential to the successful operation of the democratic thesis.

Another condition is freedom, real freedom to propagandize ideas and doctrines regardless of their acceptability to us. Perfect freedom has never existed and probably never will. The problem is to mini- 
mize, so far as possible, artificial obstacles to that freedom. Democracy is always an ideal in process of being realized. It is never an accomplished fact. Freedom to express opinions is always conditioned by the freedom of others. We cannot all use one broadcasting station at the same time, occupy the same rostrum, use the same space in a newspaper. These may be called natural obstacles.

There are also many artificial barriers to free expression of opinion. Freedom of expression is limited not only by formal censorship, but also by the financial inability of many to use modern instruments of communication, particularly agencies of mass impression. Democratic theory assumes that all ideas and doctrines have substantially an equal opportunity of being presented. But mass publics can be reached effectively only by instruments of mass impression. The problem is to find ways and means of equalizing opportunities to use them under our existing social, political, and economic system.

Democratic theory also assumes that the arena of competing propaganda will be surrounded by conditions that facilitate rather than obstruct rational processes of thought. Emotions cannot be completely divorced from thought processes, it is true. Nevertheless, in so far as propagandists rely upon emotional rather than rational appeals, to that extent they defeat the aims of democracy. It is for this reason that government interferes and prescribes rules of the game. Laws against libel and slander, legislation to promote truth in advertising are examples.

Special pleaders now have available, however, so many instruments for arousing the emotions of the masses that democracy may have to go even farther in defining unfair practices of propaganda. If, to protect juries from the wiles of special pleaders in the courtroom, elaborate rules regarding procedure, the presentation of evidence, and the questioning of witnesses are imperative, how much more necessary are rules governing the activities of special pleaders in the national arena of public opinion.

The establishment and enforcement of standards of fair practice for all is a familiar procedure under our democratic system. This is not censorship, for specific persons and ideas are not arbitrarily set apart and banned. We may discern already some appreciation of the problem in the fact that during the 1936 presidential campaign the national broadcasting companies formulated editorial policies to 
minimize the baneful effect of emotional appeals. Freedom of discussion as a principle of democratic liberalism does not mean the total absence of any rules which may improve the quality of that discussion.

The competence of public opinion to function satisfactorily in a democracy depends not only upon the adequate presentation of alternative opinions and upon the degree to which emotional stimuli are absent, but also upon the character and amount of information available to the masses. The quantity of information available today is very great. Libraries are overflowing with it. Reading matter is abundant. A large proportion of the population attends the public schools. The air, the silver screen, and the press provide additional sources of information. If the competence of public opinion is to be measured in terms of information available, that competence seems much greater today than ever before.

It is not quantity of information, however, that makes for public enlightenment. The information must be capable of being understood by the masses and related to the particular problems with which they are concerned. A mere increase in amount may confuse rather than enlighten. Information to be useful must be organized and presented so that it can be digested. Some of our newspapers are gigantic reservoirs of information. Too often, however, the reader of the New York Times or the Herald-Tribune puts his paper aside with a helpless feeling of intellectual bewilderment. Our school systems do try to bring some degree of order out of the chaos for students, but no such departmental and curriculum orderliness characterizes the banquet of facts for adults.

The assumption that the quality of opinions improves as opportunity for considering alternative points of view increases may require qualification. The ability to weigh the relative merits of conflicting opinions satisfactorily presupposes conditions that often do not exist. As previously noted, very few, if any, rules of special pleading exist in the arena of public opinion. No time is set for the hearings. There is no order of business, no rules of evidence, no calendar of cases. Issues are not defined. Special pleaders talk as often and as long as they wish. Before one question is acted upon many others are injected into the proceedings. No attempt is made to bring the protagonists together. Pleadings are for the most part ex parte. 
One of the pressing problems of our times is the ordering of public discussion. Freedom of opinion is not an end in itself; it is a means to an end-the enlightenment of public opinion. It can accomplish its purpose only as abuses are avoided and order is brought out of the chaos.

Emotions and feelings are generally regarded as impediments to straight thinking. But emotions do have an important role to play in the life of the state as well as in the life of the individual. But what role? They are powerful implements to action, and are extremely useful in translating opinions into will. Often the respective functions of will and emotion are confused. In the chaotic world of competing propagandas deliberate efforts are made to aggravate this confusion. The predisposition to think with one's feelings is frequently stimulated and strengthened by the use of symbols-emotionally toned words, pictures, dramatic stunts-to the detriment of reason.

In considering the proper role of public opinion in a democracy we must face the facts and deal with public opinion as it is. We cannot assume that conditions exist which do not. We cannot assume that the masses have information when they do not; that they have the opportunity to weigh intelligently different points of view when they do not; that emotions are controlled and assigned their proper place when this is not true. In spite of the quantities of information available the ordinary citizen does not always avail himself of it. $\mathrm{He}$, personally, may not have access to it. He may not have time to study it, or the ability to understand it.

No one has given more thoughtful consideration to these matters than Walter Lippmann. He believes that the role assigned to public opinion in early democratic theories was too idealistic; that even under the best circumstances the public is incapable of judging the merits of an issue. All it can reasonably do, he says, is to decide to which of the "inside conflicting groups" directly concerned with the problem it will give its support. It is for social scientists to provide the public with a few simple, objective criteria for making this decision. ${ }^{49}$

There are many difficulties with Lippmann's analysis. One is the difficulty of finding such a list of easily recognizable criteria. Another is the difficulty of applying these criteria to specific situations and securing agreement as to their mode of application. There is also the problem of drawing a definite line between outsiders and 
insiders. On questions relating to unemployment, war, taxes, and the like, the parties involved virtually comprise the entire population. Moreover, there is the problem of inducing the public to abandon its practice of passing upon the merits of particular issues and merely aligning itself on one side or the other.

Many other suggestions have been made for improving the quality of mass opinion. One frequently and often casually offered is education. Formal education, however, touches the lives of citizens for a few years. It seldom provides the citizen with the necessary equipment either in techniques or information for meeting rapidly changing social situations. The lag between the time when efforts are made to educate young people and the time when they are in a position to use effectively what they have learned is considerable. Techniques and information are outdated almost before graduation. Today's mass opinion, so far as it is affected by formal education, is largely the product of education of fifteen and twenty years ago.

Formal, public-school education can give students a knowledge of the historical development of the world in which they live, a background of information always helpful in solving current problems. It can also give them an attitude of mind, a method of approach to problems that is always useful. Training in the uses and abuses of logic will assist them to avoid the worst pitfalls of irrationality. Exposure to different points of view will tend to develop a spirit of tolerance and patience. But formal education cannot give the answers to many specific social problems with which students will be faced twenty years hence.

Democracy is entering an era when the town-meeting idea is being projected into the national arena. Plato's conclusion that democracy, in the sense of direct rule by public opinion, was impracticable except in small communities of five or six thousand people did not take account of the future impact of technical developments in communications upon the scope and nature of human contacts. Radio now makes it possible to address audiences of forty and fifty millions as effectively and conveniently as speakers in earlier days presented their views to gatherings of a few thousands. The dimensions of democracy have been extended far beyond the range of man's natural voice.

At the same time that technical developments expand listening 
and seeing areas, they make it possible for the masses to convey their responses to rulers almost as speedily as rulers communicate their ideas to them. It is now feasible for public officials to present questions to the masses one day and obtain answers the next. Today the people can listen to discussions of national questions and act upon them much as they did in earlier town-meeting days.

A moment's reflection, however, reveals that the nation as a whole is ill prepared for collective action of this sort. None of the safeguards for facilitating collective discussions and deliberations in town meetings exist. There is no definite time of meeting, no systematically arranged order of business, no rules of debate, no careful formulation of questions. How may the character and methods of public discussion be improved?

In the first place there is need for a clearing house of ideas and opinions, a reservoir into which individuals and groups with bright, new ideas can pour their questions. One of the primary functions of such a clearing house would be to arrange and classify these ideas, eliminate duplications, revamp and integrate others so that they could be presented to the public in a systematic manner. With orderly classification would come more significant statements of issues. The ordinary citizen cannot as a rule examine all ideas and programs and sift the less from the more important. There must be some agency to do this for him.

To some extent our legislative bodies serve this purpose. Anyone is free to bring before them, by petition or in some other way, any ideas or plans he has. Political parties also perform this function to some extent. Unfortunately, however, they do it only periodically, and election considerations often force them to gloss over real issues. However well our election machinery operates as a device for selecting candidates for public office, it fails badly as a mechanism for defining and stating issues.

If the public is to be asked to express its opinions on matters of national interest it is imperative that the method of selecting, formulating, and presenting the questions submitted be improved. The questions should be important. They should be such that the ordinary citizen might reasonably be expected to have an opinion upon them. And they should be phrased so that the answers mean something. We have a number of private agencies engaged in polling 
public opinion, but the costly machinery employed for sampling opinion is too frequently used for trivial purposes, or used in such a way that the results obtained have little or no practical significance. This machinery could be made to serve the public interest more adequately than it does. It could be made an integral and socially useful part of the democratic system as a whole.

From the point of view of the individual citizen, the subject and object of propaganda, one vital question is: Which propaganda shall he elect to accept and to follow? Is it possible to select from the many competing propagandas those that are socially desirable? Are there criteria to indicate which causes are good and which are bad?

Many are prone to evade the compelling social necessity for an answer. As social scientists, presumably detached, objective, scientific, looking down upon a world of struggling men and women, we prefer to view social behavior as the psychologist and the physiologist examine the life history or the intimate behavior of rats and mice. Impervious to social consequences, disdaining to be bothered by questions of values, ignoring, even, our own fate, we are content to describe, analyze, classify, and experiment.

The function of the social scientist, the socially immunized searcher for truth, is indispensable. The world owes much to those who devote their lives to the search for new facts and principles. But it does not owe everything. Credit must also be given to leaders of opinion, whose philosophies and ideologies have played an important part in social evolution. The search for facts and principles must go on, but meanwhile the actions of great masses of men and women will continue to be guided by beliefs, beliefs in ideals and values, the truth of which cannot in the last analysis be reduced to unimpeachable demonstrations of validity.

Undoubtedly the best antidote to propaganda is fact, fact established by the best scientific evidence available. Most of the pressing problems in modern society, however, cannot be answered in unequivocal, factual terms. Absolute truth, verifiable by scientific experimentation, encompasses only a small part of the field in which we must act. Even if it were possible to abolish all types of propaganda, simply because the ideals and purposes advocated could not be subjected to the cold test tube of scientific experiment, it is questionable whether this would be desirable. Until all truth is revealed 
there will be a place for faith, faith in some ideal, some future state that seems to be, even though it cannot be proved to be so, better than the one we now enjoy. And so, the fundamental problem which any sincere attack on the subject of propaganda encounters sooner or later is the question, Which propaganda?

A moment's reflection reveals that there are no hard and fast standards by which good and bad causes may be differentiated. This conclusion leaves the citizen, and more particularly the teacher of the social sciences, in a confusing situation. Does it follow that, because there exist no infallible standards of truth, any and all propagandas are indifferently valid? Or does it mean, perhaps, that we should disown the function of opinion leadership and withdraw to the sanctuary of demonstrable facts and principles?

Like the question of life and death, the choice will, in the final analysis, be an individual one. We can withdraw into that inner circle where only alleged facts and principles reside, or we can choose from among the varied propagandas those to follow. Theoretically the answer seems to be faced with many philosophical barriers. A more practical, realistic, common-sense view of the situation, however, suggests a reasonable course of action.

Without stipulating that any cause to elicit our support must be established and valid beyond the shadow of a doubt, we can ask certain questions as a basis for guidance. Who is advocating the program, cause, or platform? Who is actually, as distinct from apparently, behind it? Are these real leaders of opinion motivated by social or by personal interests? Do they speak from a first- or from a second-hand knowledge of the subject? Are the objectives, and the means advocated for realizing these objectives, generally approved, or are they subject to considerable criticism? Who oppose the particular cause? Do they, in our estimation, represent a more intelligent and more socially motivated group than those who advocate the program?

These and similar questions, if properly considered, will at once eliminate many causes from our support. This will leave, however, a number of others the social utility of which may be matters of debate. Although we may never be sure that we have chosen the best and only way, a careful answer to these questions will resolve the major difficulties at least and avoid the most serious mistakes. 
The democratic thesis assumes that, if free and unrestrained competition of propagandas is assured, the best, in any pragmatic sense of the term, will prevail. Without attempting to formulate a definition of what is best, we can state that anything which impedes or interferes with the freedom of all propagandas tends to make the thesis unworkable. Furthermore, those infuences which serve to raise the level of competition from the emotional to the rational work to its advantage. In the last resort, after all the facts are in, and all the pertinent principles are applied, man must rely on reason, on the best that may be found in the realm of intelligence and prudence. The social dangers of unwise choices are greatly mitigated by the operation of whatever forces give reason a chance to prevail over emotion. We cannot abolish propaganda. We may be able to raise the level and standards of competition, however, and at least improve the chances that what reason we have will survive. We should, therefore, attempt to reject propaganda that neglects reason and appeals only to emotion.

A propagandist is often said to be socially reprehensible because of the cause he is promoting. Quite as frequently he is labeled bad because of the methods employed to gain public support. Students of propaganda have shown no little industry in unearthing evidences of deliberate misrepresentation, concealment, distortion, and other evidences of public lying. There is no doubt as to the existence of practices of this kind. But public and, for that matter, private lying is not a trait peculiar to modern times. It is not the necessary nor often the actual method employed. If we eliminate from our consideration what may be called unconscious lying, that is, the sincere promotion of ideals and causes which are subsequently found to be invalid, we shall probably find that the total amount of deliberate deception is much less than is supposed.

Evaluation of methods of propaganda is an evaluation not merely of means but also of ends. Just as, in our selection of the causes to support, it is necessary to balance relative values, so, in passing judgment upon the means employed by propagandists, the validity of the goal sought must be balanced against the social utility preserved by insisting on the non-use of certain means. Here again common sense and reason must be our guide, at least in many instances. Certainly, if we decide that means employed to further the aims of the Ameri- 
can Red Cross are valid, we have little cause for condemning the same means, as means, if used to further a cause which we regard as socially reprehensible. All too frequently means which are used to further a cause in which we do not believe are condemned simply because we do not believe in the cause. Assuming the social utility of a regime of tolerance, of competitive propaganda; and assuming further the desirability of as high a level of rational discussion as possible, the propaganda methods employed become a problem of encouraging those techniques which appeal to the reason and suppressing those which are non-rational.

What does an intelligent awareness of propaganda imply? In the first place it calls for an awareness of the extent and character of propaganda; the variety of philosophies, causes, and ideologies that have been significant in world history. In the second place it calls for an understanding of the methods employed, the various types of reasoning, of conviction and persuasion that have proved efficacious in promoting causes. But of even greater importance is the necessity for an awareness of the philosophical issues involved; an awareness of the fact that the basic problem is: Which propaganda shall we follow? For we must very consciously follow some kind of propaganda if we are not to be led about like sheep. It is not enough to stress the tricks and subterfuges employed. It is not enough to emphasize the bad, as we see it. Wherever possible, facts must be sought. Where facts are not available there must be an unending search for the best opinion in whatever field we are working. In other words, the search for truth must go on, and oftentimes the most socially useful truth is merely an intelligent opinion or a prudent belief.

Throughout this course of eleven lectures I have tried to clarify the concepts "public opinion" and "propaganda" and show their relationship to the subject of public relations. Other lectures have explained the concept "public relations" in terms of actual corporate and individual practice today. What I have tried to do is to weave the multiplicity of practices into a mosaic unity in order that we may understand not only what we are doing but also why we are doing it. It is appropriate at this time, I believe, to state once more the several propositions advanced and explained.

I. Public relations, in its broader meaning, refers to those aspects 
of our personal and corporate behavior which have social implications.

2. The basic problem of public relations is to bring these relations into conformity with the public interest-a public interest which is constantly being redefined by mass opinion.

3. We have not only the duty to conform to public opinion but also the responsibility and the opportunity to mold and guide it.

4. In so doing we need to be aware of the social significance of propaganda-the role to which it is assigned in democratic theory, and the conditions essential to its proper functioning.

5. In the final analysis, public opinion is what we, collectively, make it. Only as we seek in every way possible to improve its quality do we free ourselves from the dangers of conformity. 


\section{Notes}

I. Fortune, 19:83-88 ff. (March, 1939).

2. Long, Norton E., "Public Relations Policies of the Bell System." Public Opinion Quarterly, 1:4:5-22 (October, 1937).

3. Dibrell, E. R., "Industry's Public Relations Job-Through the Trade Association." Address, District Conferences of the American Trade Association Executives, New York, March 23, I937.

4. Griffiths, Noel, "Big Business Finds a Soul-The Growing Importance of Public Relations." Unpublished manuscript.

5. Parry, Thomas W., "Public Relations-First in the Order of Business." Address, Advertising Club of St. Louis, June 15, 1937.

6. Fortune, I9:6 (March, 1939).

7. Garrett, Paul W., "Public Relations-Industry's No. I Job." Address, TwentyFirst Annual Convention of the American Association of Advertising Agencies, White Sulphur Springs, April 22, 1938.

8. Jones, John Price, and Church, David Mclaren, At the Bar of Public Opinion. New York: Inter-River Press, I939, p. I6.

9. For a statistical summary of the results of these surveys see Gallup, George, and Robinson, Claude, "American Institute of Public Opinion-Surveys, 1935-38." Public Opinion Quarterly, 2:373-398 (July, 1938).

ro. Quoted in Gallup, George, Public Opinion in a Democracy. Princeton: Princeton University Press, I939, p. 13.

I I. lbid., p. I4.

I2. Cottrell, Edwin A., "Twenty-Five Years of Direct Legislation in California." Public Opinion Quarterly, 3:30-45 (January, I939).

13. Peterson, H. C., Propaganda for War-The Campaign Against American Neutrality, I9I4-I9I7. Norman: University of Oklahoma Press, I939.

I4. Jones and Church, op. cit., pp. I 19-20 and 123 .

15. The best, concise summary of the evolution of the concept is Palmer, Paul A., "The Concept of Public Opinion in Political Theory" in Essays in History and Political Theory in Honor of Charles Howard Mcllwain. Cambridge: Harvard University Press, 1936.

I6. See Holcombe, A. N., "The Meaning of Public Opinion," an excerpt from the report of the Round Table on Political Statistics at the National Conference on the Science of Politics. American Political Science Review, 19:123-4 (February, 1925).

17. Sedman, Virginia R., "Some Interpretations of Public Opinion." Social Forces, ro:339-350 (March, 1932).

18. Allport, F. H., "Toward a Science of Public Opinion." Public Opinion Quarterly, I:I:7-23 (January, 1937). 
19. Thurstone, L. L., and Chave, E. J., The Measurement of Attitude. Chicago: University of Chicago Press, 1929, pp. 6-7.

20. Consult Cantril, Hadley, General and Specific Autitudes. Princeton: Psychological Review Company, 1932.

21. Bryce, James, Modern Democracies. New York: Macmillan, i927, Vol. I, p. 154. Quoted by special permission of the publishers.

22. Dicey, A. V., Lectures on the Relation between Law and Public Opinion in New England in the Nineteenth Century. New York: Macmillan, 1905, p. Io.

23. Gault, Robert H., Social Psychology. New York: Holt, 1923, pp. 176-7.

24. Maxey, C. C., The Problem of Government. New York: Knopf, 1925, p. 352.

25. Scholarly interest in other aspects of public opinion than the degree of unanimity expressed has produced a variety of definitions of the term stressing different aspects. See Chilns, H. L., "By Public Opinion I Mean." Public Opinion Quarterly, 3:327-36 (April, 1939).

26. Brooks, Robert C., editor, Bryce's American Commonwealth-Fiftieth Anniversary. New York: Macmillan, 1939.

27. National Industrial Conference Board, "A Statistical Survey of Public Opinion." New York, 1936. Studies, No. 222.

28. "The Press and the Public." Now Republic, 90:178-91 (March 17, 1937).

29. Woodward, Julian L., "Quantitative Newspaper Analysis as a Technique of Opinion Research.” Social Forces, 12:526-537 (May, 1934).

3o. Robinson, Claude E., "Recent Developments in the Straw Poll Field." Public Opinion Quarterly, I:3:45-56 (July, 1937); I:4:42-52 (October, 1937).

3I. Gosnell, Harold F., "How Accurate Were the Polls?" Public Opinion Quarterly, 1:1:97-105 (January, 1937).

32. Lowell, A. Lawrence, Public Opinion in War and Peace. Cambridge: Harvard University Press, 1923, P. I2.

33. Allport, Gordon, "The Genesis of Attitudes," in A Handbook of Social Psychology. Worcester: Clark University Press, 1935, pp. 798-844.

34. See note ig.

35. Lippanan, Walter, Public Opinion. New York: Macmillan, ig22.

36. Gosnell, H. F., Getting Out the Vote. Chicago: University of Chicago Press, 1927.

37. Rice, Stuart A., Quantitative Methods in Politics. New York: Crofts, 1928.

38. Gosnell, H. F., "Factoral Analysis of the Relation of the Press to Voting in Chicago." Joumnal of Social Psychology, 7:375-385 (1936).

39. Lumley, F. E., The Propaganda Menace. New York: Century, I933.

40. Institute for Propaganda Analysis, "How to Detect Propaganda." Monthly Letter, Vol. I, No. 2, November, 1937.

4I. Doob, Leonard W., and Robinson, Edward S., "Psychology and Propaganda." Annals of the American Academy of Political and Social Science, i79:88-95 (May, 1935); and his Propaganda, New York: Holt, 1935.

42. Lasswell, H. D., "The Study and Practice of Propaganda," in Propaganda and Promotional Activities-An Annotated Bibliography by Lassweld, H. D., 
Casey, R. D., and Smith, B. L. Minneapolis: University of Minnesota Press, 1935, Pp. 3-27.

43. Martin, Everett Dean, The Meaning of a Liberal Education. New York: Norton, 1926, Ch. 3 .

44. Friedrich, Carl, "Education and Propaganda." Atlantic, 159:693-7or (June, 1937).

45. The author is indebted to one of his former students, Gardner Ainsworth, Princeton, class of 1939, for much of the factual data regarding the propaganda activities of the New York World's Fair 1939.

46. Kent, Frank, Political Behavior. New York: William Morrow, 1928.

47. Albig, William, Public Opinion. New York: McGraw-Hil], I939, Ch. 18.

48. Anjgell, Norman, The Public Mind. New York: Dutton, 1927.

49. Lippanan, Walter, The Phantom Public. New York: Harcourt, Brace, I925.

\section{SELECTED REFERENCES}

\section{Public Opinion}

Albig, William, Public Opinion. New York: McGraw-Hill, 1939.

Bryce, JaMes, American Commonwealth. New York: Macmillan, I889, Vol. II, pp. $26 \mathrm{I}-403$.

Graves, W. B., Readings in Public Opinion. New York: Appleton, 1928.

Lippmann, Walter, Public Opinion. New York: Macmillan, 1922.

Odegard, Peter H., The American Public Mind. New York: Columbia University Press, I930.

Palmer, Paul A., "The Concept of Public Opinion in Political Theory." In Essays in History and Political Theory in Honor of Charles Howard Mcllwain. Cambridge: Harvard University Press, 1936.

The Public Opinion Quarterly. Princeton: Princeton University Press. Vols. I-3 (1937-1939).

\section{Public-Opinion Polls}

American Institute of Public Opinion, The New Science of Public Opinion Measurement. Princeton: American Institute of Public Opinion, 1938.

Childs, Harwood L., "Rule by Public Opinion." Atlantic, 157:755-764 (June, 1936). Gallup, George, Public Opinion in a Democracy. Princeton: Princeton University Press, 1939.

Katz, Daniel, and Cantril, Hadley, "Public Opinion Polls." Sociometry, i:155-79 (July-October, 1937).

Robinson, Claude E., Straw Votes. New York: Columbia University Press, 1932.

Warner, Lucian, "The Reliability of Public Opinion Surveys." Public Opinion Quarterly, 3:376-390 (July, 1939).

\section{Public Relations}

Bernays, Edward L., Propaganda. New York: Liveright, I928.

Federal Trade Commission, "Summary Report on Efforts by Associations and Agen- 
cies of Elective and Gas Utilities to Influence Public Opinion." Washington: U. S. Government Printing Office, 1934.

Jones, John Price, and Church, David Mclaren, At the Bar of Public Opinion. New York: Inter-River Press, 1939.

McGran-Hill Publishing Company, a Preface to Public Relations for Industry. New York: McGraw-Hill, 1938.

Mills, Alden B., Hospital Public Relations. Chicago: Physician's Record Company, 1939.

Walker, S. H., and Sklar, Paul, Business Finds Its Voice. New York: Harpers, 1938.

Wright, Milton, Public Relations for Business. New York: McGraw-Hill, 1939.

U. S. Senate, Subcommittee on Education and Labor, "Hearings pursuant to S. Res. 266-Part 17-Employer Associations and 'Citizens Committees'-National Association of Manufacturers." Washington: U. S. Government Printing Office, I 933 .

\section{Propaganda}

Childs, Harwood L., editor, "Pressure Groups and Propaganda." Annals, i79 (May, 1935).

Childs, Harwood L., editor, Propaganda and Dictatorship. Princeton: Princeton University Press, 1936.

Doob, Leonard W., Propaganda-Its Psychology and Technique. New York: Holt, 1935 .

Friedrich, Carl Joachim, "Education and Propaganda." Atlantic, i59:693-70i (June, 1937).

Lasswell, Harold D., Propaganda Technique in the World War. New York: Knopf, 1927.

Lasswell, H. D., Casey, R. D., and Smith, B. L., Propaganda and Promotional Activities-An Annotated Bibliography. Minneapolis: University of Minnesota Press, 1935 .

-Lumley, Frederick E., The Propaganda Menace. New York: Century, 1933. 


\section{Name Index}

Adams, Samuel, 76

Albig, William, I 45

Allport, Floyd H., 40

Allport, Gordon W., 62, 64

Ancillon, Friedrich, 37

Angell, Norman, I45

Austin, John, 37

Bancroft, George, 95

Bauer, Wilhela, 38

Bentham, Jeremy, 37

Bentley, A. F., 37

Bernays, Edward L., I45

Biedermann, Karl, 37

Bluntschli, J. C., 37

Bogardus, Emiory S., 40

Brooks, Robert C., I 44

Bruntz, George C., 125

Bryce, James, 33, 37, 47, 49-50

Buckle, Henry Thomas, 37

Calhoun, John C., 95

Cantril, Hadley, 144, I 45

Casey, Ralph D., I45

Chave, E. J., I 44

Cherington, Paul T., 30, 52

Christensen, Arthur, 37

Church, David McLaren, 4, 34; quoted notes 8 and $\mathrm{I} 4$

Clark, W. C., 72

Cottrell, Edvin A., 31-32

Creel, George, 93

Crossley, A. M., 52, 53, 56

Crum, W. L., 52

Dewey, John, 40

Dibrell, E. R., 3; quoted note 3

Dicey, A. V., 37, 38, 47
Dollfus, Charles, 37

Doob, Leonard W., 83-84, 98, i oo

Esmein, A., 37

Friedrich, Carl J., 87

Fries, Jakob, 36

Gallup, George, 30-31, 52, 56, 57-58, 72

Garrett, Paul W., 3; quoted note 7

Garve, Christian, 36

Gault, Robert H., 47

Gersdorf, Carl von, 38

Gneist, Rudolf, 37

Goebbels, Paul, I04, II 4

Gosnell, Harold F., 68, 73-74

Graves, W. Brooke, 145

Griffiths, Noel, 3; quoted note 4

Hänfstaengl, ERnSt, IO3

Hegel, G. W. F., 36-37

Hitler, Adolf, 93, ioi, io3, il4

Hobbes, Thomas, 35, 95

Holcombe, Arthur N., 40

Holtzendorf, Franz von, 38

Hume, David, 35, I20

JACKSON, ANDREW, 77

Jones, John Price, 4, 34; quoted notes 8 and 14

Katz, Daniel, I 45

Kent, Frank R., 99-I00

King, Clyde L., 40

Lasswell, Harold D., 37, 84-86, I 25

Lenin, Vladimir I., ioi

Lewis, George Cornewall, 38 
LEy, ROBERT, 107

Lieber, Francis, 37

LippManN, Walter, 37, 38, 40, 63, 135 136

LOCKE, JoHn, 35, 95

Long, Morton E., 143

Lowell, A. Lawrence, $36,37,3^{8}, 40$, $6 \mathrm{I}-62,63$

Lumley, Frederick, 79

Mackinnon, W. A. R., 37

Maine, Henry Sumner, 37

Marshall, John, 95

Martin, Everett Dean, $86-87$

MARX, KaRL, 95

Maxey, Chester C., 47

Mrlls, Alden B., 146

Necker, Jacques, 36

Odegard, Peter H., I 45

Paine, Thomas, 76,95

Palmer, Paul A., I 45

Parry, Thomas W., 3; quoted note 5

Pascal, Blaise, 35

Peterson, H. C., 32, I 25

Plato, iol

Rice, Stuart A., 69-7I

Ritchie, D. G., 37

Robinson, Claude, 51-52
Roosevelt, Theodore, 32

Roper, Elajo B., Jr., 52

Rosenkrantz, Karl, 37

Rousseau, Jean-Jacques, 35-36

Sedian, Virginia, 40

Sklar, Paul, $4_{4} 6$

Sleyster, Rock, 19-20

Smith, Bruce L., 145

Stahl, Friedrich Julius, 37

Stern-Rubarth, Edgar, 37

Tarde, Gabriel, 37

TAYLOR, John, 37

Thurstone, Louis L., 62

Tocqueville, Alexis de, 38

Tönnies, Ferdinand, 38

Urquhart, David, 37

VAIL, Theodore, I5

Voltaire, 35

WALKER, S. H., I 46

Wallas, Graham, 37, 95

WARner, Lucien, 145

WesLey, John, 95

Wieland, C. M., 36

Willoughby, W. W., 37

Wilson, WoOdrow, 95

Woodward, Julian L., 5 I

Wright, Milton, I 46 


\section{Subject Index}

American Anti-Slavery Society, 78

American Civil Liberties Union, 78

American Farm Bureau Federation, 77

American Federation of Labor, 77, 93

American Gas Association, 9I

American Institute of Public Opinion, polls, 26-3I, 38, 48, 5I, 52, 53, 55, 56,61

theory of, 65-66

American Council on Public Relations, 24

American Legion, 78

American Medical Association, 19-20

American Peace Society, 78

American Sales Book Company, 90

American Sugar Refining Company, 90

American Telephone and Telegraph

Company, I5, 91, I30

Anti-Saloon League of America, 78

Argument, strategy of, 93-95

Attitudes, definition of, 62

Baltimore and Ohio Railroad, public relations of, 2

Bandwagon effect of polls, 56

Bell Telephone System, public relations of, 2-3, I5

Chamber of Commerce of the United States, 77, 93

Chicago Journal, straw polls of, $5 \mathrm{I}$

Cincinnati Enquirer, straw polls of, $5 \mathrm{I}$

Colgate-Palmolive-Peet, 9I

Columbus Dispatch, straw polls of, $5 \mathrm{I}$

Congress of Industrial Organizations, I5, 77

Congressional investigations, I24
Counsel on Public Relations, functions of, I4, 20, 2I

Democracy, conditions of its success, 132I 35

growth of and effect on public relations, 6

relation of dictatorial propaganda to, I I5-I I 8

role of propaganda in, $12 \mathrm{I}-123$

Dictatorial propaganda, antidotes to, I I6I 18

effect on democracies, I 15

theory of, II9, I2I

Direct legislation in California, 3I

Economic developments, effect on public relations, IO-I I

Education, and propaganda, $87-88, \mathrm{I} 26$ effect on public relations, 7 Nazi philosophy of, I09-I Io

Electric Utilities Exhibit Corporation, 9I

Fortune magazine, polls, 26, 38, 52, 54, $56,57,5^{8}, 61,72$

quoted, I, 6 theory of, 65

Freedom, obstacles to, I32-1 33

General Motors Corporation, I 30

German Food Estate, I03, I04

German Labor Front, I03, I04, II2

German Ministry of Education, 109

German Ministry of Propaganda and

Popular Enlightenment, library of, I04

organization of, III-II4 
Government, public relations of, I6-1 7 Guggenheim Foundation, I03

Harvard University, 22

Harvest Festival of German Peasants, 104

Hitler Youth Organization, I04, 106, 109

Institute for Propaganda Analysis, 80-83,

$$
9^{8}, 124,127
$$

Interest groups, claims of, 25, 57

function of, 132

in Germany, 103-104

influence on public opinion, 37

Labor relations, 17-19

League of Nations, 17, I 6

Literary Digest, straw polls of, 52, 54

Logic, importance of, 127

Mass impression, agencies of, effect on public relations, 8-io

McGraw-Hill Public Relations Forums, I 29 - I 30

Medical Society of New Jersey, I9

Motion pictures, 9

Multiple-factor analysis, 73-74

National Association of Manufacturers, 77

National Civil Service Reform League, 78

National Council for the Prevention of War, 78

National Electric Light Association, 15

National Grange, 77

Nazi Party, activities abroad, 107, I I I-I 12 doctrines of, 105-106, 109-110 organization of, 108

Nazi Party rally, 104

Nazi propaganda, doctrines of, $105-106$ features of, I04-I 15

organization of, 108-II4

resources of, 114 world-wide extent of, I06-108

New York Times editorial on polls, 55-57
New York World's Fair of 1939, advisory committees of, 93

department of library and research of, 94

expenditures of, 119

feature publicity bureau of, 90

press department of, 90

propaganda technique of, $89-98$

spectacles of, $9^{6}$

symbols and slogans of, 97

use of sex appeal, $9^{8}$

Newspapers, as indices of public opinion, 50-5 I

influence of, study by Gosnell, 73-74

polls of, 5I-52

use of, by New York World's Fair, 90-91

Opinion, charting changes in, 69

conflicts of, 39

definition of, 42-43, 61-62

formation of, 62-74

immediate determinants of, 67

influence of specific factors on, 68-69

uniformity of, $47-48$

Organization, strategy of, 92-93

Persuasion, strategy of, 95-98

Population growth, effect on public relations, 6

Press, sce Newspapers

Pressure groups, see Interest groups

Propaganda, alleged principles of, 98, 102 and democracy, I I9-128

and dictatorship, 103-1 18

and education, 86-88, 126

art of, $89-9^{8}$

competition, effects of, I3I

defined, 75

density of, 199

detection of, II9-1 20

Doob on, 83-84

evaluation of, 139-14I

history of, $75-7^{8}$ 


\section{Propaganda-(Continued)}

Institute of Propaganda Analysis on, 8o- 83

Lasswell on, $84-86$

Lumley on, $79-80$

problem of, $78-79$

regulation of, I23-I26, I33-134

role in democracies, I2I-123, 126

role in dictatorships, I2 I

strategies of, 89

studies of, $38,79-88$

unfair methods of, I23-I 26

Propagandists, compulsory registration of, I23-124

responsibility of, in democracies, I32

Public interest, as shown by direct legislation, $3 \mathrm{I}-32$

as shown by public-opinion polls, $26-3 \mathrm{r}$ definition of, 4, 23-24, 32-34

Publicity, strategy of, 89-92

Public opinion, as a means of social control, 38

as criterion of public interest, $24-34$

attempts to define, 40, 47-48

competence of, 7, 26, 37, 39, 57

Fascist and liberal theories of, contrasted, I20-12I, I30-I3I

formation of, $37,38,58-59,62-74$

improving quality of, $134^{-1} 38$

influence of interest groups on, 37

meaning of, $40-46$

origin of term, 35

relation to law and political institutions, 37

research on, 38, 68-74

social control of, I29-I42

theories of, $35-38$

Public-opinion indices, elections, 58 newspapers, 50-5 I

Public-opinion polls, accuracy of, 54-55

Bryce on, 49-5o

dangers of, $59-60$

development of, 5I-52
Public-opinion polls-(Continzed)

influence of, 56-57

laws to prohibit, 55

sampling techniques of, 52-53

usefulness of, 57-59

Public relations, as problem of government, I6-I7

definitions of, 2-4, 45-46

Fortune magazine on, I, 6

of the medical profession, I9-20

origin of term, 2

problems of, I3-I4, I6, 2I, I29-I3I

programs of, I4-16

scope of, $4^{-12}$

Publics, kinds of, $4 \mathrm{I}-42$

Radio, 8-9, 77

Radio Corporation of America, 9

Reich Chamber of Culture, Io6

Reichsgruppe Industrie, I03

Representative government, influence of polls on, 57

Roman Catholic Church, 75-76

Sacred Congregation for the Propagation of the Faith, 75

Sampling public opinion, proportional method of, 54

random method of, 53-54

Socialized medicine, I9

Social Science Research Council, I03

Society for the Propagation of the Gospel, 76

Stereotypes, Lippmann on, 63

Television, effect on public relations, $\mathrm{I} 3$

United States Steel Corporation, public relations policy of, I4-15, I30

War referendum, 57

World Court, I7

World War propaganda, Peterson on, 32 



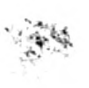


Date Due

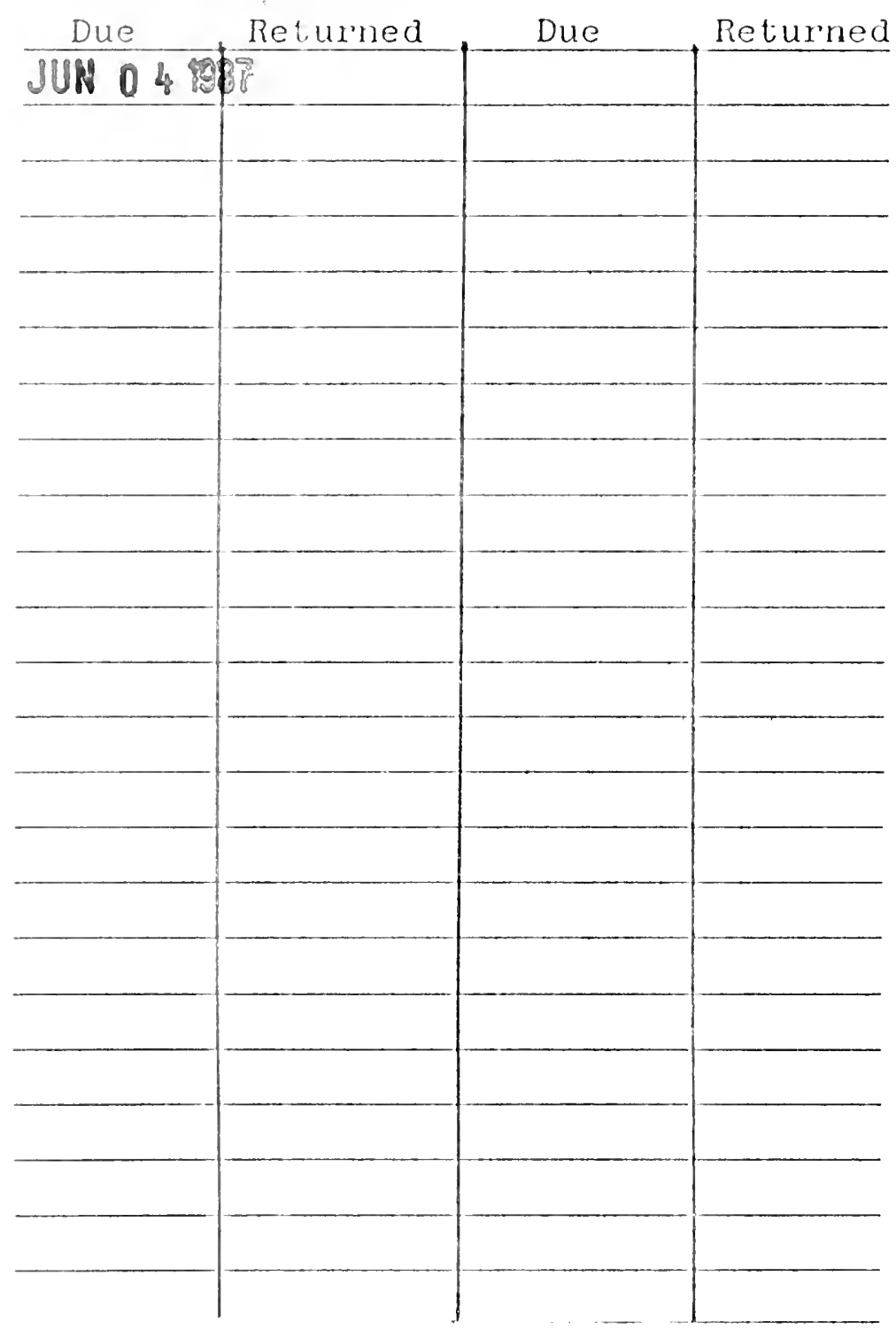




$$
942
$$




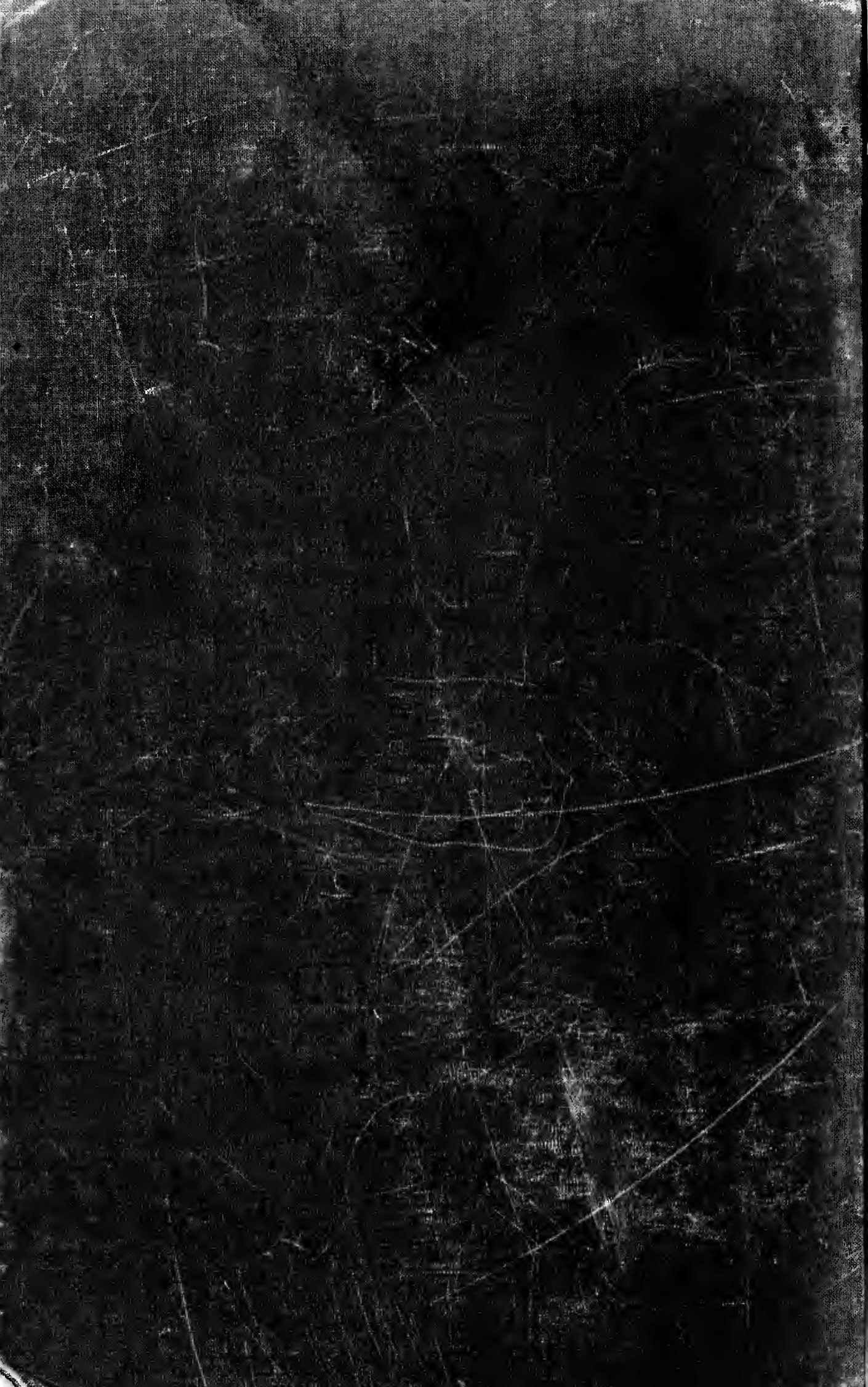

